UNIVERSIDADE DE SÃO PAULO

ESCOLA DE ENFERMAGEM DE RIBEIRÃO PRETO

AVALIAÇÃO DA ATIVIDADE ANTIMICROBIANA E CITOTÓXICA IN VITRO DO VINAGRE E ÁCIDO ACÉTICO: PERSPECTIVA NA TERAPÊUTICA DE FERIDAS

Iwa Keiko Aida Utyama 
UNIVERSIDADE DE SÃO PAULO

ESCOLA DE ENFERMAGEM DE RIBEIRÃO PRETO

\section{AVALIAÇÃO DA ATIVIDADE ANTIMICROBIANA E CITOTÓXICA IN VITRO DO VINAGRE E ÁCIDO ACÉTICO: PERSPECTIVA NA TERAPÊUTICA DE FERIDAS}

Iwa Keiko Aida Utyama

Dissertação de mestrado, apresentada à Escola de Enfermagem de Ribeirão Preto da Universidade de São Paulo, para obtenção do Título de Mestre em Enfermagem, no Curso de Pós-Graduação em Enfermagem - Área de concentração: Enfermagem Fundamental - Linha de Pesquisa: Doenças Infecciosas: Problemática, especificidade e estratégias de enfrentamento.

Orientadora: Prof ${ }^{\mathrm{a}}$ Dra. Denise de Andrade 
Utyama, Iwa Keiko Aida

Avaliação antimicrobiana e citotóxica do vinagre e do ácido acético: perspectiva na terapêutica de feridas

. Ribeirão Preto, 2003.

113 p. : il. ; $30 \mathrm{~cm}$

Dissertação de Mestrado, apresentada à Escola de Enfermagem de Ribeirão Preto/USP - Área de concentração: Enfermagem Fundamental.

Orientadora: Andrade, Denise de.

1. Ácido acético. 2. Vinagre. 3. Atividade antimicrobiana. 4. Citotoxicidade. 5. Ferida. 6. Infecção. 
Data da Defesa: 29/09/003

\section{BANCA EXAMINADORA}

Profa. Dra.: Denise de Andrade

Julgamento: aprovada

Assinatura:

Profa. Dra.: Maria Helena Larcher Caliri

Julgamento: aprovada

Assinatura:

Profa. Dra.: Fabiana Cristina Pimenta

Julgamento: aprovada

Assinatura: 


\section{Dedico este estudo a}

\section{"Minha Família"}

Que tem sido a razão da minha existência neste mundo.

Ao Sadao, esposo, companheiro que tem sido o maior incentivador em tudo que faço, assumindo o papel de mãe durante a minha ausência.

Ao Kleber, Jeimes e Karin meus filhos a razão do meu orgulho, o meu muito obrigado pelo grande auxílio, apoio e estímulo na elaboração deste trabalho.

Aos meus pais pelo exemplo de paciência, dedicação, responsabilidade e amor pela vida e pela natureza. 


\section{AGRADECIMENTOS}

A todos que colaboraram direta ou indiretamente na concretização deste trabalho, com certeza sem a ajuda e compreensão de todos que nos cercam é impossível à realização de tamanha grandeza.

A minha amiga Júlia, pela amizade e luta em prol da amiga indefesa propiciando a realização deste mestrado.

As amigas Mitsuko, Nair, Maria Clara, Maria Helena, Márcia Volpato, Mitiko, Márcia Eiko por terem propiciado este momento para o meu crescimento pessoal e profissional.

A Professora Dra Jacinta S. Pelayo e Doutoranda, minha pupila Cláudia Ross, pela inestimável ajuda, ensinamento e reflexão.

As professoras Sonia, Hissae, Fernanda, Mary, Gilda, Maria Angélica pelo apoio e experiências compartilhadas.

A amiga Cristina Bobroff pelo incentivo e pela disponibilidade na tradução.

As novas amigas do mestrado Cristina Fontes e Inês G. Rodrigues pela solidariedade.

A Zeneide Soubhia pelos ensinamentos de pesquisa com paciência e dedicação.

A Professora Dra Geni Varéa pela colaboração em ceder material bibliográfico de seu acervo pessoal.

Ao Professor Dr Francisco Pereira pelo incentivo e pelas excelentes sugestões.

A Universidade Estadual de Londrina e Departamento de Enfermagem pela oportunidade e afastamento parcial para realização do mestrado.

A Escola de Enfermagem de Ribeirão Preto da USP pelas facilidades oportunizadas durante todas as etapas de elaboração deste estudo.

Ao Laboratório de Microbiologia do Departamento de Análises Clínicas Toxicológicas e Bromatológicas da Faculdade de Ciências Farmacêuticas de 
Ribeirão Preto da Universidade de São Paulo pela oportunidade concedida a minha pessoa para realização da etapa experimental.

As funcionárias Maraisa Palhão Verri e Benedita de Almeida Panari do Laboratório de Microbiologia da Faculdade de Ciências Farmacêuticas de Ribeirão Preto da Universidade de São Paulo pelo preparo de material para realização da coleta de dados e pela simpatia e acolhimento.

A secretária Amélia Regina Azevedo A. Albuquerque do Laboratório de Microbiologia da Faculdade de Ciências Farmacêuticas de Ribeirão Preto da Universidade de São Paulo pela elaboração do fluxograma e disponibilidade.

A Profa Dra Maria Helena Larcher Caliri pela concessão do material bibliográfico, pelo profundo conhecimento acerca da terapêutica de feridas crônicas e estímulo na conclusão deste trabalho.

A Profa Dra Fabiana Cristina Pimenta e Prof. José Daniel Gonçalves Vieira pela disponibilidade sugestões e contribuição na realização dos testes de citotoxicidade. Ao Departamento de Microbiologia, Imunologia, Parasitologia e Patologia da Universidade Federal de Goiânia pelos recursos físicos, humanos e tecnológicos para execução da avaliação citotóxica nossos agradecimentos.

A Profa Dra Cláudia e aluna de Graduação em Enfermagem Bruna da Escola de Enfermagem de Ribeirão Preto-USP, no auxílio estatístico.

\section{Em especial;}

A Profa Dra Izabel Yoko Ito pela generosidade, pela extraordinária capacidade e conhecimento no âmbito da microbiologia, pela colaboração, pela orientação e total disponibilidade na construção deste trabalho.

Ao amigo mestrando Evandro Watanabe que participou nessa trajetória contribuindo ativamente na fase laboratorial, bem como, esmerando com excelentes sugestões. 
Ainda, em agradecimento especial

À Profa Dra Denise de Andrade, um exemplo de pessoa, mulher, professora e profissional que conduziu esta caminhada com paciência, carinho, dedicação, segurança e competência científica. 


\section{SUMÁRIO}

Lista de Tabelas

Lista de Figuras

Resumo

Summary

Resumem

Autorização do Comitê de Ética

Autorização para inclusão de artigos e periódicos

\section{APRESENTAÇÃo}

1. INTRODUÇÃO................................................................................ 1

1.1 - O Cuidado de Feridas: aspectos técnicos-assistenciais........................... 1

1.2.- Ácido acético pode ser uma alternativa viável no tratamento de feridas?.... 14

1.3.- Relevância e justificativa do estudo......................................................... 20

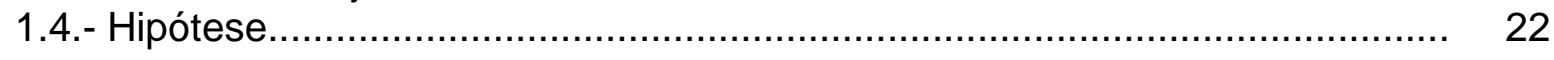

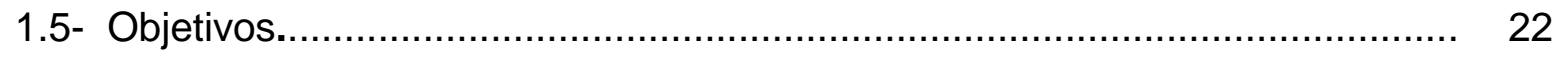

2. MATERIAL E MÉTODO........................................................................ 24

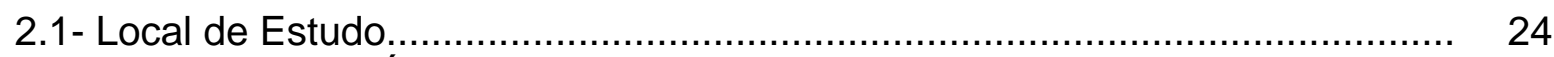

2.2- Procedimentos Éticos em Pesquisa............................................... 24

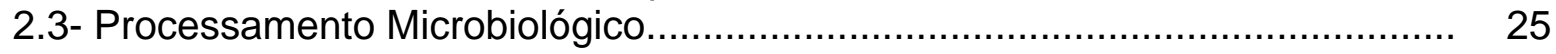

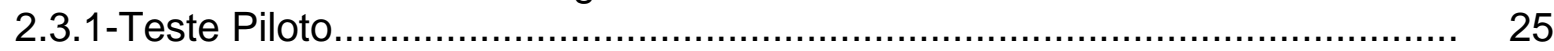

2.3.1.1- Técnica do Poço (well).............................................................. 24

2.3.2- Leitura e Mensuração da Atividade Antimicrobiana............................... 29

2.3.3- Documentação Fotográfica.......................................................... $\quad 30$

2.3.2- Atividade antimicrobiana do vinagre/ácido acético............................... 32

2.3.3- Determinação da Concentração Inibitória Mínima (CIM) ........................... 32

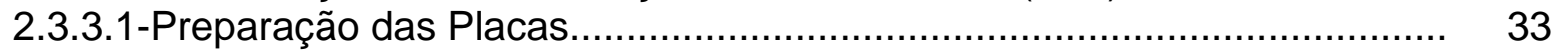

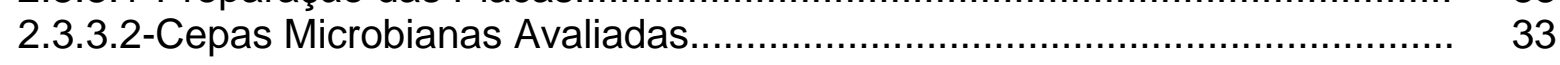

2.3.3.3-Técnica de Semeadura para Determinação da Concentração Inibitória 34 Mínima.

2.4 Verificação de atividade citotóxica do ácido acético e vinagre utilizando 36 
como modelo de toxicidade a Artemia salina Leach

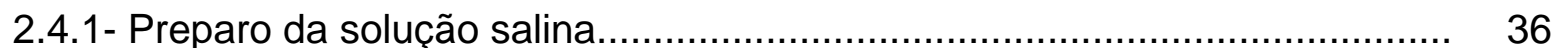

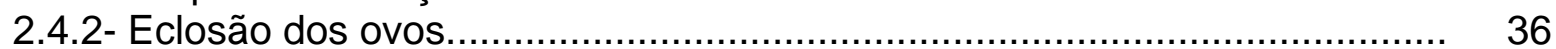

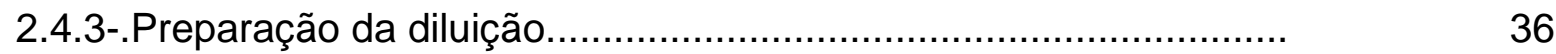

2.4.4-.Determinação da atividade.citotóxica 37

2.4.5- Cálculo da porcentagem (\%) de mortalidade de Artemia salina................ 37

2.5- Procedimento Estatístico................................................................... 38

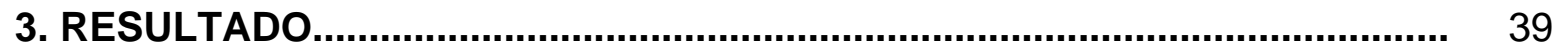

4. DISCUSSÃO........................................................................................ 73

5- CONCLUSÃO............................................................................................ 83

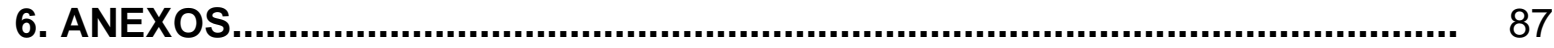

6.1- Anexo A - Parecer do Comitê de Ética em Pesquisa.................................. 87

6.2- Anexo B - Protocolo de medidas do halo de inibição pelo Método do Poço... 88

6.3- Anexo C - Protocolo de Concentração Inibitória Mínima................................ 89

6.4- Anexo D- Resultado da Atividade antimicrobiana..................................... 90

Protocolo 1- Atividade antimicrobiana do vinagre branco/tinto a 30,0, 25,0 e 10,0\% e do ácido acético a 1,0 e 7\% sobre 22 cepas de $\begin{array}{llll}P . a e r u g i n o s a & \text { pelo do } 90\end{array}$ poço.

Protocolo 2- Atividade antimicrobiana do vinagre branco/tinto a 30,0, 25,0e $10,0 \%$ e do ácido acético a 1,0\% e 0,7\% sobre 21 cepas de $E$. coli pelo método do poço.

Protocolo 3- Atividade antimicrobiana do vinagre branco/tinto a 30,0, 25,0 e 10,0\% e do ácido acético a 1,0 e 0,7\% sobre cepas de Staphylococcus aureus pelo método do 92 poço.

6.5- Anexo E- Resultado da Concentração Inibitória Mínima..... 93

Protocolo 1- CIM do vinagre tinto sobre cepas de S.aureus.......................... 93

Protocolo 2- CIM do vinagre tinto sobre cepas de E. coli............................... 94 
Protocolo 3- CIM do vinagre tinto sobre cepas de P.aeruginosa................... 95

Protocolo 4- CIM do vinagre branco sobre cepas de S.aureus..................... 96

Protocolo 5- CIM do vinagre branco sobre cepas de E. coli......................... 97

Protocolo 6- CIM do vinagre branco sobre cepas de $P$.aeruginosa................ 98

Protocolo 7- CIM do ácido acético sobre cepas de S.aureus....................... 99

Protocolo 8- CIM do ácido acético sobre cepas de E. coli........................... 100

Protocolo 9- CIM do ácido acético sobre cepas de P.aeruginosa................ 101

7- REFERÊNCIAS BIBLIOGRÁFICAS............................................................ 102

\section{APÊNDICE}

8.1- Apêndice 1-Meios de cultura, composição e preparação

8.2-Apêndice 2- Diluição dos produtos para teste piloto, técnica de poço (well) e determinação da Concentração Inibitória Mínima (CIM) 


\section{LISTA DE TABELAS}

p.

Tabela 1- Microrganismos padrão, campo/hospitalar e da comunidade/campo utilizados como indicadores da atividade antimicrobiana do ácido acético e vinagre. Ribeirão Preto, 2003

Tabela 2- Atividade antimicrobiana de vinagre branco/tinto, e ácido acético (PA) in vitro pelo método de poço frente aos diferentes microrganismos, Ribeirão Preto, 2003.

Tabela 3- Distribuição da média do diâmetro dos halos de inibição em milímetro dos vinagres branco/tinto a $30,0 \%$ sobre 22 cepas de P.aeruginosa pelo método de difusão do poço, Ribeirão Preto, 2003

Tabela 4- Distribuição da média do diâmetro dos halos de inibição em milímetro dos vinagres branco/tinto a 25,0\% e do ácido acético a 1,0\% sobre 22 cepas de $P$.aeruginosa pelo método de difusão de poço, Ribeirão Preto, 2003.

Tabela 5- Distribuição da média do diâmetro dos halos de inibição em milímetro dos vinagres branco/tinto a 10,0\% e do ácido acético a $0,7 \%$ sobre 22 cepas de $P$.aeruginosa pelo método de difusão de poço, Ribeirão Preto, 2003.

Tabela 6- Distribuição da média do diâmetro dos halos de inibição em milímetro, do ácido acético 1,0 e 0,7\% sobre 22 cepas de $P$.aeruginosa pelo método de difusão de poço, de Ribeirão 
Preto, 2003.

Tabela 7- Distribuição da média do diâmetro dos halos de inibição em milímetro dos vinagres branco/tinto a 30,0, 25,0 e 10,0\% sobre 22 cepas de $P$.aeruginosa pelo método de difusão depoço, Ribeirão Preto, 2003.

Tabela 8- Distribuição da média do diâmetro dos halos de inibição em milímetro, do ácido acético a 1,0 e 0,7\% sobre 22 cepas de $P$.aeruginosa pelo método de difusão de poço, Ribeirão Preto, 2003.

Tabela 9- Distribuição da média do diâmetro dos halos de inibição em milímetro dos vinagres branco/tinto a 30,0\% sobre 21 cepas de $E$. coli pelo método de difusão de poço, Ribeirão Preto, 2003

Tabela 10- Distribuição da média do diâmetro dos halos de inibição em milímetro dos vinagres branco/tinto a $25,0 \%$ e do ácido acético a 1,0\% sobre 21 cepas de E. coli pelo método de difusão de poço, Ribeirão Preto, 2003.

Tabela 11- Distribuição da média do diâmetro dos halos de inibição em milímetro dos vinagres branco/tinto a 10,0\% sobre 21 cepas de E. coli pelo método de difusão do poço, Ribeirão Preto, 2003.

Tabela 12- Distribuição da média do diâmetro dos halos de inibição em milímetro do ácido acético a 1,0 e 0,7\% sobre 21 cepas de

E. coli pelo método de difusão de poço, Ribeirão Preto, 2003

Tabela 13- Distribuição da média do diâmetro dos halos de inibição em milímetro dos vinagres branco/tinto a 30,0, 25,0 e 10,0\% sobre 21 cepas de $E$. coli pelo método de difusão de poço, Ribeirão Preto, 2003 
Tabela 14- Distribuição da média do diâmetro dos halos de inibição em milímetro do ácido acético a 1,0 e 0,7\% sobre 21 cepas de $E$. coli pelo método de difusão de poço, Ribeirão Preto, 2003......

Tabela 15- Distribuição da média do diâmetro dos halos de inibição em milímetro dos vinagres branco/tinto a 30,0, 25,0 e 10,0\% sobre 22 cepas de P.aeruginosa (Pa), S.aureus (Sa) e 21 cepas de E.coli $(\mathrm{Ec})$ pelo método de difusão de poço, Ribeirão Preto, 2003

Tabela 16- Distribuição da média do diâmetro dos halos de inibição em milímetro do ácido acético a 1,0 e 0,7\% sobre 22 cepas de P.aeruginosa $(\mathrm{Pa})$, S.aureus (Sa) e 21 cepas de E.coli (Ec) pelo método de difusão de poço, Ribeirão Preto, 2003............

Tabela 17 Distribuição dos resultados dos testes estatísticos da avaliação dos halos de inibição em milímetros pelo método de difusão de poço sobre 22 cepas de Pseudomonas aeruginosa do vinagre branco (VB), tinto (VT) e do ácido acético (AA) nas concentrações $30,0,25,0,10,0,1,0$ e 0,7\% respectivamente, Ribeirão Preto, 2003.

Tabela 18 Distribuição dos resultados dos testes estatísticos da avaliação dos halos de inibição em milímetros pelo método de difusão de poço sobre 21 cepas de E. coli do vinagre branco (VB), tinto (VT) e do ácido acético (AA) nas concentrações $30,0,25,0,10,0,1,0$ e 0,7\% respectivamente, Ribeirão Preto, 2003

Tabela 19- Distribuição dos resultados da Concentração Inibitória Mínima de vinagres branco/tinto (Castelo) e ácido acético PA (Merck) sobre 20 cepas hospitalar/campo de P.aeruginosa, Ribeirão Preto, 2003

Tabela 20- Distribuição dos resultados da Concentração Inibitória Mínima 
de vinagres branco/tinto (Castelo) e ácido acético PA (Merck) sobre 20 cepas hospitalar/campo de E. coli, Ribeirão Preto, 2003.

Tabela 21 Distribuição dos resultados de Concentração Inibitória Mínima de vinagres branco/tinto (Castelo) e ácido acético PA (Merck) sobre 12 cepas hospitalar/campo e 8 cepas comunidade de S.aureus, Ribeirão Preto, 2003.

Tabela 22- Distribuição dos resultados de Concentração Inibitória Mínima de vinagres branco/tinto (Castelo) e ácido acético PA (Merck) sobre 20 cepas hospitalar/campo de P.aeruginosa (Pa) E.coli (Ec) e S.aureus (Sa), Ribeirão Preto, 2003.

Tabela 23- Distribuição dos resultados da atividade citotóxica do vinagre branco/tinto (Castelo) e do ácido acético (PA) sobre Artemia salina Leach, Ribeirão Preto, 2003. 


\section{LISTA DE FIGURAS}

p.

Figura 1- $\quad$ Fluxograma da Técnica de Difusão do Poço........................

Figura 2- Vista panorâmica da ação antimicrobiana do vinagre e do ácido acético pela técnica do poço sobre as cepas Micrococcus luteus, Pseudomonas aeruginosa, Enterobacter/Klebsiella e Candida albicans.

Figura 3- $\quad$ Fluxograma da Concentração Inibitória Mínima 35

Figura 4- Representação gráfica dos dados da tabela 3. 41

\section{Figura 5-}

Representação gráfica dos dados da tabela 4. 43

Figura 6Histograma dos dados da tabela 4. 44

Figura 7Representação gráfica dos dados da tabela $5 .$. 46

Figura 8Histograma dos dados da tabela 5.

Figura 9-

Representação gráfica dos dados da tabela 6. 49

Figura 10Histograma dos dados da tabela 7 e 8 .

Figura 11Representação gráfica dos dados da tabela 9.

Figura 12Histograma dos dados da tabela 10.

Figura 13- Representação gráfica dos dados da tabela 11..

Figura 14Representação gráfica dos dados da tabela 12.

Figura 15Histograma dos dados da tabela 13 e 14. Histograma dos dados da tabela 15 e $16 .$.

Figura 17- Vista Panorâmica da CIM do vinagre branco sobre 20 cepas de P.aeruginosa:A - 1,5 e B - 1,0\%)....

Figura 18- Vista Panorâmica da CIM do vinagre tinto sobre 20 cepas de P.aeruginosa : A - 1,5 e B - 1,0\%).

Figura 19- Vista Panorâmica da CIM do ácido acético sobre 20 cepas de P.aeruginosa : A - 0,25 e B -controle.

Figura 20- Vista Panorâmica da CIM do vinagre branco sobre 20 cepas de E.coli : A - 2,0 e B - 1,0\%.....

Figura 21- Vista Panorâmica da CIM do vinagre tinto sobre 20 cepas 
de E.coli : A - 1,5 e B - 1,0\%

Figura 22- Vista Panorâmica da CIM do ácido acético sobre 20 cepas de E.coli : A - 0,25\% e B - controle.

Figura 23- Vista Panorâmica da CIM do vinagre branco sobre 20 cepas de S.aureus : A - 3,0, B - 2,0 e C - 1,5\%.

Figura 24- Vista Panorâmica da CIM do vinagre tinto sobre 20 cepas de S.aureus : A - 3,0, B - 1,5 e C - 1,0\%

Figura 25- Vista Panorâmica da CIM do ácido acético sobre 20 cepas de S.aureus : A - 0,25 e B-controle.

Figura 26- Constituição das paredes celulares das bactérias Gramnegativas e Gram- positivas. 


\section{RESUMO}

UTYAMA, I. K. A. Avaliação da atividade antimicrobiana e citotóxica in vitro do vinagre e ácido acético: perspectiva na terapêutica de feridas. Ribeirão Preto. 108p. Dissertação (mestrado) Escola de Enfermagem de Ribeirão Preto, Universidade de São Paulo.

O uso correto de produtos químicos com ação antimicrobiana na terapêutica de feridas tem sido uma das preocupações dos profissionais da saúde. A temática em questão representa uma séria problemática agravada, principalmente, pela diversidade de opções, o que traz a insegurança sobre qual é a mais indicada, bem como, pelo uso indiscriminado o que pode resultar na seleção de cepas resistentes. Diante do exposto, foi estabelecido como objetivos: avaliar in vitro a atividade antimicrobiana do ácido acético e do vinagre por meio da Técnica de Difusão de Poço sobre as cepas de Pseudomonas aeruginosa, E. coli e Staphylococcus aureus; determinar a Concentração Inibitória Mínima (CIM); e revelar a citotoxicidade dos referidos produtos sobre Artemia salina Leach. Para análise estatística foi usado o teste de variância ANOVA - ONEWAY seguida do teste de comparações múltiplas; com nível de significância $\alpha=5 \%$. Assim sendo, pelo método de difusão de poço o vinagre branco, tinto (30,0 e 25,0\%) e o ácido acético a 1,0 são mais eficazes que o ácido acético a $0,7 \%$, vinagre branco e tinto a 10,0\% $(p<0.05)$ sobre as cepas de Pseudomonas aeruginosa e Escherichia coli. Vale considerar que os produtos analisados não apresentaram ação antimicrobiana sobre Staphylococcus aureus. A Concentração Inibitória Mínima (CIM) do ácido acético nas cepas avaliadas foi a 0,25\%, e do vinagre branco a 2,0\% para Pseudomonas aeruginosa e Escherichia coli sendo que para Staphylococcus aureus a $3,0 \%$. As cepas de $P$. aeruginosa e $E$. coli foram todas inibidas pelo vinagre tinto a 1,5\%, e sobre as de Staphylococcus aureus a 3,0\%. Ainda, com relação a CIM dos produtos químicos testados, não se verificou diferença entre 
cepas de Staphylococcus aureus hospitalar e comunidade. O ácido acético foi citotóxica em todas as concentrações estudadas. Já, o vinagre branco e tinto em $0,25 \%$ e $0,125 \%$ não apresentaram citotoxicidade. Ainda que, não tenha sido a preocupação nesse momento de buscar correlação entre os dados desse estudo com o uso in vivo é importante atentar que tais produtos têm sido amplamente utilizados como agente antimicrobiano no tratamento de feridas, e muitas vezes em concentrações elevadas que podem causar danos aos tecidos dificultando, assim, o processo de cicatrização. A nosso ver é premente despertar nos profissionais da saúde a consciência crítica-reflexiva em relação à utilização das evidências científicas de maneira que possam analisar e aplicar com critério os resultados das pesquisas em prol da qualidade da assistência à saúde.

Palavras-chave: vinagre; ácido acético; atividade antimicrobiana; citotoxicidade feridas; infecção.

Key words: vinegar; acetic acid, citotoxicid, antimicrobial activity, wound, infection. 


\begin{abstract}
UTYAMA, I. K. A. In vitro evaluation of antimicrobial and cytotoxicity activities of vinegar and acetic acid: perspectives for wound therapeutics Ribeirão Preto. 108p. Dissertation (masters) School of Nursing of Ribeirão Preto, University of São Paulo.
\end{abstract}

One of the concerns of health professionals has been the correct use of chemical products with antimicrobial action on wound therapeutics. This issue represents a serious problem, which is made even worse due to the facts that there is a diversity of options of products, which builds insecurity in regards to which product is more appropriate, and there is an uncontrolled use that may result in the selection of resistant species. In this sense, we set the following goals for this study: perform an in vitro assessment of the antimicrobial activity of acetic acid and vinegar using the Technique of Diffusion of Well on strains of Pseudomonas aeruginosa, E. coli, and Staphylococcus aureus; determine the Minimal Inhibitory Concentration (MIC); and reveal the cytoxicity of the referred products over Artemia salina Leach. ANOVA - ONEWAY test was used for statistic analysis, followed by the multiple comparison test; with a significance level $\alpha=5 \%$. By the well diffusion technique, the white vinegar, red vinegar (30 and 25\%), and the acetic acid at $1.0 \%$ are more effective than the acetic acid at $0.7 \%$, white and red vinegar at $10 \%(p<0,05)$ over the strains of Pseudomonas aeruginosa and Escherichia coli. The analyzed products did not present antimicrobial actions over Staphylococcus aureus. The Minimal Inhibitory Concentration for the acetic acid on the species was $0.25 \%$. For white vinegar on Pseudomonas aeruginosa and Escherichia coli was $2.0 \%$, and $3.0 \%$ on Staphylococcus aureus. All P. aeruginosa and E. coli were inhibited by red vinegar at $1.5 \%$, and at $3.0 \%$ for Staphylococcus aureus. In regard to the MIC of the tested chemical products, no difference was found between the hospital and community Staphylococcus aureus. Acetic acid was cytotoxic in all studied 
concentrations, while white and red vinegar in $0.25 \%$ and $0.125 \%$ did not show any cytoxicity. Although this study was not concerned with finding a relation among the study's data with the in vivo use, it is important to observe that such products have been largely used as antimicrobial agents for wound treatment, at concentrations often so high that human tissue might suffer damage; thus hindering the healing process. It is, therefore, essential to stimulate health professionals a critical-reflexive consciousness regarding the use of scientific evidence in a way to analyze and apply the research outcomes in favor of a quality health care.

Key words: vinegar; acetic acid, cytotoxicity, antimicrobial activity, wound, infection. 


\section{RESUMEM}

UTYAMA, I. K. A. Evaluación de la actividad antimicrobiana y citotóxica in vitro del vinagre y del ácido acético: perspectivas en la terapéutica de heridas. Ribeirão Preto. 108p.Tesis (maestría) Escuela de Enfermaria de Ribeirao Preto, Universidad de São Paulo.

El uso correcto de productos químicos con acción antimicrobiana en la terapéutica de heridas se convertió en una de las preocupaciones de los profesionales de la salud. La temática en cuestión representa una séria problemática agravada, principalmente, por la diversidad de opciones, lo que trae la inseguridad sobre cual es la más indicada, así como, por el uso indiscriminado, lo que puede resultar en la selección de cepas resistentes. Delante de eso, fue establecido como objetivos: evaluar in vitro la actividad antimicrobiana del ácido acético y del vinagre a travéz de la Técnica de Difusión de Pozo sobre las cepas de Pseudomonas aeruginosa, E. coli e Staphylococcus aureus; determinar la concentración inhibitoria Mínima (CIM); y revelar la citotoxicidad de los referidos productos sobre Artemia salina Leach. Para análise estatística fue utilizado un test de variáncia ANOVA - ONEWAY seguida del test de comparaciones múltiples; con nivel de significáncia $\alpha=5 \%$. De este modo, por el método de difusión de Pozo el vinagre blanco, tinto (30,0 e 25,0\%) y el ácido acético a 1,0 son más eficazes que el ácido acético a 0,7\%, vinagre blanco y tinto a $10,0 \%(p<0.05)$ sobre las cepas de Pseudomonas aeruginosa y Escherichia coli. Vale considerar que los productos analisados no presentan acción antimicrobiana sobre Staphylococcus aureus. La concentración inhibitoria Mínima (CIM) del ácido acético en las cepas evaluadas fue a 0,25\% y del vinagre blanco a 2,0\% para Pseudomonas aeruginosa y Escherichia coli, siendo que para Staphylococcus aureus a $3,0 \%$. Las cepas de $P$. aeruginosa y $E$. coli fueron todas inhibidas por el vinagre 
tinto a 1,5\%, y sobre las de Staphylococcus aureus a 3,0\%. Aún con relación a CIM de los productos químicos testados, no se verificó diferencia entre cepas de Staphylococcus aureus hospitalar y comunidad. El ácido acético fue citotóxico en todas las concentraciones estudiadas. Ya el vinagre blanco y tinto en $0,25 \%$ y $0,125 \%$ no presentan citotoxicidad. Aúnque no tenga sido la preocupación en esse momento, de buscar correlación entre los datos de ese estudio con el uso in vitro es importante atentar que tales productos son amplamente utilizados como agentes antimicrobiano en el tratamiento de heridas, y muchas veces en concentraciones elevadas que pueden causar daños a los tejidos dificultando, así, el proceso de cicatrización. En nuestro punto de vista es premente despertar en los profesionales de la salud la consciéncia crítica-reflexiva en relación a la utilización de las evidéncias científicas de manera que puedan analisar y aplicar con critério los resultados de las investigaciones en favor de la calidad de la asisténcia a la salud.

Palabras-llave: vinagre; ácido acético; actividad antimicrobiana, citotoxicidad, infección, heridas. 


\section{AUTORIZAÇÃO}

Autorizo a reprodução e/ou divulgação total ou parcial da presente obra, por qualquer meio convencional ou eletrônico, desde que citada a fonte.

Nome dos Autores: Iwa Keiko Aida Utyama

Denise de Andrade

Assinatura dos autores:

Instituição: Universidade de São Paulo

Local: Escola de Enfermagem - Ribeirão Preto

Endereço: Rua Lucila Balalai, 65

Londrina - Paraná

E-mail: utyama@sercomtel.com.br 


\section{APRESENTAÇÃo}

A minha vivência profissional na assistência e no ensino de enfermagem foi um período marcado por grandes transformações resultado de profundas reflexões acerca de uma educação predominantemente tecnicista. Assim, reformas na área da educação aconteciam de forma a contemplar as necessidades políticas, sociais e econômicas do país.

Especificamente na experiência docente atuei no nível médio de enfermagem a partir de 1978, e em 1981 passei a ministrar aulas no ensino superior do Curso de Enfermagem da Universidade Estadual de Londrina. No ano seguinte, com o objetivo de dar oportunidade aos alunos do Curso de Graduação em Enfermagem de prestar assistência ambulatorial, foi elaborado projeto de extensão multiprofissional, envolvendo médico, enfermeiro, assistente social, executado em caráter experimental por seis meses. A experiência foi tão positiva para os docentes de enfermagem, medicina, serviço social, alunos de enfermagem e de medicina que até hoje este projeto é desenvolvido no Ambulatório do Hospital de Clínicas da Universidade Estadual de Londrina.

Em 1991, o Centro de Ciências da Saúde da Universidade Estadual de Londrina, foi selecionado entre várias universidades para integrar o projeto UNI (Uma Nova Iniciativa de Educação dos Profissionais de Saúde com a Comunidade), projeto financiado pela Fundação Kellogg. Este projeto exerceu grande influência nas práticas de ensino do Curso de Graduação em Enfermagem, estimulando mudanças no cenário do processo ensinoaprendizagem e nas práticas assistenciais por meio da interdisciplinaridade e da multiprofissionalidade.

Considero essa oportunidade ímpar na incorporação do novo paradigma didático-pedagógico com repercussões, particularmente, na disciplina de Fundamentos de Enfermagem. Cabe destacar que, tal disciplina tem 
responsabilidade de fornecer conhecimentos e habilidades fundamentais para o desempenho de atividades básicas no cuidado de enfermagem. Assim, a disciplina de Fundamentos de Enfermagem deve contemplar no seu conteúdo programático, o conhecimento sobre feridas e sua terapêutica entre outros.

A busca incansável pela qualidade da assistência dos indivíduos com feridas culminou no ano de 1997 a implementação do projeto de ensino interdisciplinar com a participação das diferentes disciplinas do ciclo básico, representadas pela Histologia, Imunologia, Nutrição e Patologia, Farmacologia, Microbiologia e Fundamentos de Enfermagem do profissionalizante. Este projeto intitulado "Feridas - Integração Interdisciplinar" está sendo implementado, até o momento.

O livro "Feridas - cuidados e condutas" de nossa autoria, editada em 2001, representa o fruto de nossas experiências nos projetos de extensão e ensino.

Participando das atividades de ensino e extensão, percebemos que a maior inquietação sentida pelos profissionais de saúde reside na implementação de atividades para prevenção e controle de infecção que sejam realmente efetivas.

Para o tratamento da ferida em geral com suspeita de infecção por Pseudomonas, por muitos anos no nosso serviço ambulatorial temos utilizado e indicado a aplicação diária do ácido acético a 3\% por até duas semanas e para uso domiciliar o vinagre branco diluído. Temos observado que o ácido acético e vinagre auxiliam no controle dessa infeç̧ão demonstrando a redução do exsudato, do odor e conseqüente formação do tecido de granulação.

O avanço técnico-científico ocorrido em todas as áreas do conhecimento nas últimas décadas trouxe a necessidade premente de atualização dos profissionais da área da saúde quanto a sua prática no tratamento de feridas crônicas com vistas a subsidiar a escolha do produto a ser utilizado, bem como, esclarecer demais aspectos relativos a terapêuticas. 
Por outro lado, evidenciou-se escassez de estudos relativos a literatura médica e de enfermagem tem da utilização do ácido acético e vinagre em feridas. No Brasil, estes produtos são de baixo custo, disponível, de fácil manejo, e largamente utilizado na prática popular o que compatibiliza com a situação econômica da nossa população que na maior parte das vezes arca com os custos dos produtos usados para o tratamento.

Assim, pretende-se neste estudo in vitro avaliar a atividade antimicrobiana e citotoxicidade do ácido acético e do vinagre sobre as bactérias Gram-positivo e negativo, como primeira etapa para avaliação da prática clínica existente.

Posteriormente, almejamos realizar um estudo in vivo (em modelo animal) com diferentes microrganismos, a exemplo Pseudomonas aeruginosa e Escherichia coli e Staphylococcus aureus com vistas a avaliar a atividade antimicrobiana desses produtos químicos comumente utilizados no tratamento de feridas.

Torna-se necessário atentar para o fato de que os microrganismos se alteram, sofrem mutações e adaptações pela ação dos antibióticos, antisépticos, desinfetantes, dentre outros, mudanças essas que levam a necessidade de avaliações permanentes e periódicas, com o propósito de substituir as intervenções de eficiência questionável frente às reais condições microbiológicas.

Se por um lado, os controles das opções terapêuticas representam melhores recursos para os profissionais de saúde na luta contra as infecções das feridas, por outro, traz a insegurança sobre qual é a mais indicada. Vale considerar que a literatura científica atual deixa transparecer algumas lacunas e aspectos conflitantes entre uma escolha e outra. 


\section{1- INTRODUÇÃO}

\section{1- O Cuidado de Feridas: aspectos técnicos-assistenciais}

$\mathrm{Na}$ retrospectiva histórica relacionada ao tratamento de feridas é possível evidenciar antigas orientações por meio de registros que coincide com a existência do homem no mundo. Provavelmente, o cuidar de feridas teve início na pré-história com o homem primitivo, quando este, na luta pela sobrevivência sofria algum tipo de ferimento, necessitando de tratamento. O primeiro cuidador de ferimento, pode ter sido uma mãe aflita que socorreu o seu filho das presas de um carnívoro (Whipple, 1961).

Ferida é uma palavra de origem latina (ferire) representa a separação dos tecidos do corpo ou qualquer lesão tecidual, seja epitelial, mucosas ou órgãos com prejuízo de suas funções básicas. As feridas podem ser produzidas por fatores extrínsecos como a incisão cirúrgica e as lesões acidentais, corte ou trauma, ou por fatores intrínsecos, como aquelas produzidas por infecção, e as úlceras crônicas, causadas por alterações vasculares, defeitos metabólicos ou neoplasias (Centre for Medical Education, 1994).

A ferida pode acarretar sérios prejuízos ao seu portador, às vezes, de difícil reparação. Neste sentido, a infecção tem se destacado uma vez que retarda o processo de cicatrização, prolonga a plena recuperação, aumenta o custo tanto para os indivíduos como para os cofres públicos. Vale considerar que para o indivíduo além das despesas com material gasto, tempo destinado para realização de curativo, aumento do período de hospitalização existe a possibilidade da perda de qualidade de vida, produtividade, rendimento, e finalmente, a preocupação com a morbidade duradoura, ou até mesmo, com a mortalidade. Outros distúrbios devem ser pontuados como a dor, mal estar, isolamento, e demais sofrimentos que perpassam pelo indivíduo com ferida. Enfim, as circunstâncias culturais, sócio-econômicas podem deixar a pessoa 
com ferida vulnerável, indefesa e com auto-estima diminuída (Ferraz, 1990; Krasner \& Kane, 1997).

O tratamento das feridas exige um conjunto de atividades as quais devem ser estabelecidas mediante a avaliação da lesão, bem como, das condições clínicas do paciente. É inerente ao homem ao ferir uma parte do corpo a atitude de tentar reverter esse trauma, para não causar, posteriormente, prejuízos.

Whipple (1961) refere que a primeira informação sobre tratamento de feridas encontra-se no Edwin Smith Papyrus de Egito datado de cerca de 3.000 a.C. Este papiro registra aspectos de suma importância da civilização egípcia, dentre eles mais de 700 substâncias utilizadas, que atualmente tem sua importância consagrada no tratamento popular como alho, cebola, mel, figo, óleo de oliva, óleo de rícino (mamona) Aloe vera (babosa), para queimaduras e o óleo de acácia (ácido tânico).

Estudiosos mencionam que desde tempos remotos diversos produtos de origem animal, vegetal e mineral tem sido largamente usado na terapêutica das feridas (Krasner \& Kane, 1997).

O papiro de Elbers, referente ao ano de 1550 a.C., que se encontra na Alemanha, na Universidade de Leipzig recomenda manter as bordas das feridas unidas/aproximadas por meio de bandagens de linho embebidas em mirra e mel e removidas/retiradas após quatro dias (Dealey, 1996).

O procedimento místico e doença como castigo de divinos são também registrados no papiro. Ainda, esta civilização possuía um livro que descrevia o tratamento para mais de 50 lesões traumáticas, como o uso de óleos vegetais, oclusão das feridas com cataplasmas ou com faixas de algodão, hemostasia com carne fresca, papa com pão para lesões infecciosas e algumas ervas com a finalidade de acelerar a cicatrização. Os egípcios sabiam e julgavam fundamental o equilíbrio dos líquidos pelo corpo o que implicava no bem estar total do organismo. 
Hipócrates (460-377 a.C.) criou a base da medicina científica com ênfase na observação cuidadosa. Em geral, preconizava a manutenção das feridas limpas e secas. Como na civilização egípcia utilizavam óleos vegetais (rícino, oliva), ervas medicinais, mel, acrescidos de leite, banhas, secreção de caramujo, vinho. Recomendava água tépida, vinho para limpar a ferida, e para assepsia o vinagre. Sugeria a aplicação de emplastos ou cataplasma em feridas com indícios de inflamação para amaciar os tecidos e permitir drenagem de pús.

Galeno (129-199 d.C.) que viveu na época do Império Romano, como médico dos gladiadores, observou que feridas recentes extensas, quando lavadas com vinho e fechadas com fio de linho, curavam logo sem formação de pus (Whipple, 1961). Passou a ser conhecido pela teoria do pus louvável, que por muitos eram considerados benéficos, fazendo pensar que acelerava a cicatrização. O mesmo considerava que a aplicação nas feridas de tinta de caneta, fios de teia de aranha e barro era eficaz (Thomaz \& Herdy, 1997).

Há registro de que Galeno, no século II, revolucionou o tratamento de feridas baseado na crença de que o estado de saúde do indivíduo necessita do fluir harmônico de líquidos e humores no interior do organismo, isto é, a interrupção ou presença de humores negativos causava doenças. Para reequilibrar os fluidos, o barbeiro realizava corte na veia do antebraço ou da região frontal deixando o sangue drenar, antes dessa intervenção, o cliente supersticioso, pronunciava a frase "Jesus e Maria sempre virgem". Para auxiliar a cicatrização da ferida, utilizava um pó composto de sangue humano desidratado, pêlo de lebre, esterco de asno negro recolhido na primavera. Este procedimento traumático de sangria foi proibido em 1311, quando as sanguessugas passaram a ser utilizadas para aderirem a pele e sugar o sangue considerado excessivo (Cândido, 2001).

Ainda o mesmo autor descreve que no período medieval a bruxaria assume importante papel no tratamento de feridas, associando preces, plantas medicinais, teia de aranha, ovo, e cauterização com óleo quente. A partir do 
século $\mathrm{XI}$, da era Medieval, os padres foram proibidos pela igreja de desenvolverem atividades que envolviam contato com sangue humano, assim surge a figura do barbeiro-cirurgião. Com o passar dos tempos os barbeiros saíram dos muros do monastério para curar nos feudos e nos povoados.

No Evangelho São Lucas, também menciona o uso do óleo e vinho no tratamento de feridas do viajante (Bíblia 1970).

Celsius fez a copilação histórica e detalhada da evolução da prática médica desde a época de Hipócrates até o ano 100 d.C. Este estudioso classificou os tipos das feridas, os tratamentos, as técnicas de desbridamento e descreveu os quatro sinais clássicos da infecção, tal como, dor, calor, rubor e edema. Ainda, preconizou a limpeza e a remoção de corpos estranhos antes do fechamento primário de lesões por meio de sutura (Dealey 1996).

Ainda, na época medieval, a "spezieria", considerada a farmácia de manipulação na atualidade, preparava produtos naturais provenientes de ervas, venenos, pele de cobras. Na farmacopéia medieval, o óleo de oliva era empregado no tratamento de feridas e úlceras ou misturado com vinho. No final do século XVI, Ambroise Paré, passou a defender o princípio da intervenção mínima, afirmando que o processo de cicatrização ocorreria naturalmente, ainda verificou que com a instilação de terebentina em feridas por arma de fogo obtinha-se uma cicatrização melhor que a instilação de óleo fervente (Cândido, 2001).

Chenu refere que na Guerra da Criméia (1853-1856) em um exército de 300.000 homens, 10.000 foram mortos em combates e o mesmo número morreu de feridas e infecções (Ferraz, 1982). Nesta época houve um avanço enorme na produção de tecidos para curativos, os quais, entretanto eram pobres considerando a absorção de exsudatos.

No século XVIII e início do século XIX, as esponjas para lavagem de feridas eram coletivas e os curativos reutilizados sem qualquer procedimento de lavagem (Alexander, 1985). 
No final do século XIX e início do século XX, Halsted \& Carrel mostraram a importância da limpeza da ferida por meio de desbridamento meticuloso e a possibilidade de aproximação das bordas por meio da sutura. Por outro lado, Lister, Pasteur e Semmelweis mudaram inteiramente o panorama da área de saúde neste século, demonstrando a importância do controle da infecção por meio da limpeza, higienização, anti-sepsia, desinfecção e esterilização de instrumentos cirúrgicos (Ferraz, 1982).

$\mathrm{Na}$ I Guerra Mundial, os feridos tinham que esperar por vários dias para receberem um simples curativo, assim sendo, muitos ferimentos infeccionavam e gangrenavam. Com esta catástrofe foram criados anti-sépticos como Eusol (Edinburgh University Solution of Lime), solução de ácido bórico com alvejante e solução de Dakin para resolver o problema da infecção nas úlceras das pernas (Dealey, 1996).

Apesar do uso de vinho no tratamento de feridas datar desde Hipócrates, o avanço da química, no início do século XX, tornou esse uso comum por meio de um dos componentes do vinho, o álcool, indicado na limpeza de materiais e anti-sepsia da pele (Cruse \& McPhedran, 1991).

Em 1928, a descoberta da Penicilina por Fleming, revolucionou a terapêutica de feridas infectadas considerando sua utilização clínica em fevereiro de 1941 na cidade de Oxford, e a sua produção em escala industrial a partir de 1942. Na época julgou-se essa droga miraculosa para o controle bacteriano, no entanto, o aparecimento de bactérias resistentes à droga, acabou desencantando os adeptos desta droga (Williams \& Epstein, 1967).

Dealey (1996) afirma que, por milhares de anos, tem-se aplicado substâncias naturais para ajudar na cicatrização da ferida. Ainda hoje o cuidado com feridas é realizado de maneira ritualística algumas vezes sem fundamentação científica. Alerta para as desvantagens desse ritual e explica que o curativo não significa simples cobertura. Rijswijk (1997) explica que a palavra curativo, do francês drecie (to arrange), to dress literalmente significa, fazer reto, fazer correto, para colocar em ordem correta. 
Particularmente, em relação ao desempenho técnico dos responsáveis pelo curativo é sabido que essa tarefa foi executada por diferentes pessoas com níveis de conhecimentos e condutas adversas. Todavia, a realização do curativo passou gradativamente para freiras experientes, e posteriormente, para o domínio das enfermeiras. Originalmente este procedimento era realizado por médicos e estudantes de medicina da área médico-cirúrgica. Atualmente, tem sido enfatizado no tratamento da ferida o envolvimento de diferentes profissionais, isto é, o desempenho multidisciplinar e interdisciplinar. A atuação de diferentes profissionais tem contribuído sobremaneira na terapêutica de feridas uma vez que permite analisar todos os fatores relacionados, e conseqüentemente compreender a complexidade da cura (Krasner \& Kane, 1997).

Retomando a retrospectiva histórica dos avanços e das mudanças no tratamento de feridas há registros de que nas décadas 30, 40 e 70, a técnica de curativo era feita de forma rígida com exacerbação de medidas de assepsia, dando ênfase à posição do equipamento, das pinças, da freqüência e do tempo de lavagem das mãos. A rotina era estabelecida de maneira que a troca dos curativos ocorresse uma a duas vezes independentemente do tipo de ferida.

No entanto, na década de 1960, um novo conceito no cuidado com a ferida foi introduzido, ou seja, a manutenção do leito da ferida limpo e úmido, pois, esses fatores aceleram a cicatrização. O estudo realizado por Winter (1962) utilizando modelo animal, verificou que a epitelização foi duas vezes mais rápida nas feridas cobertas com filme. Posteriormente, Eaglstein et al., (1990) e Dealey (1996) verificaram a diminuição da dor local com curativo úmido. Estudiosos detectaram que os processos autolíticos aumentavam no meio úmido, provocando a lise dos tecidos necróticos, iniciando a revolução dos curativos.

Turner em 1986 revisou e listou os tipos de curativos com base na Farmacopéia Britânica, observando que de 1923 a 1980, poucas mudanças foram registradas a respeito. Ressaltou que o curativo era feito sempre com os 
materiais que estivessem à mão como gazes, chumaços de lã de algodão, gaze impregnada, fitas de gaze e bandagens com medicamentos (Dealey, 2001).

Ainda, os estudiosos esclarecem que nas décadas passadas uma variedade de substâncias químicas foram utilizadas no tratamento da ferida, sem qualquer fundamentação científica. Dados estes encontrados por Walsh \& Ford (1992), Murray (1988), Millward (1989) apud Dealey (2001). Muitos escolhiam os produtos para aplicação em feridas sem questionar o por que de usar este ou aquele produto, geralmente a escolha era feita sem base científica.

Atualmente é amplamente reconhecida que, para estabelecer o tratamento adequado das feridas infectadas é necessária a identificação do agente etiológico. Em suma, o produto de escolha para o tratamento de feridas deve apresentar atividade antimicrobiana contra o agente infectante, e conseqüentemente, contribuir para a cicatrização da lesão (Bajay et al.,1999).

Nesse sentido, vale considerar os principais fatores que afetam 0 processo de cicatrização. Estes podem ser divididos em fatores intrínsecos e extrínsecos. Os intrínsecos relacionados ao paciente são: idade avançada, condições locais da ferida como tecido necrótico, queda da temperatura local, desidratação, edema, excesso de exsudato, infecção, hipóxia, corpos estranhos; fatores fisiopatológicos, como, deficiência nutricional ou erro alimentar, redução do suprimento de oxigênio na ferida, distúrbios cardiovasculares, imunológicos, metabólicos e endócrinos. Os fatores extrínsecos apresentados são o uso prolongado de esteróides, a radioterapia e uso de drogas citotóxicas/quimioterápicas; bem como, os fatores psicossociais (Kumar et al., 1992; Cotran et al., 1994; Krasner \& Kane, 1997; Borges, 2000; Waldrop \& Doughty, 2000; Ohnishi et al., 2001).

Os tecidos desvitalizados ou necróticos fornecem nutrientes para multiplicação bacteriana, favorecendo a instalação da infecção e retardo da cicatrização. O edema é outro fator que dificulta a cicatrização, pelo excesso de líquido intersticial interferindo na proliferação celular e na síntese protéica, bem como, na manutenção de baixo $\mathrm{pH}$, na alta tensão de $\mathrm{CO}_{2}$ e na baixa 
concentração de $\mathrm{O}_{2}$, favorecendo a necrose e a multiplicação microbiana. A hipóxia dificulta a destruição dos microrganismos pelos leucócitos que são dependentes do oxigênio para exercer esta função, particularmente nas feridas infectadas por Staphylococcus aureus, Proteus vulgaris, Klebsiella pneumoniae, E. coli, Salmonella thyphimurium, bem como, as contaminadas por anaeróbios. O nível crítico de oxigênio parece ser $30 \mathrm{mmHg}$, entretanto, os indivíduos hipotensos, hipovolêmicos ou desidratados, com comprometimento cardiovascular ou pulmonar, doença periférica vascular e angiopatia diabética possivelmente são elementos de risco para infecção (Morison et al., 1997).

Segundo Eaglstein et al. (1990) a reparação tecidual é influenciada pelos fatores locais que facilitem a epitelização, a formação de colágeno e angiogênese e a contração da ferida. Estas condições ideais podem ser conseguidas com a manutenção da temperatura, hidratação, suprimento de oxigênio e nutrientes. Porém, em feridas crônicas nem sempre estas exigências estão contempladas, tendo como fatores dificultadores da cicatrização de ferida o ressecamento e a quebra da fibrina pela presença de infecção.

Kumar et al., (1992) ressaltaram que a infecção representa a causa mais importante de retardo na cicatrização uma vez que estimula os leucócitos a liberar lisozimas. Vale explicar que esta enzima destrói o colágeno existente. Ainda, acresce-se o fato de os microrganismos invasores captam o oxigênio e nutrientes necessários à cicatrização, podendo estender a infecção aos tecidos adjacentes, à corrente sanguínea podendo desencadear a septicemia e até a morte caso não tratada.

Glide (1992) relata que a gaze ou bolas de algodão pode funcionar como fonte de infecção ou corpo estranho, pois podem perder suas fibras na superfície da ferida e encravar no tecido de granulação.

Desde os meados do século $X X$, vem crescendo o desenvolvimento de pesquisas com vistas a avaliar o tratamento mais eficaz, e conseqüentemente, favorecer o processo de cicatrização. Em se tratando de feridas é possível identificar que há lacunas no conhecimento as quais devem ser identificadas e 
atendidas, principalmente, reconhecendo a complexidade multifatorial que envolve o processo de cicatrização.

O uso de produtos químicos com ação germicida para o tratamento de feridas representa uma séria problemática agravada, principalmente, pela diversidade de opções o que gera insegurança no profissional da saúde sobre qual é a mais indicada.

Muitos recursos naturais ou industrializados, tem sido alvo freqüente de investigação, na busca de estabelecer estratégias eficazes de prevenção da infecção e de tratamento por meio de estimulação da cicatrização da ferida (Nogueira, 1983; Monetta, 1987; Haddad, 1994; Declair, 1994; Monetta, 1998; Borges \& Couto, 2000; Martins, 2000; Borges, 2000; Borges et al., 2001). No entanto, poucos estudos apresentam evidências significativas que possam garantir a segurança do tratamento e a sua viabilidade na prática.

A cicatrização não pode ocorrer até que todo material estranho ou resultante do processo inflamatório seja removido do leito das feridas; no entanto, feridas submetidas a traumas pela limpeza são mais suscetíveis a infecção e tem mais dificuldade para cicatrização (Bergstrom et al. 1995).

Rodeheaver (2001) recomenda não utilizar força mecânica, para limpar a ferida com gaze, algodão ou esponja, pois podem traumatizar o tecido que se torna mais suscetível à infecção e com cicatrização mais lenta.

As feridas não cicatrizam enquanto estiverem clinicamente infectadas, portanto, esse diagnóstico de infecção exige em alguns casos o desbridamento ou drenagem de exsudatos, com vistas a ocasionar a promoção do suprimento sanguíneo adequado. Acresce-se a necessidade de instituir o uso de antibióticos apropriados e manutenção do meio úmido da ferida (Morison et al., 1997).

Thomlinson apud Dealey (1996) estudando o método de limpeza da ferida, verificou que a limpeza mecânica com uso de gazes não reduzia a quantidade de bactérias na superfície da pele apenas as redistribuía. 
Para não causar trauma na ferida, os autores a seguir indicam a irrigação suave com solução fisiológica porque esta solução não prejudica os tecidos e promove a limpeza da ferida adequadamente. A literatura médica aponta vários estudos relacionados à limpeza de feridas com irrigação suave de solução fisiológica (Glide, 1992; Carr, 1993; Corum, 1993; Bergstrom et al., 1995; Rodeheaver, 1997; dentre outros).

Os estudiosos supracitados afirmam que a irrigação de soro na limpeza da ferida é o procedimento mais indicado, pois remove corpos estranhos e os tecidos frouxamente aderidos, além de preservar o tecido de granulação neoformado. A pressão hidráulica de oito libras de pressão por polegada quadrada (psi - pounds per square inch) de tecido é conseguida por meio da utilização de soro fisiológico $0,9 \%$, em uma seringa de $35 \mathrm{~mL}$ e uma agulha calibre 19, num ângulo de 45 graus; assim, a solução forçada desloca o material que contamina a superfície da ferida propiciando a redução da colonização de bactérias. Esta irrigação é chamada de branda ou suave recomendada para limpeza superficial de feridas com tecido de granulação e que não estejam infectadas. No entanto no Brasil não dispomos de seringa ou agulha com estas especificações. Porém, Yamada (1999) em sua técnica de irrigação tem utilizado seringa de $20 \mathrm{~mL}$ com agulha calibre 18.

Martins (2000) avaliando as três técnicas de limpeza de feridas infectadas, sendo duas com utilização de seringa de 20ml e agulha 25x8 e outra seringa com a mesma capacidade e agulha 40X12, ambas por meio de técnica de irrigação, e a outra técnica remoção mecânica tradicional, verificou que quando se utiliza uma agulha de calibre menor 25X8 (21G), gera uma pressão de 12,5 "psi" (pounds per square inch) libra por polegada ao quadrado, portanto uma pressão maior que a agulha 40x12 de 18G (9,5 "psi"). Ainda, observou que a irrigação com agulha 25X8 (21G) houve redução bacteriana significativa em comparação com a agulha 40×12 (18G) e remoção mecânica. Embora, as pressões aplicadas estarem dentro da faixa estabelecida pela literatura (4 a 15 "psi"), não observou significância estatística na redução bacteriana. 
No geral, os estudiosos sobre feridas têm mostrado, também que as substâncias utilizadas no tratamento podem prejudicar ou facilitar o processo da cicatrização. Convencionalmente, o tratamento da ferida envolve a aplicação de produtos com a finalidade de limpeza. Vale esclarecer que a limpeza é feita com os seguintes objetivos: eliminar restos celulares, materiais estranhos; remover sujidade, tecido necrótico, desvitalizados e fragmentos soltos; e reduzir a carga microbiana com vistas a prevenir a infecção (Dealey, 1996; Ohnishi et al., 2001).

No entanto, Rodeheaver (2001) recomendou não usar anti-sépticos em feridas para redução da bactéria, pois o uso contínuo destes pode prejudicar as células e dificultar a cicatrização, ao contrário dos antibióticos que matam as bactérias sem causar danos aos tecidos. Alertam que substâncias formuladas para limpeza de pele íntegra não devem ser utilizadas em feridas devido a possível citotoxicidade. Ainda, reforçou que o benefício do anti-séptico como limpeza da ferida não tem sido documentado científicamente.

Morison et al. (1997) observaram a desvantagem da limpeza vigorosa com algodão ou gaze por causar trauma, prolongando a resposta inflamatória, ou até mesmo introduzir corpos estranhos nos tecidos conseqüentemente, o aumento do risco de infecção dificultando assim a cicatrização.

Portanto, urge a necessidade de conhecer as indicações, contra indicações, precauções e advertências relacionadas a cada anti-séptico. Mister se faz, selecionar cuidadosamente o anti-séptico de maneira que seja considerada a condição da ferida, tipo de agente infectante, o mecanismo de ação antimicrobiana do produto.

É inquestionável a importância da realização da avaliação pormenorizada e sistemática da ferida para, posteriormente, esclarecer o tipo de limpeza, bem como o produto a ser empregado. Se o objetivo do cuidado é criar um ambiente ideal para a reparação do tecido, portanto, ao selecionar o anti-séptico é necessário conhecer sua atividade antimicrobiana e o seu potencial citotóxico. 
Doughty (1994) referiu que nas últimas décadas houve uma mudança no enfoque de cicatrização de ferida, de "prevenção de infecção" para "criação de um ambiente ideal do processo de cicatrização de feridas". Para autora, o tratamento de feridas requer que o profissional da saúde considere a concentração de microrganismos infectantes da ferida, o poder imune do hospedeiro, a fase da cicatrização e os efeitos de vários agentes tópicos sobre os agentes infectantes nas células responsáveis pela reparação da ferida.

Nesse sentido, cabe mencionar a legislação brasileira que considera adequadas as seguintes substâncias anti-sépticas como microbicidas ou microbiostáticas de uso na pele, mucosas e ferimentos: soluções alcoólicas, soluções iodadas, iodóforos, clorexidina, solução aquosa de permanganato de potássio, formulações à base de prata e outros princípios que atendam á legislação específica. Não permitindo formulações que contém mercuriais orgânicos, acetona, quaternário de amônio (cloreto de benzalcônio), líquido de Dakin, éter e clorofórmio (Brasil, 1992).

Há estudos na literatura que descrevem os benefícios de diferentes antisépticos, entretanto, não há documentação científica validando o benefício. Citam que os anti-sépticos são substâncias químicas tóxicas quando utilizados na limpeza de feridas causam mais prejuízo que benefício. É significante a produção científica que documenta a extrema toxicidade destes agentes, tanto in vitro, bem como, in vivo em animais e humanos, portanto, devem ser indicados conforme a recomendação dessa literatura (Krasner, Rodeheaver \& Sibbald, 2001).

Quanto ao tratamento das feridas, a literatura médica apresenta uma variedade significativa de produtos e condutas que são utilizadas como: clorexidina, peróxido de hidrogênio, iodo, permanganato de potássio, nitrato de prata, hipoclorito de sódio, violeta de genciana, mercúrio-cromo, pomadas a base de antibióticos, solução salina isotônica, alginato de cálcio, carvão ativado, hidrocolóide, hidrogel, pasta de açúcar, estreptoquinases e recentemente ácidos graxos essenciais com triglicerídio de cadeia média, papaína, fator de 
crescimento derivado de plaquetas, oxigenoterapia hiperbárica, laserterapia, ácido acético/vinagre, plantas medicinais, toque, fala, cura espiritual, dentre outros (Nogueira, 1987; Frantz \& Gardner, 1994; Tiago, 1996; Shuttleworth \& Banfield, 1997; Esteves, 1999; Martins, 2000; Krasner, Rodeheaver \& Sibbald, 2001; Cândido, 2001; Ohnishi et al. 2001).

Bergstrom et al. (1995) afirmaram que soluções anti-sépticas formuladas para limpeza de pele íntegra, não devem ser utilizadas na ferida crônica. Os anti-sépticos como polivinilpirrolidona-iodo (PVP-I), hipoclorito de sódio, água oxigenada, cloreto de benzalcônio e ácido acético não devem ser usados para limpeza de feridas por que são citotóxicos para fibroblastos humano, portanto, quando usados, precisam ser diluídos para diminuir a toxicidade.

Poletti (2000) na revisão integrativa de 173 artigos, sobre cuidado com feridas crônicas, evidenciaram que a maior parte das publicações foi de natureza teórica, ou seja, são escassos os investimentos em pesquisas. Outro aspecto apontado pela autora foi que, mesmo com avanço da indústria farmacêutica no tratamento de feridas, e com entendimento do processo de cicatrização, o cuidado na maioria das vezes é baseada em prática tradicional, tanto pela falta de acesso as evidências do conhecimento científico quanto pela dificuldade de obtenção dos recursos tecnológicos.

No geral, os estudos mostram uma tendência significativa dos países desenvolvidos para utilizarem produtos industrializados. O Brasil, onde a maioria da população tem baixo poder aquisitivo, e cuja intervenção na saúde pública parece não ser prioridade do governo, existe um consumo elevado de produtos alternativos como açúcar, papaína e ácidos graxos essenciais.

Pieper \& Caliri (2003) na avaliação das evidências científicas quanto ao uso de substâncias alternativas no tratamento de feridas mais uma vez observaram um número elevado de pesquisas descritivas e estudos de caso. Com base nos achados reforçam a importância de investir na realização de estudos com diferentes abordagens metodológicas. 
Além da escassez de evidências científicas os poucos resultados de pesquisa, mostram aspectos conflitantes. Os resultados não são significantes, porque as pesquisas são realizadas com amostras pequenas, com métodos não apropriados e ou são experimentos com animais cuja transposição desses resultados para humano muitas vezes não é viável e recomendável. Acresce-se a essa realidade os estudos de Polleti (2000) e de Pieper \& Caliri (2003) que reconhecem e enfatizam essa problemática como um dos impeditivos para transpor os resultados de pesquisa para a prática clínica, particularmente, no cuidado de feridas.

\section{2- Ácido acético pode ser uma alternativa viável no tratamento de feridas?}

O número de ácidos orgânicos conhecidos ultrapassa de mil, dentre eles o ácido acético pertencente à classe dos carboxílicos. O ácido acético representa um dos mais importantes ácidos desta classe. É um etanóico conhecido em forma de vinagre desde antiguidade, difundido no reino vegetal em estado livre. O ácido acético do latim acetum significa vinagre; do catalão vinagre o "vi" significa vino e "agre" significa agrio, é um ácido orgânico com a fórmula estrutural $\mathrm{CH} 3-\mathrm{COOH}$ que se produz pela fermentação (oxidação) do álcool etílico, por ação da bactéria Acetobacter aceti $(\mathrm{CH}-\mathrm{COOH}+1 / 2 \mathrm{O} 2+$ $\mathrm{CH}-\mathrm{COOH}$ ), no estado anidro se solidifica a $16^{\circ} \mathrm{C}$, em forma de cristais, parecidos com gelo; por isso recebe o nome de ácido acético cristalizável ou ácido acético glacial. Seu peso molecular é de 60,05, com 40\% de carbono, $6,71 \%$ de hidrogênio e 53,29\% de oxigênio densidade do ácido acético é de 1,047, ponto de congelamento não abaixo de 15,6\% e ponto de ebulição 117 a $118^{\circ}$. É um líquido transparente e incolor, de cheiro forte, picante e irritante, paladar azedo, quando muito diluído com água tem sabor ácido. Em pequenas concentrações os ácidos são responsáveis por muitas fragrâncias deliciosas. 0 máximo de concentração corresponde a um líquido com 76 a 79 partes de ácido por 100 partes de mistura. É miscível em todas as proporções com a água, álcool, éter, carbono tetraclorídrico e a glicerina; também dissolve fósforo, 
ácidos halogênio e sulfúrico. Praticamente insolúvel em carbono disulfídrico. Sua conservação deve ser em frascos bem fechados (Morrisson \& Boyd,1983 ; Budavari et al., 1989; Molineros et al. ,1991).

Allinger et al. (1978) ressaltaram que o ácido acético, seus derivados e outros ácidos são encontrados na natureza e desempenham importante papel no metabolismo animal e vegetal. Particularmente, o ácido acético é fundamental para a biossíntese de uma variedade de produtos naturais, desde ácidos graxos até a borracha natural.

Quando ingerido, o ácido acético ou vinagre provoca irritação severa da mucosa da boca e do trato gastrintestinal, com vômito, hematêmese, diarréia, colapso circulatório, uremia e morte. A exposição crônica pode causar erosão do esmalte dentário, bronquite, irritação ocular (Richey,1986; Budavari et al., 1989).

Constata-se na literatura o uso freqüente do ácido acético ou vinagre: no tingimento de tecido de seda, como acidulante e preservação de alimentos, solvente de goma, resina, óleos voláteis e outras substâncias; agente desinfetante de artigos semi-críticos, no tratamento de verruga, na escleroterapia de cistos renais, nos acidentes caseiros como a queimadura, no corte da pele com faca, no gargarejo para processos inflamatório da boca e garganta, no tratamento de otites, na picada de inseto, no diagnóstico de neoplasias do cérvix uterino, como agente anti-séptico para feridas abertas, especialmente, onde há suspeita de Pseudomonas. É largamente empregado na síntese orgânica e nas formulações farmacêuticas, e também como reagente químico industrial. A concentração comumente usada no tratamento da ferida é de 0,25\% (Benassati et al.,1994; Aminifarshidmehr,1996; Wenninger apud Rund, 1997; Sankaranarayanam et al., 1998; Guelrud \& Herrera, 1998; Thorp et al., 1998; Cronje et al., 2000; Seo et al., 2000;. Singh et al., 2001; Pogue et al., 2001; Belinson, 2001; Rund, 2001; Galvane et al., 2002; Jung et al., 2002).

Em síntese, o ácido acético tem sido empregado em sua forma diluída como um antimicrobiano, a Haemophilus e Pseudomonas spp.; como 
antifúngico e antiprotozoário vaginal, irrigações e preparações tópicas para pele e unhas, ou gotas para ouvidos, como expectorantes, como espermicida, loção adstringente calosidades, picadas como a da água viva (vinagre ou 3 a 10\% de solução de ácido acético) e como cáustico. Uma gota de vinagre dentro da bolsa de urostomia pode reduzir o odor da urina (Martindale, 1996).

O ácido acético representa um dos agentes químicos com longa história e aplicabilidade humana incluindo o tratamento clínico em feridas. Sua aplicação como anti-séptico, foi divulgada, por vários autores por meio de relato de experiência, resultados de estudos clínicos in vitro e in vivo (experimental e quase-experimental).

Molineros et al. (1991) na análise bacteriológica in vitro verificou que o ácido acético a 2,5; 5,0 e 99,5\% são eficazes sobre Pseudomonas aeruginosa, Escherichia coli e Proteus vulgaris, entretanto a 1,0\%, sua atividade contra estes microrganismos foi quase nula.

Araújo et al. (1995) no estudo in vitro com 20 cepas de Pseudomonas spp. isoladas do sítio cirúrgico e uma amostra padrão de Pseudomonas aeruginosa (ATCC 27853), constataram que todas as cepas foram inibidas in vitro pelo ácido acético a 2,0, 1,0, 0,5 e 0,25\%, comprovando a eficácia do produto in vitro nas bactérias do gênero Pseudomonas. Esses autores na prática clínica do Hospital Universitário do Maranhão, utilizam vinagre diluído meio a meio com soro fisiológico a 0,9\%, formando uma solução com concentração final variando de 2,0 a 3,0\%, tendo em vista a variação da concentração do vinagre comercial de 4,0 a $6,0 \%$. Isto significa que a concentração utilizada do vinagre é significativamente maior, comparada com a concentração de 0,25\% que demonstrou ser eficaz in vitro. Recomendam mais estudos in vivo para determinar a concentração inibitória do ácido acético e agressões teciduais para aplicação segura nas infecções de parte moles por Pseudomonas spp.

Akiyama et al., (1999) em estudo in vitro comparando o efeito do ácido acético e ácido clorídrico sobre cepas de Staphylococcus aureus isoladas 
deimpetigo e furúnculo utilizando o mesmo $\mathrm{pH}$, constataram que a quantidade de colônias de Staphylococcus aureus de biofilme fresco em plasma contendo ácido acético (2,5\% com pH 4,2 e 0,25\% com pH 5,2) foi 10 vezes menor que aquelas contidas no ácido hidroclorídrico ( $\mathrm{pH} \mathrm{4,2)} \mathrm{após} \mathrm{incubação} \mathrm{de} 24$ horas. Os autores destacam o efeito bactericida do ácido acético a 2,5\% sobre biofilme fresco de Staphylococcus aureus, não atribuindo ao baixo $\mathrm{pH}$, e sim até certo ponto a ação química do próprio produto. Acreditam que o ácido acético a 2,5\% é eficaz na eliminação de biofilme de estafilococos e sugerem mais estudos para comprovar a eficácia.

Pereira (2002) em estudo experimental in vitro analisou a concentração e tempo de exposição de ácido acético e vinagre para inibir o crescimento de sete cepas de Pseudomonas aeruginosa isoladas de feridas do paciente por meio de swab. Verificaram que algumas cepas foram mais sensíveis ao ácido acético do que as outras. No total da distribuição observou-se que duas cepas foram sensíveis ao ácido acético a 0,5\%, três cepas a 0,6\% e duas a 0,7\%. Em relação ao vinagre, uma cepa foi sensível a $10 \%$ e todas as outras a $15 \%$. O pH nas diferentes concentrações de ácido acético e vinagre não apresentou variação significativa. A autora propõe estudo in vivo para avaliar a eficácia do ácido acético a 1\% e vinagre a 20\% (diluído em água esterilizada ou fervida).

Já, Molineros et al. (1991) avaliando pela microscopia eletrônica o efeito do ácido acético na epiderme do abdomem de rato em diferentes concentrações $(1,0 ; 3,5$ e $25,0 \%)$ e observaram que o produto em concentrações menor ou igual a 3,5\% danificou somente 4,0 a 5,0\% das células e causou pequena redução da matriz citoplasmática. Para esses autores este dado indica a possibilidade de recuperação celular e tecidual. Entretanto, o potencial de regeneração de Pseudomonas aeruginosa é eliminado pela ação citolítica do ácido acético.

O estudo in vitro de McKenna (1992) com ácido acético a 0,0025\%, uma concentração não tóxica para fibroblastos, mostrou fraca inibição para Staphylococcus aureus, moderada para Pseudomonas aeruginosa e sem efeito 
para, Escherichia coli, Enterococcus grupo D e Bacteroides fragilis, outros microrganismos.

Woodart (1989) relata a eficácia do vinagre em queimadura provocada por hidróxido de sódio em um adulto (sexo masculino) de aproximadamente 30 anos com queimadura de $1^{\circ}$ grau e comprometimento de $20 \%$ da área corporal. Foi aplicada solução de vinagre empiricamente diluído a 50\%, embebida na toalha sobre a área queimada. O alívio da dor foi dramaticamente suavizado em dez minutos e a queimadura evoluiu sem complicações. O autor recomenda o aprofundamento dessa temática por meio de estudos para estabelecer a eficácia da neutralização da queimadura provocada por hidróxido de sódio utilizando o ácido acético.

Nagoba et al. (1997) em um estudo de caso de uma senhora de 60 anos, com ferida cirúrgica infectada por Pseudomonas aeruginosa resistente a ciproflaxacina, netilmicina, tobramicina e ticarcillina, sensível a gentamicina, amicacina, tobramicina e ceftazidime, observaram a eliminação desta bactéria com aplicação de ácido acético a 3,0 e 5,0\%, pelo método de irrigação no sétimo dia de tratamento.

Phillips et al. (1968) desenvolveram estudo experimental randomizado com vinte pacientes, com feridas infectadas (superficiais e queimaduras) por Pseudomonas aeruginosa. No grupo experimental (dez pacientes, sendo oito do sexo masculino), a ferida foi tratada com ácido acético a 5,0\% e o curativo trocado duas vezes ao dia. No grupo controle dez pacientes sendo sete do sexo masculino foi tratada a ferida com clorexidina ou hipoclorito. Observaram que no grupo experimental em oito casos, o $P$. aeruginosa foi eliminada em menos de uma semana. Entretanto em um paciente com sarcoma de Kaposi, o microrganismo persistiu sem diminuir, e um outro paciente com úlcera de pressão o microrganismo voltou a multiplicar assim que cessou o tratamento. Concluíram que o ácido acético a 5\% é útil no tratamento de feridas superficiais infectadas por Pseudomonas. 
Molineros et al. (1991) conduziram um estudo experimental com 24 pacientes (22 com infecções em fratura aberta e 2 com queimadura). Nestes, 15 (grupo experimental) receberam como tratamento o curativo com ácido acético a 3,5\% (vinagre branco tipo comercial) 9 (grupo controle) o tratamento foi com solução salina. A análise estatística mostrou diferença significativa entre os grupos de estudo, comprovando a eficácia do ácido acético a 3,5\% como anti-séptico, porém, quanto à cicatrização não houve diferença significativa entre os grupos analisados. Concluíram que o ácido acético pode retardar a cicatrização, mas, analisando o risco-benefício, ainda é aconselhável e seguro o emprego deste produto a 3,5\% (vinagre branco comercial).

Milner (1992) realizou uma avaliação prospectiva do uso do ácido acético a 5\% em feridas de 9 pacientes infectados com Pseudomonas aeruginosa, sendo sete úlceras (duas de pressão e cinco venosa) e duas queimaduras, as quais receberam curativos diariamente. Verificou que em duas feridas Pseudomonas spp. foi eliminada em dois dias e em quatro feridas apresentou cultura positiva por uma semana sendo que somente uma apresentou até três semanas. Após erradicação do microrganismo a cicatrização da ferida ocorreu com facilidade. O autor relata que nenhum paciente queixou de desconforto durante a aplicação do ácido acético.

Hansson \& Faereggermann (1995) em cultura quantitativa de 45 úlceras venosas de pernas ficaram surpresos com a efetividade do ácido acético a 0,25\% sobre Staphylococcus aureus e Bacilo Gram - negativo quando aplicado por 15 minutos nas respectivas úlceras.

Quanto a citotoxicidade do ácido acético, Cooper et al. apud Dought (1994), em estudos utilizando culturas de fibroblastos humanos e queratinócitos in vitro constataram que a concentração a 0,25\% era tóxica havendo redução da toxicidade na concentração a 0,125\% e 0,025\%. Somente na concentração a 0,0025\% é que o ácido acético não apresentou citotóxico, porém, foi também ineficaz como anti-séptico. Existem vários estudos com Artemia salina Leach (Artemiidae), que é uma larva de camarão salmoura, invertebrada usada no 
teste alternativo para determinar a toxicidade e fototoxicidade de produtos naturais e químicos considerando que estas larvas apresentam sensibilidade a substâncias tóxicas. Além disso, tem a vantagem de ser um sistema rápido, barato e requer pouca habilidade do pesquisador acrescido ao fato de haver correlação entre o fibroblasto da larva com humano (Kerster \& Schaeffer, 1983; Ojala et al., 1999; Pelka et al., 2000; Logarto Parra et al., 2001; Santos Pimenta et al., 2003).

\subsection{Relevância e justificativa do estudo}

Muito mais do que apenas utilizar os produtos químicos existentes para combater microrganismos, é preciso conhecer cientificamente a eficiência de cada um deles frente à diversidade de situações clínicas e microbiológicas, bem como, se faz necessário estabelecer o seu potencial de toxicidade para as células humanas.

Considerando o volume de estudos relacionados ao uso de produtos químicos no tratamento de feridas, a existência de lacunas e controvérsias a serem esclarecidas, a presença de microrganismos multirresistentes, nos propomos a realizar um estudo de avaliação antimicrobiana e citotoxicidade do ácido acético e vinagre sobre diferentes cepas de hospitalar/campo e comunitária isoladas de universitários saudáveis. A cepa comunitária foi selecionada para o estudo com o intuito de comparar com a da hospitalar, se aquela cepa com baixo grau de resistência é facilmente inibida pelos produtos em estudo.

Do ponto de vista da composição dos agentes químicos biocidas é reconhecido que a presença de um ou vários compostos ativos pode fortemente influenciar compatibilidades físico-químicas, alterando a sua atividade antimicrobiana. Desta maneira, justifica a premência de avaliação dessa atividade, principalmente considerando as particularidades dos casos a ser solucionados na área da saúde. 
Vale ressaltar que o uso do ácido acético/vinagre ou qualquer outro produto químico na terapêutica de feridas deve ser realizado com critério e com respaldo científico. As publicações sobre o uso do ácido acético permitem vislumbrar controvérsias acerca de seu emprego, principalmente, no que concerne a concentração inibitória, bem como, seu mecanismo de ação e aspectos relacionados a citotoxicidade. Vale ressaltar que é vasta a literatura relacionada ao uso de ácido acético e vinagre, porém, os resultados mostram discrepâncias quanto a sua concentração de uso, eficácia e toxicidade. Conflitos em torno da concentração devem ser esclarecidos e padronizados. Temos a consciência do desafio a vencer, principalmente, quando se almeja trabalhar em uma linha de pesquisa que busca à longo prazo uma terapêutica eficaz da ferida e livre de danos a saúde.

Neste sentido, reconhecendo o largo uso do ácido acético e do vinagre nos propomos a avaliar a sua atividade antimicrobiana in vitro, bem como, a sua citotoxicidade com vistas a subsidiar outros estudos, para futuramente fundamentar a sua aplicabilidade no tratamento de feridas em humanos. Portanto, questiona-se:

- A atividade antimicrobiana do ácido acético e do vinagre in vitro sobre diferentes cepas ocorre em qual concentração?

Em outras palavras:

-Qual é a concentração inibitória mínima do ácido acético e do vinagre para eliminar microrganismos causadores de infecção?

Ainda, contextualizando quanto a citotoxicidade, questionamos:

- O ácido acético e o vinagre apresentam citotoxicidade, determinada pelo teste com Artemia salina Leach? 


\section{4.- Hipótese}

- A atividade antimicrobiana in vitro do ácido acético e do vinagre é variável considerando a natureza do microrganismo e a concentração dos respectivos produtos.

- A atividade antimicrobiana in vitro do ácido acético e do vinagre é variável entre as cepas de campo/ hospitalar e comunitária.

- A atividade antimicrobiana in vitro do ácido acético e do vinagre parece ter relação com os componentes químicos da estrutura da parede celular das cepas investigadas.

- A citotoxicidade do ácido acético e do vinagre para náltiplos de Artemia salina Leach é variável considerando a concentração dos produtos analisados.

- Quanto maior for a concentração do princípio ativo do ácido acético maior é a citotoxicidade para a Artemia salina Leach.

Frente ao exposto, estabelecemos os objetivos que se seguem:

\section{5.- Objetivos}

Objetivo Geral:

- Avaliar in vitro a atividade antimicrobiana e a citotoxicidade do ácido acético e do vinagre. 
Objetivos específicos:

- Avaliar a atividade antimicrobiana do vinagre e do ácido acético por meio do Método de Difusão de Poço sobre as cepas padrão e de hospitalar/campo e da comunidade;

- Determinar a Concentração Inibitória Mínima (CIM) do vinagre e do ácido acético sobre cepas padrão, cepas hospitalar/campo e da comunidade/campo;

- Determinar a citotoxicidade do vinagre e do ácido acético sobre Artemia salina Leach. 


\section{2- MATERIAL E MÉTODO}

A trajetória metodológica descrita de natureza laboratorial foi delineada com a finalidade de atender os objetivos preestabelecidos: avaliar a atividade antimicrobiana e citotóxica do vinagre e do ácido acético.

\section{1- Local de Estudo}

Este estudo para atender os objetivos preestabelecidos, envolveu diferentes locais:

Hospital das Clínicas da Faculdade de Medicina de Ribeirão Preto da Universidade de São Paulo (HCFMRP-USP) que forneceu as cepas de hospitalar/campo isoladas de pacientes hospitalizados.

Laboratório de Microbiologia do Departamento de Análises Clínicas Toxicológicas e Bromatológicas da Faculdade de Ciências Farmacêuticas de Ribeirão Preto da Universidade de São Paulo em parceria com a Profa. Dra Izabel Yoko Ito e sua equipe. Neste laboratório foi realizado a etapa experimental relacionada a atividade antimicrobiana, bem como, forneceu as cepas da comunidade oriundas de portadores universitários saudáveis.

Laboratório de Bacteriologia do Departamento de Microbiologia, Imunologia, Parasitologia e Patologia do Instituto de Patologia Tropical e Saúde Pública da Universidade Federal de Goiânia em parceria com Profa. Dra Fabiana Cristina Pimenta e seus colaboradores. Por meio dessa parceria foi possível avaliar a citotoxicidade dos produtos analisados.

\section{2- Procedimentos éticos em pesquisa}

O projeto de pesquisa foi aprovado pelo Comitê de Ética em Pesquisa do Hospital das Clínicas da Faculdade de Medicina de Ribeirão Preto-USP (ANEXO A), em atendimento às Normas de Pesquisa em Saúde do Conselho Nacional de Pesquisa em Saúde, Resolução 196/96 (Brasil, 1996). 


\section{3- Processamento microbiológico}

\subsubsection{Teste Piloto}

O estudo foi submetido ao teste piloto com vistas a calibrar o pesquisador em como vislumbrar a atividade antimicrobiana do vinagre/ácido acético sobre importantes cepas no cenário das infecções. Assim, ficou estabelecido na leitura dos resultados no plano piloto:

- Diâmetro do halo em mm indica inibição do crescimento

- 0 (indica desenvolvimento microbiano, ineficácia do produto, sem atividade antimicrobiana).

- $\mathrm{t}$ (indica crescimento fino/tênue, traço).

\subsubsection{1-Técnica do Poço (well)}

O teste piloto para a determinação da atividade antimicrobiana foi realizado com base na técnica de Poço em camada dupla, conforme Groove \& Randall (1955).

Os materiais necessários para a realização da técnica de Poço foram: Agar Müeller Hinton - MH (Oxoid), Agar MacConkey - Mc - (Difco), Caldo Nutriente - Cn (Oxoid), Agar Ni (Ito et al. 1968), Vinagre branco e tinto, marca Belmont, Ácido acético, PA Labsynth, Solução fisiológica, Água esterilizada.

As etapas da Técnica de Poço como, preparação do inóculo, preparação da suspensão bacteriana para composição da camada seed, preparo das placas de Petri com meio $\mathrm{MH}$ e $\mathrm{MHb}$, perfuração dos poços, bem como, determinação da atividade antimicrobiana do vinagre branco e tinto e do ácido acético, estão descritas detalhadamente no Apêndice - 1 e resumidamente etapas desta técnica podem ser observados na Figura 1. 
$\mathrm{Na}$ realização da Técnica de Difusão de Poço, os antimicrobianos analisados foram vinagre branco (VB) e vinagre tinto (VT) puro, a 50, 25\% da marca Belmont e o ácido acético a 1,0\% da Labsynth (PA). 


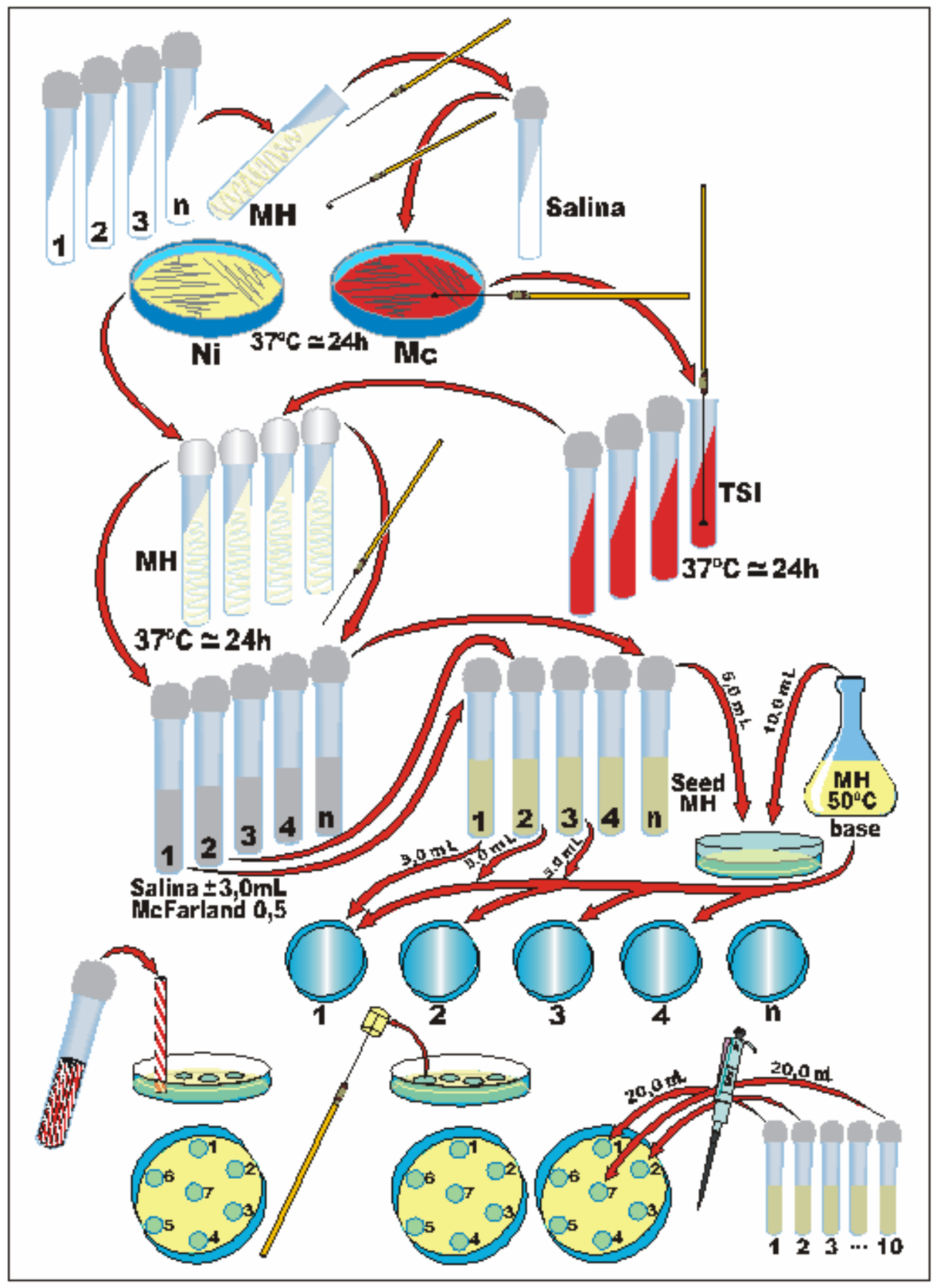

Figura1. Fluxograma da Técnica de Difusão de Poço 
Como revelador da atividade antimicrobiana do vinagre e do ácido acético sobre diferentes microrganismos utilizou cepas padrão, de campo/hospitalar e da comunidade (Tabela 1).

Tabela1-Microrganismos padrão, hospitalar/campo e da comunidade/campo utilizados como indicadores da atividade antimicrobiana do ácido acético e vinagre.

\begin{tabular}{ccc}
\hline Código & Microrganismos & Procedência \\
\hline 6538 & Staphylococcus aureus & ATCC-6538 \\
$\mathrm{P}+$ & Staphylococcus aureus & Cepa de campo \\
$\mathrm{P}-$ & Staphylococcus aureus & Cepa de campo \\
$6 \mathrm{epi}$ & Staphylococcus epidermidis & Cepa de campo \\
9341 & Micrococcus luteus & ATCC-9341 \\
$\mathrm{Ef}$ & Enterococcus faecalis & ATCC-10541 \\
$\mathrm{Ec}$ & Escherichia coli & ATCC-10538 \\
$\mathrm{E} 21$ & Escherichia coli & Cepa hospitalar \\
$\mathrm{Ca}$ & Candida albicans & ATCC-1023 \\
$\mathrm{Cas}$ & Candida albicans & Cepa de campo \\
$\mathrm{Ct}$ & Candida tropicalis & Cepa de campo \\
$\mathrm{Pa}$ & Pseudomonas aeruginosa & ATCC- 27853 \\
060 & Enterobacter/Klebsiella & Cepa hospitalar \\
064 & Enterobacter/Klebsiella & Cepa hospitalar \\
067 & Enterobacter/Klebsiella & Cepa hospitalar \\
069 & Enterobacter/Klebsiella & Cepa hospitalar \\
$\mathrm{Smp}$ & Streptococcus mutans & ATCC 25175 \\
$\mathrm{Sm}$ & Streptococcus mutans & Cepa de campo \\
$\mathrm{S} 9$ & Streptococcus sobrinus & Cepa de campo \\
\hline & & \\
\hline
\end{tabular}


2.3.2- Leitura e mensuração da atividade antimicrobiana

Decorrido o período de incubação foram efetuadas a leitura de todas as placas e mensuração do diâmetro do halo de inibição em milímetros. Os resultados da leitura foram anotados em fichas apropriadas (Anexo B). Vale acrescentar que a leitura das placas em duplicata foi executada por duas pessoas, para manter a fidedignidade e evitar interferência ou manipulação do resultado.

Assim, os resultados obtidos no teste piloto sobre a atividade antimicrobiana in vitro de vinagre branco e tinto (Belmont) puro a 50\% e a $25 \%$, e ácido acético PA (Labsynth) a 1\% pelo Método de Poço, frente as 19 diferentes cepas são apresentados na Tabela 2. 
Tabela 2- Atividade antimicrobiana de vinagre branco e tinto, e ácido acético (PA) in vitro pelo método de poço frente as diferentes microrganismos.

\begin{tabular}{|c|c|c|c|c|c|c|c|c|}
\hline \multirow[t]{2}{*}{ Microrganismo } & \multirow[t]{2}{*}{ Procedência } & \multicolumn{3}{|c|}{ Belmont branco } & \multicolumn{3}{|c|}{ Belmont tinto } & \multirow{2}{*}{$\begin{array}{l}\begin{array}{l}\text { Ácido } \\
\text { acético }\end{array} \\
1 \%\end{array}$} \\
\hline & & Puro & $50 \%$ & $25 \%$ & Puro & $50 \%$ & $25 \%$ & \\
\hline Micrococcus luteus & ATCC 9341 & $19 *$ & $t^{* *}$ & 0 & 18 & $\mathrm{t}$ & 0 & 0 \\
\hline Staphylococus aureus & ATCC 6538 & 7 & $\mathrm{t}$ & 0 & 9 & $\mathrm{t}$ & 0 & 0 \\
\hline Staphylococcus aureus $(P+)$ & Cepa de campo & 17 & $\mathrm{t}$ & 0 & 15 & $\mathrm{t}$ & 0 & 0 \\
\hline Staphylococcus aureus(P-) & Cepa de campo & 15 & $\mathrm{t}$ & 0 & 15 & $\mathrm{t}$ & 0 & 0 \\
\hline Staphylococcus epidemidis & Cepa de campo & $\mathrm{t}$ & $\mathrm{t}$ & 0 & $\mathrm{t}$ & $\mathrm{t}$ & 0 & 0 \\
\hline Pseudomonas aeruginosa & ATCC 27853 & 10 & 8 & $\mathrm{t}$ & 9 & 7 & $\mathrm{t}$ & $\mathrm{t}$ \\
\hline Escherichia coli & ATCC 10538 & 8 & $\mathrm{t}$ & $\mathrm{t}$ & 6 & $\mathrm{t}$ & 0 & $\mathrm{t}$ \\
\hline Escherichia coli (E21) & Cepa hospitalar & 6 & $\mathrm{t}$ & $\mathrm{t}$ & 9 & $\mathrm{t}$ & $\mathrm{t}$ & $\mathrm{t}$ \\
\hline Enterobacter/Klebsiella(060) & Cepa hospitalar & 10 & $\mathrm{t}$ & $\mathrm{t}$ & 9 & $\mathrm{t}$ & $\mathrm{t}$ & 0 \\
\hline Enterobacter/Klebsiella (064) & Cepa hospitalar & 8 & 6 & $\mathrm{t}$ & 8 & 6 & $\mathrm{t}$ & $\mathrm{t}$ \\
\hline Enterobacter/Klebsiella (067) & Cepa hospitalar & 6 & $\mathrm{t}$ & 0 & 6 & $\mathrm{t}$ & 0 & 0 \\
\hline Enterobacter/Klebsiella (069) & Cepa hospitalar & 9 & 6 & $\mathrm{t}$ & 9 & 6 & 0 & 0 \\
\hline Streptococcus mutans & ATCC 25175 & $\mathrm{t}$ & 0 & 0 & $\mathrm{t}$ & 0 & 0 & 0 \\
\hline Streptococcus mutans & Сepa campo & $\mathrm{t}$ & 0 & 0 & $\mathrm{t}$ & 0 & 0 & 0 \\
\hline Streptococcus sobrinus & Cepa campo & $\mathrm{t}$ & 0 & 0 & $\mathrm{t}$ & 0 & 0 & 0 \\
\hline Enterococcus faecalis & ATCC 10541 & 9 & 0 & 0 & 9 & 0 & 0 & 0 \\
\hline Candida albicans & ATCC 1023 & $\mathrm{t}$ & 0 & 0 & $\mathrm{t}$ & 0 & 0 & 0 \\
\hline Candida albicans & Сера саmpo & $\mathrm{t}$ & 0 & 0 & $\mathrm{t}$ & 0 & 0 & 0 \\
\hline Candida tropicalis & Сepa campo & $\mathrm{t}$ & 0 & 0 & $\mathrm{t}$ & 0 & 0 & 0 \\
\hline
\end{tabular}

*diâmetro do halo de inibição em milímetro

** traço de inibição: igual a $5 \mathrm{~mm}$

Belmont branco e tinto (Lençóis Paulista - SP)

Ácido acético PA ( Labsynth - SP)

Vinagre puro $=4,0 \%$ de ácido acético; Vinagre $50,0 \%=2,0 \%$ de ácido acético

Vinagre $25,0 \%=1,0 \%$ de ácido acético

\subsubsection{Documentação fotográfica}

Após mensuração dos halos de inibição, foram selecionadas algumas placas de Pseudomonas aeruginosa, Enterobacter/Klebsiella, Micrococcus luteus e Candida albicans, e fotografadas para documentar o 
resultado. Para visualização e melhor compreensão do leitor segue, uma vista panorâmica de quatro placas (Figura 2) que representam a ação antimicrobiana do vinagre e do ácido acético por meio da técnica do poço sobre as cepas Micrococcus luteus, Pseudomonas aeruginosa, Enterobacter/Klebsiella e Candida albicans.
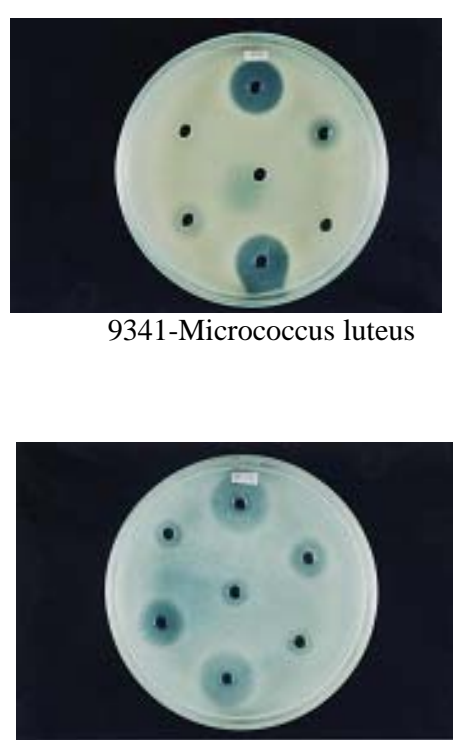

c 67- Enterobacter/Klebsiella

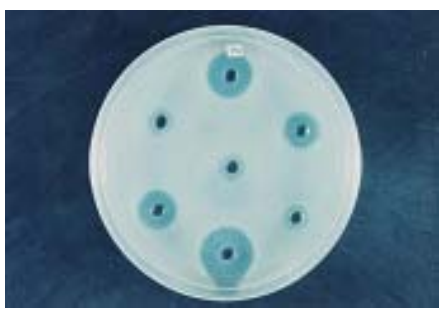

Pseudomonas aeruginosa

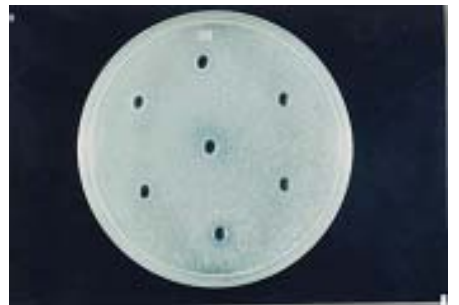

Candida albicans

Figura 2- Vista Panorâmica da ação antimicrobiana do ácido acético e vinagre por meio da técnica do poço sobre as cepas Micrococcus luteus, Pseudomonas aeruginosa, Enterobacter/ Klebsiella e Candida albicans.

Nota-se pela Figura 2 que, Micrococcus luteus, Pseudomonas aeruginosa e Enterococcus/Klebsiella foram sensíveis a vinagre branco e tinto puro, a 50,0\% apresentou crescimento tênue e ao ácido acético a 1,0\% foi resistente exceto para Pseudomonas aeruginosa que teve crescimento tênue. Os produtos testados não apresentam ação antimicrobiana para Candida albicans.

Conforme a Tabela 2 e Figura 2 ácido acético e o vinagre se mostraram por meio da técnica de Difusão de Poço, agentes capazes de inibir o 
crescimento de algumas cepas de campo/hospitalar ( $P$. aeruginosa, E. coli e Enterobacter/Klebsiella). Frente aos resultados é possível afirmar que tais produtos tem ação antimicrobiana sobre as cepas epidemiologicamente importantes no cenário da infecção hospitalar.

\subsection{2- Atividade antimicrobiana do vinagre/ácido acético}

Subsidiado nos resultados do teste piloto selecionou-se para o presente estudo as cepas de Pseudomonas aeruginosa, Escherichia coli e Staphylococcus aureus. Vale ressaltar que estes gêneros representam microrganismos epidemiologicamente importante no cenário dos agravos à saúde.

Para avaliação da atividade antimicrobiana dos vinagres Belmont branco e tinto e ácido acético PA (Labsynth) foi realizada pelo método de poço (Figura 1) como no teste piloto (2.3.1).

Essa atividade antimicrobiana foi determinada frente a 22 cepas hospitalar/campo de Pseudomonas aeruginosa, 21 de Escherichia coli (bastonetes Gram - negativo) e 22 de Staphylococcus aureus (cocos Gram positivo).

\subsection{3- Determinação da Concentração Inibitória Mínima (CIM)}

Os estudos relacionados a avaliação da atividade antimicrobiana dos biocidas (anti-sépticos, desinfetantes e esterilizantes químicos) para atender a finalidade a que se propõe de uso deve considerar a sua concentração com vistas a estabelecer a formulação adequada. O alerta é o de que caso seja utilizado uma concentração inferior a recomendada possívelmente não apresentará atividade antimicrobiana, e conseqüentemente poderá exercer pressão seletiva sobre as cepas em favor da resistência ao produto (Mazzola et al., 2000). 
Subsidiado nos resultados do teste piloto selecionou-se para o presente estudo 20 cepas de Pseudomonas aeruginosa, e de Escherichia coli e 12 cepas hospitalar/campo e 8 cepas da comunidade em um total de 20 cepas de Staphylococcus aureus, vale ressaltar que estes gêneros representam os importantes microrganismos no âmbito de infecção, especialmente, aquelas causadores de infecção em feridas.

Ainda para a CIM foi escolhido o vinagre da marca Castelo uma vez que esta é de menor custo e maior consumo na cidade de Londrina (Pr).

\subsubsection{1- Preparação das placas}

Para determinação da Concentração Inibitória Mínima (CIM) os produtos químicos analisados foram submetidos à diluição dupla até $8^{0}$ tubo em diferentes proporções, conforme o tipo do produto. O procedimento "básico" está apresentado no fluxograma apresentada na Figura 3 e Apêndice - 2.

Cabe ressaltar que o tubo de número $9 \mathrm{com} 2,0 \mathrm{~mL}$ de água, foi utilizado como o controle. A seguir, $18,0 \mathrm{~mL}$ do meio $\mathrm{MH}$ a cerca de $50^{\circ} \mathrm{C}$, foram adicionados a cada tubo, homogeneizado e vazados em placas de $20 \times 100 \mathrm{~mm}$ codificadas.

\subsubsection{2- Cepas microbianas avaliadas}

Foram avaliadas 20 cepas hospitalares/campo de Pseudomonas aeruginosa e Escherichia coli utilizadas no item 2.3 .2 e 12 cepas hospitalares/campo (2.3.2) e 8 cepas de Staphylococcus aureus da comunidade, em um total de 20 cepas. 
2.3.3.3-Técnica de Semeadura para determinação da Concentração Inibitória Mínima.

Os diferentes microrganismos foram cultivados em ágar $\mathrm{MH}$, incubados a $37^{\circ} \mathrm{C}$ durante 24 horas. Decorrido o tempo de incubação, as suspensões bacterianas foram preparados comparada com a turbidez corresponde a metade 0,5 da escala 1 de MacFarland, que corresponde, aproximadamente a $1,5 \times 10^{7}$ ufc/mL(Figura 3)

Estas suspensões foram colocadas nos alvéolos do multi-aplicador de Steers, em quantidade suficiente (Figura 3)

A semeadura foi realizada a partir da placa de maior diluição (tubo 8) para a de menor diluição, sendo posteriormente feita a carimbagem/semeadura das placas em duplicatas e placas controle (Figura 3)

Após a secagem do inóculo, as placas foram incubadas a $37^{\circ} \mathrm{C}$ por 24 horas, e depois submetidos à leitura. As placas de cada anti-séptico foram observadas individualmente e comparadas com o controle. Os resultados foram anotados em fichas próprias (Anexo - C).

Foi considerado como Concentração Inibitória Mínima, a menor concentração que ocasionou inibição completa das cepas, nas duplicatas. 


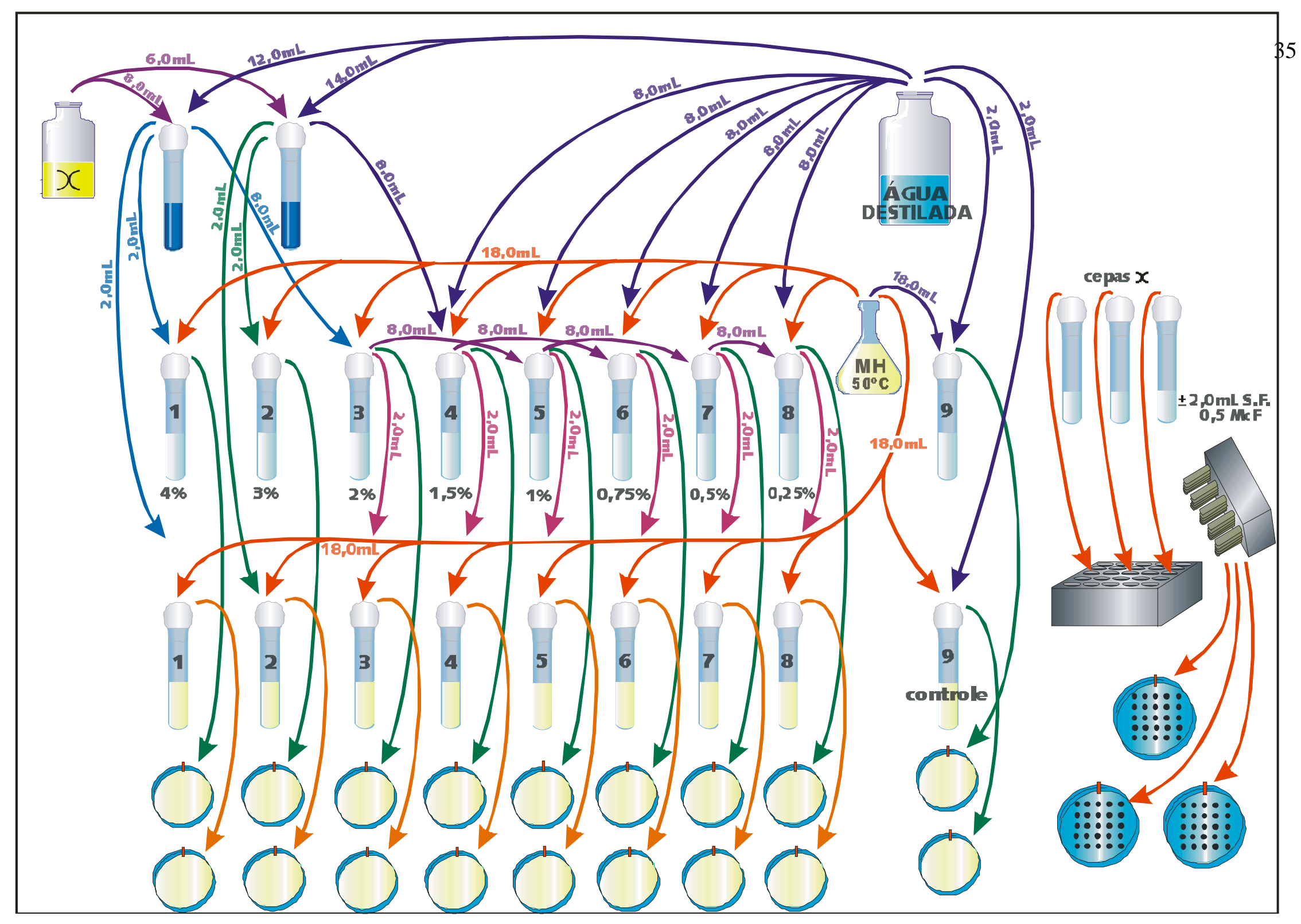

Figura 3. Fluxograma da Concentração Inibitória Mínima (CIM) 
2.4 Verificação de atividade citotóxica do ácido acético e vinagre utilizando como modelo de toxicidade a Artemia salina Leach .

\subsection{1- Preparo da solução salina.}

Foram adicionados 35g/L de sal marinho e ajustado o pH com $\mathrm{NaOH}$, $0,1 \mathrm{~N}$ até pH 8-9. Esta solução foi utilizada para eclosão de ovos de Artemia salina e preparo das diluições.

\subsection{2- Eclosão dos ovos:}

Os ovos de Artemia salina ( $200 \mathrm{mg} / 400 \mathrm{~mL}$ ) foram postos para eclodir em solução salina por 48 horas com aeração constante e expostos a luz diurna.

\section{Variação da eclosão:}

-adicionar água doce filtrada ou água do mar ou $20 \mathrm{~g}$ de sal grosso a cada litro; -não exceder $3 g$ de ovos por cada litro;

-manter a temperatura entre 27 a $30^{\circ} \mathrm{C}$;

-manter $\mathrm{pH}$ entre 8 a 9;

-na primeira hora do processo manter iluminação (20W) sobre o recipiente; -verificar o tempo de eclosão de 24 a 36 horas.

\subsection{3- Preparação da diluição}

O Quadro 1 demonstra como foram realizadas as diluições dos produtos com respectivas concentrações em porcentagens (20.000ppm, 10.000ppm, 5.000ppm, 2.500ppm e 1250ppm em 10mL de água) 
Quadro 1- Diluição dos produtos testados: vinagre branco, tinto e ácido acético e suas respectivas concentrações em porcentagem.

\begin{tabular}{ccc}
\hline ppm & diluição & $\%$ \\
\hline 20.000 & $200,0 \mu \mathrm{L}+10 \mathrm{~mL}$ de água & 2,0 \\
10.000 & $100,0 \mu \mathrm{L}+10 \mathrm{~mL}$ de água & 1,0 \\
5.000 & $50,0 \mu \mathrm{L}+10 \mathrm{~mL}$ de água & 0,5 \\
& & \\
2.500 & $25,0 \mu \mathrm{L}+10 \mathrm{~mL}$ de água & 0,25 \\
1.250 & $12,5 \mu \mathrm{L}+10 \mathrm{~mL}$ de água & 0,125 \\
& & \\
\hline
\end{tabular}

\subsection{4- Determinação da atividade citotóxica}

A cada tubo de cada diluição foram adicionadas 10 larvas de Artemia salina. Os tubos foram mantidos sob iluminação e as larvas sobreviventes foram contadas após 24 horas. Foi feito o controle utilizando somente solução salina. Cabe lembrar que, cada diluição foi feita em triplicata.

2.4.5- Cálculo da porcentagem (\%) de mortalidade de Artemia salina.

Para verificação do percentual de mortalidade de Artemia salina, após a contagem das larvas, foi aplicada a fórmula seguinte:

$\%$ de mortalidade $=\underline{n^{0} \text { mortos ou com inibição de movimentoX100 }}$ $\mathrm{n}^{0}$ total de Artemia salina

Os resultados de $100 \%$ significam elevada toxicidade e $0 \%$ sem toxicidade. 


\section{5- Procedimento Estatístico}

Foi realizada a análise de variância ANOVA - ONEWAY seguida do teste de comparações múltiplas denominado Tukey Lloyd \& Fisher (1993). O nível de significância utilizado foi $\alpha=5 \%$. Aplicou-se esta análise sobre os resultados obtidos na avaliação antimicrobiana do ácido acético e vinagre, sobre as seguintes cepas: Staphylococcus aureus, Pseudomonas aeruginosa e Escherichia coli. 


\section{RESULTADO}

Com o intuito de facilitar a visualização, interpretação e análise dos resultados, os mesmos estão apresentados em forma de tabelas e figuras seguindo a ordem dos objetivos específicos:

- avaliação da atividade antimicrobiana pelo método de difusão de poço;

- determinação da Concentração Inibitória Mínima (CIM);

- avaliação da citotoxicidade.

Os resultados da atividade antimicrobiana de vinagre branco e tinto Castelo e ácido acético PA (Merck) sobre 22 cepas hospitalar/campo e comunidade/campo de Staphylococcus aureus, Pseudomonas aeruginosa e 21 cepas de Escherichia coli pelo método de poço estão documentados no Anexo D e compilados nas tabelas 3 a 18 e figuras 4 a16.

A determinação da Concentração Inibitória Mínima (CIM/MIC) de vinagres branco e tinto (Castelo) e ácido acético PA (Merck) sobre 20 cepas (bacilo gram-negativo) hospitalar/campo de Pseudomonas aeruginosa e Escherichia coli e 12 cepas (cocos gram-positivo) hospitalar/campo e 8 cepas, de Staphylococcus aureus da comunidade estão documentadas no Anexo E apresentadas nas tabelas 19 a 22 e figuras 17 a 23.

Vale esclarecer que nas figuras de CIM o primeiro carimbo posto a esquerda, da primeira linha corresponde a primeira cepa e a última da direita a quinta cepa e a última cepa da direita, da quarta linha a $20^{\mathrm{a}}$ cepa.

A atividade citotóxica do vinagre branco e tinto (Castelo) e do ácido acético PA em Artemia salina Leach está apresentada na tabela 23. 
Tabela 3 - Distribuição da média do diâmetro dos halos de inibição em milímetros do vinagre branco e tinto a $30,0 \%$ sobre 22 cepas de Pseudomonas aeruginosa pelo método de difusão de poço, Ribeirão Preto, 2003.

\begin{tabular}{|c|c|c|c|c|c|c|}
\hline \multirow{2}{*}{$\begin{array}{l}\text { Produtos } \\
\text { Cepas }\end{array}$} & \multicolumn{3}{|c|}{ Vinagre branco 30\% } & \multicolumn{3}{|c|}{ Vinagre tinto $30 \%$} \\
\hline & 1 & 2 & $\mathrm{~m}$ & 1 & 2 & $\mathrm{~m}$ \\
\hline $\mathrm{P1}$ & 12,0 & $\overline{12,0}$ & 12,0 & 11,0 & 11,0 & 11,0 \\
\hline P3 & 11,0 & 14,0 & 12,5 & 11,0 & 11,0 & 11,0 \\
\hline P4 & 13,0 & 12,0 & 12,5 & 11,0 & 10,0 & 10,5 \\
\hline P5 & 12,0 & 12,0 & 12,0 & 11,0 & 11,0 & 11,0 \\
\hline P6 & 13,0 & 12,0 & 12,5 & 11,0 & 11,0 & 11,0 \\
\hline P7 & 11,0 & 11,0 & 11,0 & 11,0 & 12,0 & 11,5 \\
\hline P8 & 12,0 & 11,0 & 11,5 & 11,0 & 12,0 & 11,5 \\
\hline P9 & 11,0 & 10,0 & 10,5 & 12,0 & 10,0 & 11,0 \\
\hline P10 & 12,0 & 11,0 & 11,5 & 14,0 & 11,0 & 12,5 \\
\hline P11 & 13,0 & 13,0 & 13,0 & 11,0 & 10,0 & 10,5 \\
\hline P12 & 12,0 & 11,0 & 11,5 & 11,0 & 11,0 & 11,0 \\
\hline P14 & 11,0 & 11,0 & 11,0 & 12,0 & 12,0 & 12,0 \\
\hline P15 & 11,0 & 11,0 & 11,0 & 11,0 & 12,0 & 11,5 \\
\hline P17 & 11,0 & 11,0 & 11,0 & 11,0 & 12,0 & 11,5 \\
\hline P18 & 11,0 & 13,0 & 12,0 & 11,0 & 10,0 & 10,5 \\
\hline P20 & 12,0 & 10,0 & 11,0 & 11,0 & 12,0 & 11,5 \\
\hline P23 & 11,0 & 11,0 & 11,0 & 10,0 & 10,0 & 10,0 \\
\hline P24 & 12,0 & 10,0 & 11,0 & 12,0 & 11,0 & 11,5 \\
\hline P26 & 11,0 & 11,0 & 11,0 & 12,0 & 11,0 & 11,5 \\
\hline P27 & 14,0 & 10,0 & 12,0 & 11,0 & 13,0 & 12,0 \\
\hline P28 & 11,0 & 10,0 & 10,5 & 12,0 & 11,0 & 11,5 \\
\hline P29 & 10,0 & 11,0 & 10,5 & 12,0 & 10,0 & 11,0 \\
\hline Total & 257,0 & 248,0 & 252,5 & 250,0 & 244,0 & 247,0 \\
\hline Média & 11,7 & 11,3 & 11,5 & 11,4 & 11,1 & 11,2 \\
\hline
\end{tabular}




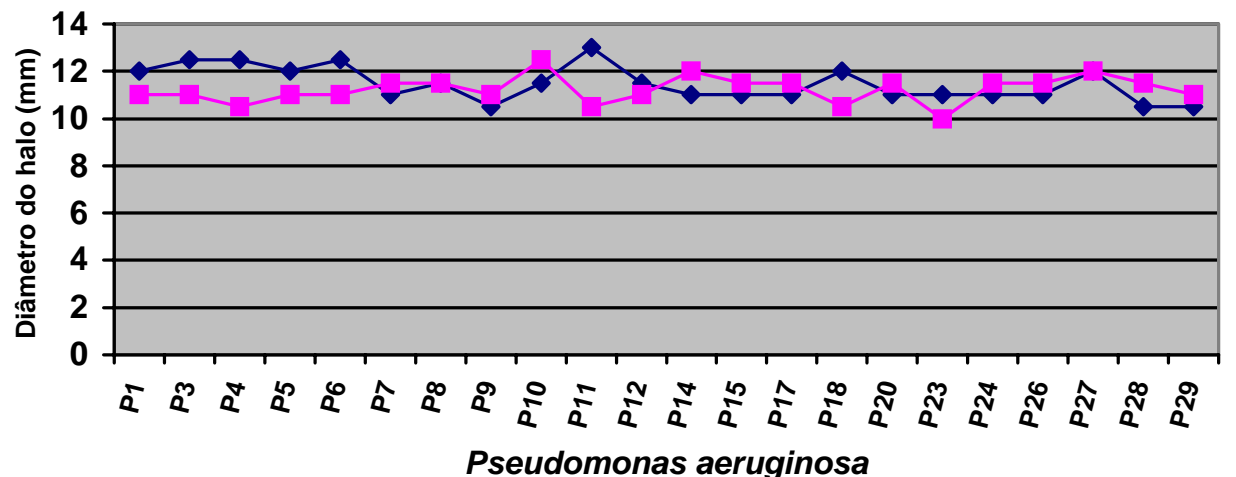

Figura 4 : Representação gráfica dos dados da tabela 3.

$$
\begin{gathered}
- \text { vinagre branco } \\
30 \% \\
- \text { vinagre tinto } \\
30 \%
\end{gathered}
$$


Tabela 4 - Distribuição do diâmetro dos halos de inibição em milímetros do vinagre branco, tinto a $25,0 \%$ e do ácido acético a $1,0 \%$ sobre 22 cepas de Pseudomonas aeruginosa pelo método de difusão de poço, Ribeirão Preto, 2003.

\begin{tabular}{|c|c|c|c|c|c|c|c|c|c|}
\hline \multirow{2}{*}{$\begin{array}{l}\text { Produtos } \\
\text { Cepas }\end{array}$} & \multicolumn{3}{|c|}{ Vinagre branco 25\% } & \multicolumn{3}{|c|}{ Vinagre tinto $25 \%$} & \multicolumn{3}{|c|}{ Ácido acético 1\% } \\
\hline & 1 & 2 & $\mathrm{~m}$ & 1 & 2 & $\mathrm{~m}$ & 1 & 2 & $\mathrm{~m}$ \\
\hline P1 & 12,0 & 12,0 & 12,0 & 10,0 & 10,0 & 10,0 & 10,0 & 10,0 & 10,0 \\
\hline P3 & 11,0 & 11,5 & 11,2 & 10,0 & 11,0 & 10,5 & 11,0 & 12,0 & 11,5 \\
\hline P4 & 11,0 & 12,0 & 11,5 & 11,0 & 10,0 & 10,5 & 11,0 & 10,5 & 10,7 \\
\hline P5 & 11,0 & 11,0 & 11,0 & 10,0 & 10,0 & 10,0 & 11,0 & 11,0 & 11,0 \\
\hline P6 & 12,0 & 10,0 & 11,0 & 10,0 & 10,0 & 10,0 & 10,0 & 11,0 & 10,5 \\
\hline P7 & 10,0 & 10,0 & 10,0 & 10,0 & 10,0 & 10,0 & 10,0 & 10,0 & 10,0 \\
\hline P8 & 11,0 & 11,0 & 11,0 & 10,0 & 10,0 & 10,0 & 12,0 & 10,0 & 11,0 \\
\hline P9 & 10,0 & 9,0 & 9,5 & 9,0 & 10,0 & 9,5 & 8,0 & 10,0 & 9,0 \\
\hline P10 & 12,0 & 12,0 & 11,0 & 10,0 & 11,0 & 10,5 & 11,0 & 10,0 & 10,5 \\
\hline P11 & 11,0 & 11,0 & 11,0 & 10,0 & 9,0 & 9,5 & 10,0 & 10,0 & 10,0 \\
\hline P12 & 10,0 & 10,0 & 10,0 & 10,0 & 10,0 & 10,0 & 11,0 & 9,0 & 10,0 \\
\hline P14 & 11,0 & 11,0 & 11,0 & 10,0 & 10,0 & 10,0 & 10,0 & 10,0 & 10,0 \\
\hline P15 & 11,0 & 10,0 & 10,5 & 11,0 & 10,0 & 10,5 & 11,0 & 11,0 & 11,0 \\
\hline P17 & 9,0 & 11,0 & 10,0 & 10,0 & 10,0 & 10,0 & 10,0 & $\mathrm{t}$ & 7,5 \\
\hline P18 & 10,0 & 2,0 & 11,0 & 11,0 & 9,0 & 10,0 & 10,0 & 10,0 & 10,0 \\
\hline P20 & 12,0 & 10,0 & 11,0 & 10,0 & 11,0 & 10,5 & 10,0 & 10,0 & 10,0 \\
\hline P23 & 11,0 & 11,0 & 11,0 & 10,0 & 8,0 & 9,0 & 9,0 & 10,0 & 9,5 \\
\hline P24 & 11,0 & 10,0 & 10,5 & 12,0 & 10,0 & 11,0 & 12,0 & 10,0 & 11,0 \\
\hline P26 & 10,0 & 10,5 & 10,2 & 10,0 & 10,0 & 10,0 & 10,0 & 10,0 & 10,0 \\
\hline P27 & 13,0 & $\mathrm{t}$ & 9,0 & $\mathrm{t}$ & 11,0 & 8,0 & 12,0 & 10,0 & 11,0 \\
\hline P28 & 10,0 & 11,0 & 10,5 & 10,0 & 9,0 & 9,5 & 10,0 & 10,0 & 10,0 \\
\hline P29 & 10,0 & 10,0 & 10,0 & 10,0 & 9,0 & 9,5 & 12,0 & 10,0 & 11,0 \\
\hline Total & 239,0 & 230,0 & 234,5 & 219,0 & 218,0 & 218,5 & 231,0 & 219,5 & 225,2 \\
\hline Média & 10,9 & 10,5 & 10,6 & 10,0 & 9,9 & 9,9 & 10,5 & 10,0 & 10,2 \\
\hline
\end{tabular}




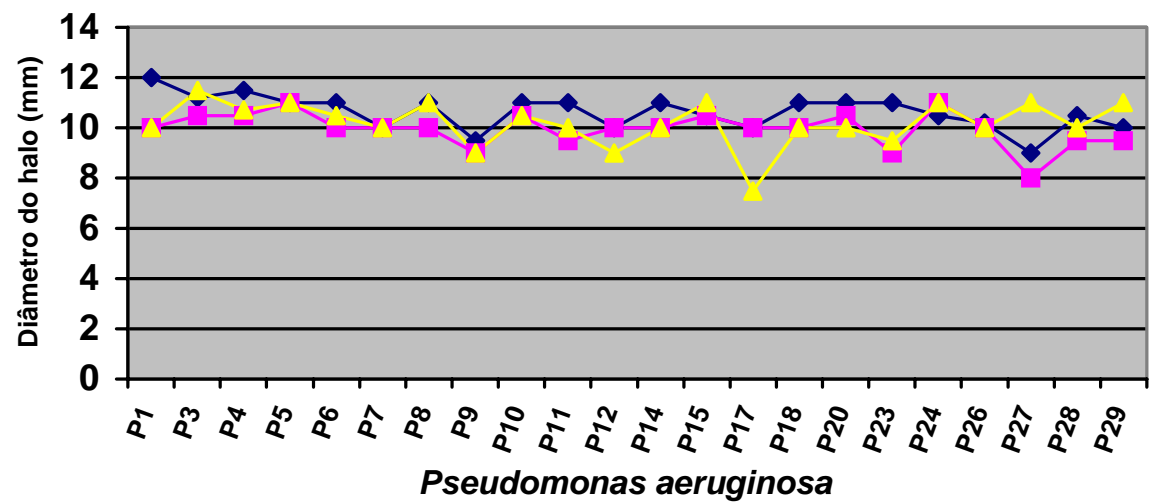

Figura 5 : Representação gráfica dos dados da tabela 4

$\longrightarrow$ vinagre branco $25 \%$ - vinagre tinto $25 \%$ ácido acético $1 \%$ 


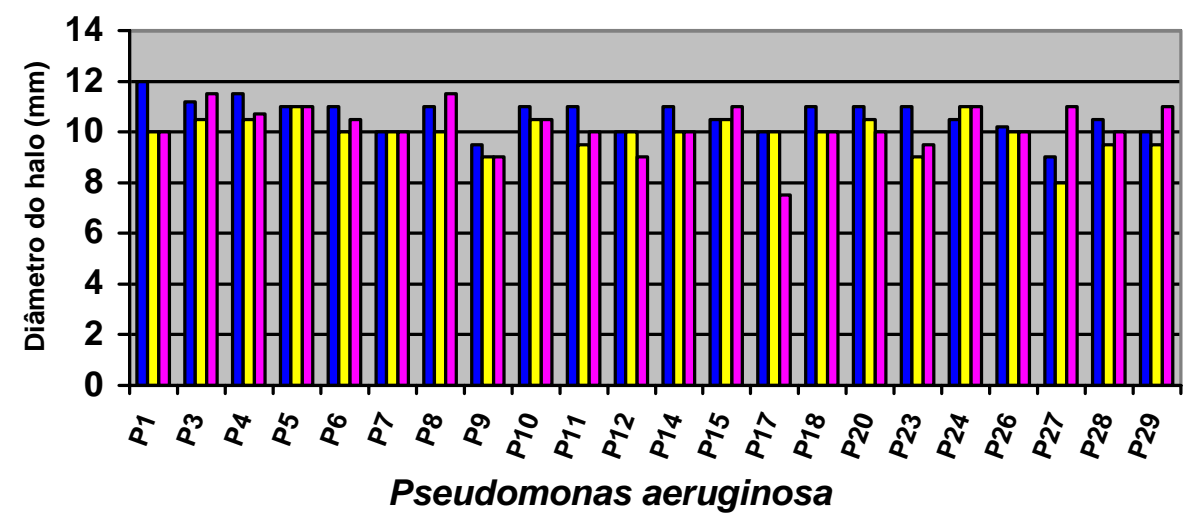

Figura 6: Histograma dos dados da tabela 4

avinagre branco $25 \%$

$\square$ vinagre tinto $25 \%$

口ácido acético $1 \%$ 
Tabela 5- Distribuição da média do diâmetro dos halos de inibição em milímetros do vinagre branco, tinto a 10,0\% e do ácido acético a 0,7\% sobre 22 cepas de Pseudomonas aeruginosa pelo método de difusão de poço, Ribeirão Preto, 2003.

\begin{tabular}{|c|c|c|c|c|c|c|c|c|c|}
\hline \multirow{2}{*}{$\begin{array}{l}\text { Produtos } \\
\text { Cepas }\end{array}$} & \multicolumn{3}{|c|}{ Vinagre branco 10\% } & \multicolumn{3}{|c|}{ Vinagre tinto $10 \%$} & \multicolumn{3}{|c|}{ Ácido acético 0,7\% } \\
\hline & 1 & 2 & $\mathrm{~m}$ & 1 & 2 & $\mathrm{~m}$ & 1 & 2 & $\mathrm{~m}$ \\
\hline P1 & $\mathrm{t}$ & $\mathrm{t}$ & 5,0 & $\mathrm{t}$ & $\mathrm{t}$ & 5,0 & 9,0 & 9,0 & 9,0 \\
\hline P3 & $\mathrm{t}$ & $\mathrm{t}$ & 5,0 & $\mathrm{t}$ & $\mathrm{t}$ & 5,0 & $\mathrm{t}$ & $\mathrm{t}$ & 5,0 \\
\hline P4 & 0,0 & 0,0 & 0,0 & 0,0 & 0,0 & 0,0 & 9,0 & 9,0 & 9,0 \\
\hline P5 & 0,0 & 0,0 & 0,0 & 0,0 & 0,0 & 0,0 & $\mathrm{t}$ & $\mathrm{t}$ & 5,0 \\
\hline P6 & 0,0 & 0,0 & 0,0 & 0,0 & 0,0 & 0,0 & 9,0 & 8,0 & 8,5 \\
\hline P7 & 0,0 & 0,0 & 0,0 & 0,0 & 0,0 & 0,0 & 9,0 & 9,0 & 9,0 \\
\hline P8 & 0,0 & 0,0 & 0,0 & 0,0 & 0,0 & 0,0 & 9,0 & 9,0 & 9,0 \\
\hline P9 & 0,0 & 0,0 & 0,0 & 0,0 & 0,0 & 0,0 & $\mathrm{t}$ & $\mathrm{t}$ & 5,0 \\
\hline P10 & 0,0 & 0,0 & 0,0 & 0,0 & 0,0 & 0,0 & 11,0 & 9,0 & 10,0 \\
\hline P11 & 0,0 & 0,0 & 0,0 & 0,0 & 0,0 & 0,0 & $\mathrm{t}$ & $\mathrm{t}$ & 5,0 \\
\hline P12 & 0,0 & 0,0 & 0,0 & 0,0 & 0,0 & 0,0 & $\mathrm{t}$ & $\mathrm{t}$ & 5,0 \\
\hline P14 & 0,0 & 0,0 & 0,0 & 0,0 & 0,0 & 0,0 & $\mathrm{t}$ & $\mathrm{t}$ & 5,0 \\
\hline P15 & 0,0 & 0,0 & 0,0 & 0,0 & 0,0 & 0,0 & $\mathrm{t}$ & 9,0 & 7,0 \\
\hline P17 & 0,0 & 0,0 & 0,0 & 0,0 & 0,0 & 0,0 & $\mathrm{t}$ & $\mathrm{t}$ & 5,0 \\
\hline P18 & 0,0 & 0,0 & 0,0 & 0,0 & 0,0 & 0,0 & $\mathrm{t}$ & $\mathrm{t}$ & 5,0 \\
\hline P20 & 0,0 & 0,0 & 0,0 & 0,0 & 0,0 & 0,0 & 10,0 & 10,0 & 10,0 \\
\hline P23 & 0,0 & 0,0 & 0,0 & 0,0 & 0,0 & 0,0 & $\mathrm{t}$ & $\mathrm{t}$ & 5,0 \\
\hline P24 & 0,0 & 0,0 & 0,0 & 0,0 & 0,0 & 0,0 & $\mathrm{t}$ & 8,0 & 6,5 \\
\hline P26 & 0,0 & 0,0 & 0,0 & 0,0 & 0,0 & 0,0 & $\mathrm{t}$ & $\mathrm{t}$ & 5,0 \\
\hline P27 & 0,0 & 0,0 & 0,0 & 0,0 & 0,0 & 0,0 & $\mathrm{t}$ & $\mathrm{t}$ & 5,0 \\
\hline P28 & 0,0 & 0,0 & 0,0 & 0,0 & 0,0 & 0,0 & $\mathrm{t}$ & $\mathrm{t}$ & 5,0 \\
\hline P29 & 0,0 & 0,0 & 0,0 & 0,0 & 0,0 & 0,0 & $\mathrm{t}$ & $\mathrm{t}$ & 5,0 \\
\hline Total & 10,0 & 10,0 & 10,0 & 10,0 & 10,0 & 10,0 & 141,0 & 145,0 & 143,0 \\
\hline Média & 5,0 & 5,0 & 5,0 & 5,0 & 5,0 & 5,0 & 6,4 & 6,6 & 6,5 \\
\hline
\end{tabular}

1,2: série duplicada

m: média dos diâmetros dos halos de inibição

t: diâmetro do halo considerado 5,0mm 


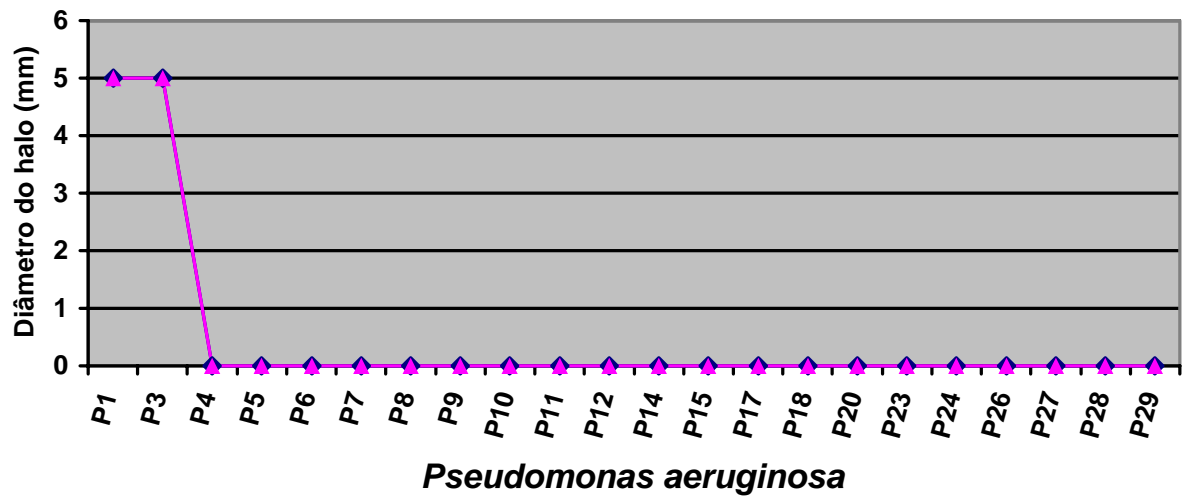

Figura 7: Representação gráfica dos dados da tabela 5

$\neg$ vinagre branco $10 \%$ $\longrightarrow$ vinagre tinto $10 \%$ 


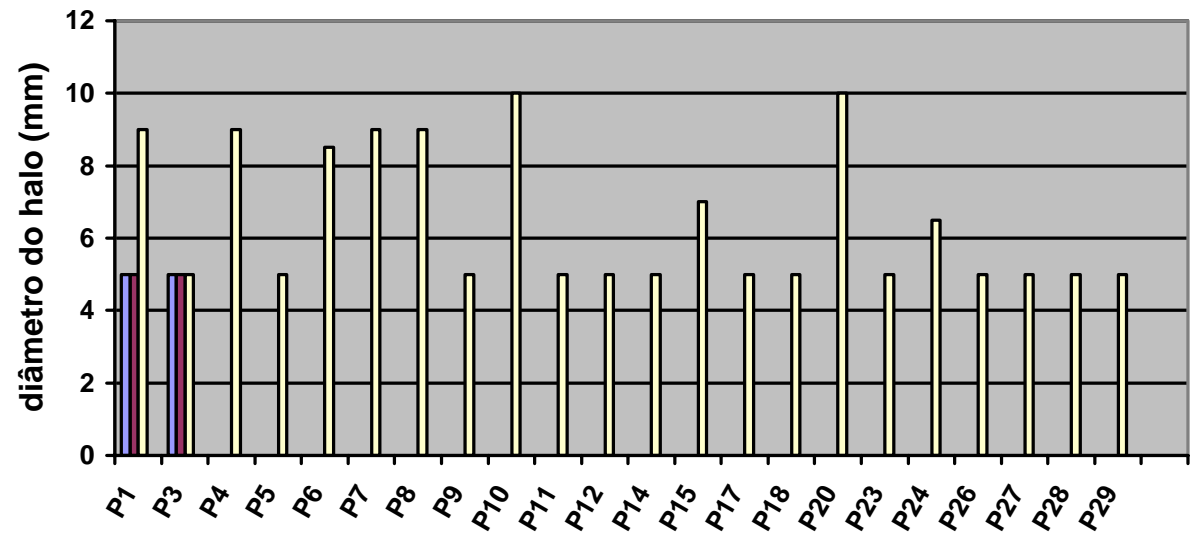

Pseudomonas aeruginosa

Figura 8: Histograma dos dados da tabela 5

$\square$ vinagre branco $10 \%$

$\square$ vinagre tinto $10 \%$

$\square$ ácido acético $0,7 \%$ 
Tabela 6- Distribuição da média do diâmetro dos halos de inibição em milímetros do ácido acético a 1,0 e 0,7\% sobre 22 cepas de Pseudomonas aeruginosa pelo método de difusão de poço, Ribeirão Preto, 2003.

\begin{tabular}{lrrrrrr}
\hline Produtos & Ácido acético $1 \%$ & \multicolumn{5}{c}{ Ácido acético $0,7 \%$} \\
Cepas & 1 & 2 & $\mathrm{~m}$ & 1 & 2 & $\mathrm{~m}$ \\
\hline P1 & 10,0 & 10,0 & 10,0 & 9,0 & 9,0 & 9,0 \\
P3 & 11,0 & 12,0 & 11,5 & $\mathrm{t}$ & $\mathrm{t}$ & 5,0 \\
P4 & 11,0 & 10,5 & 10,7 & 9,0 & 9,0 & 9,0 \\
P5 & 11,0 & 11,0 & 11,0 & $\mathrm{t}$ & $\mathrm{t}$ & 5,0 \\
P6 & 10,0 & 11,0 & 10,5 & 9,0 & 8,0 & 8,5 \\
P7 & 10,0 & 10,0 & 10,0 & 9,0 & 9,0 & 9,0 \\
P8 & 12,0 & 10,0 & 11,0 & 9,0 & 9,0 & 9,0 \\
P9 & 8,0 & 10,0 & 9,0 & $\mathrm{t}$ & $\mathrm{t}$ & 5,0 \\
P10 & 11,0 & 10,0 & 10,5 & 11,0 & 9,0 & 10,0 \\
P11 & 10,0 & 10,0 & 10,0 & $\mathrm{t}$ & $\mathrm{t}$ & 5,0 \\
P12 & 11,0 & 9,0 & 10,0 & $\mathrm{t}$ & $\mathrm{t}$ & 5,0 \\
P14 & 10,0 & 10,0 & 10,0 & $\mathrm{t}$ & $\mathrm{t}$ & 5,0 \\
P15 & 11,0 & 11,0 & 11,0 & $\mathrm{t}$ & 9,0 & 7,0 \\
P17 & 10,0 & $\mathrm{t}$ & 7,5 & $\mathrm{t}$ & $\mathrm{t}$ & 5,0 \\
P18 & 10,0 & 10,0 & 10,0 & $\mathrm{t}$ & $\mathrm{t}$ & 5,0 \\
P20 & 10,0 & 10,0 & 10,0 & 10,0 & 10,0 & 10,0 \\
P23 & 9,0 & 10,0 & 9,5 & $\mathrm{t}$ & $\mathrm{t}$ & 5,0 \\
P24 & 12,0 & 10,0 & 11,0 & $\mathrm{t}$ & 8,0 & 6,5 \\
P26 & 10,0 & 10,0 & 10,0 & $\mathrm{t}$ & $\mathrm{t}$ & 5,0 \\
P27 & 12,0 & 10,0 & 11,0 & $\mathrm{t}$ & $\mathrm{t}$ & 5,0 \\
P28 & 10,0 & 10,0 & 10,0 & $\mathrm{t}$ & $\mathrm{t}$ & 5,0 \\
P29 & 12,0 & 10,0 & 11,0 & $\mathrm{t}$ & $\mathrm{t}$ & 5,0 \\
Total & 231,0 & 219,5 & 225,2 & 141,0 & 145,0 & 143,0 \\
Média & 10,5 & 10,0 & 10,2 & 6,4 & 6,6 & 6,5 \\
& & & & & & \\
& & & & & &
\end{tabular}

1,2: série duplicada

m: média dos diâmetros dos halos de inibição

t: diâmetro do halo considerado 5,0mm 


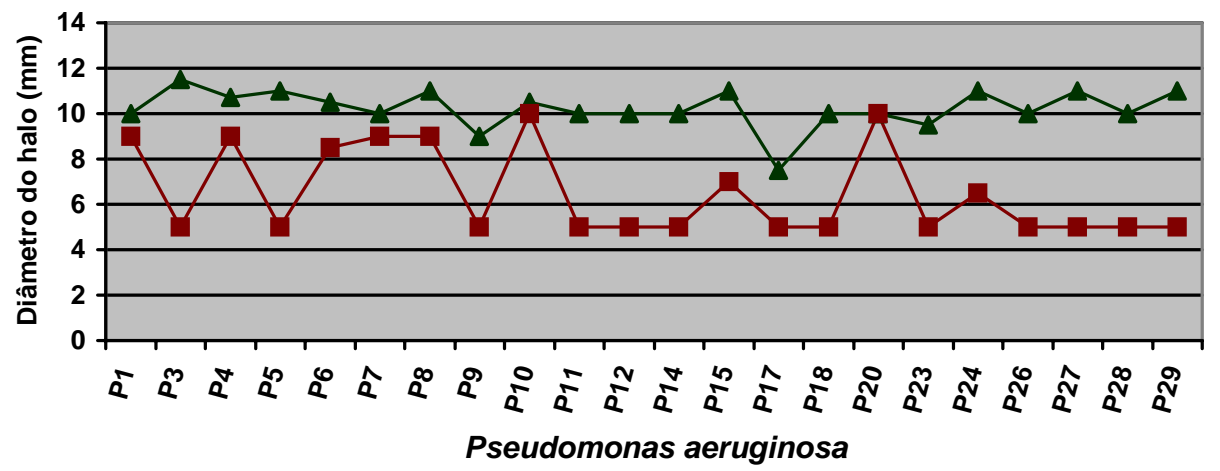

Figura 9: Representação gráfica dos dados da tabela 6

- ácido acético a 1\% $\rightarrow$ ácido acético 0,7\%

Tabela 7 -Distribuição da média do diâmetro dos halos de inibição em milímetros do vinagre branco e tinto a 30,0, 25,0 e 10,0\% sobre 22 
cepas de Pseudomonas aeruginosa pelo método de difusão de poço, Ribeirão Preto, 2003.

\begin{tabular}{ccc}
\hline Concentração \% & Vinho branco & Vinho tinto \\
\hline 30,0 & 11,5 & 11,2 \\
25,0 & 10,6 & 9,9 \\
10,0 & 5,0 & 5,0 \\
\hline
\end{tabular}

Tabela 8- Distribuição da média do diâmetro dos halos de inibição em milímetros do ácido acético a 1,0 e $0,7 \%$ sobre 22 cepas de Pseudomonas aeruginosa pelo método de difusão de poço, Ribeirão Preto, 2003.

\begin{tabular}{cc}
\hline Concentração \% & Ácido acético \\
\hline 1,0 & 10,2 \\
0,7 & 6,5 \\
\hline
\end{tabular}




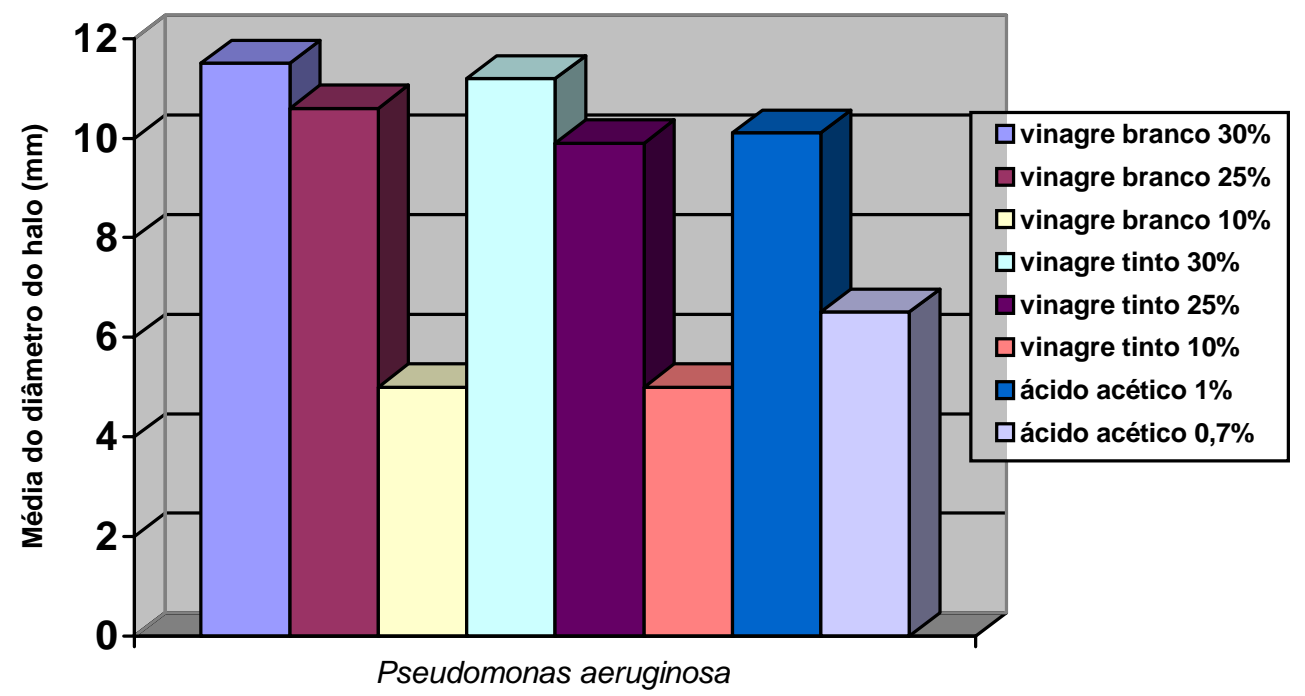

Figura 10: Histograma dos dados das tabelas 7 e 8 
Tabela 9 -Distribuição da média do diâmetro dos halos de inibição em milímetros do vinagre branco e tinto a $30,0 \%$ sobre 21 cepas de Escherichia coli pelo método de difusão de poço, Ribeirão Preto, 2003.

\begin{tabular}{|c|c|c|c|c|c|c|}
\hline \multirow{2}{*}{$\begin{array}{l}\text { Produtos } \\
\text { Cepas }\end{array}$} & \multicolumn{3}{|c|}{ Vinagre branco $30 \%$} & \multicolumn{3}{|c|}{ Vinagre tinto $30 \%$} \\
\hline & 1 & 2 & $\mathrm{~m}$ & 1 & 2 & $\mathrm{~m}$ \\
\hline E1 & 12,0 & 11,0 & 11,5 & 11,0 & 11,0 & 11,0 \\
\hline E2-1 & 12,0 & 11,0 & 11,5 & 11,0 & 11,0 & 11,0 \\
\hline E5 & 10,0 & 11,0 & 10,5 & 12,0 & 10,5 & 11,2 \\
\hline E5-1 & 11,0 & 12,0 & 11,5 & 10,0 & 10,5 & 10,2 \\
\hline E6 & 12,0 & 12,0 & 12,0 & 11,0 & 11,0 & 11,0 \\
\hline E7 & 11,0 & 12,0 & 11,5 & 10,0 & 10,0 & 10,0 \\
\hline E9 & 12,0 & 11,0 & 11,5 & 12,0 & 11,0 & 11,5 \\
\hline È10 & 11,0 & 11,0 & 11,0 & 11,0 & 9,0 & 10,0 \\
\hline E11-1 & 10,0 & 11,0 & 10,5 & 12,0 & 10,0 & 11,0 \\
\hline E12 & 12,0 & 11,0 & 11,5 & 11,0 & 11,0 & 11,0 \\
\hline E13 & 11,0 & 11,0 & 11,0 & 10,0 & 11,0 & 10,5 \\
\hline E14 & 11,0 & 11,0 & 11,0 & 10,0 & 11,0 & 10,5 \\
\hline E17 & 12,0 & 11,0 & 11,5 & 11,0 & 11,0 & 11,0 \\
\hline E18-1 & 12,0 & 11,0 & 11,5 & 10,0 & 9,0 & 9,5 \\
\hline E19 & 12,0 & 12,0 & 12,0 & 10,0 & 11,0 & 10,5 \\
\hline E20 & 12,0 & 12,0 & 12,0 & 12,0 & 10,0 & 11,0 \\
\hline E21 & 11,0 & 11,0 & 11,0 & 11,0 & 10,0 & 10,5 \\
\hline E22 & 12,0 & 12,0 & 12,0 & 11,0 & 11,0 & 11,0 \\
\hline E24 & 12,0 & 10,0 & 11,0 & 12,0 & 10,0 & 11,0 \\
\hline E25 & 12,0 & 11,0 & 11,5 & 10,0 & 10,0 & 10,0 \\
\hline E25-1 & 12,0 & 11,0 & 11,5 & 12,0 & 11,0 & 11,5 \\
\hline Total & 242,0 & 236,0 & 239,0 & 230,0 & 220,0 & 225,0 \\
\hline Média & 11,6 & 11,2 & 11,4 & 10,9 & 10,5 & 10,7 \\
\hline
\end{tabular}




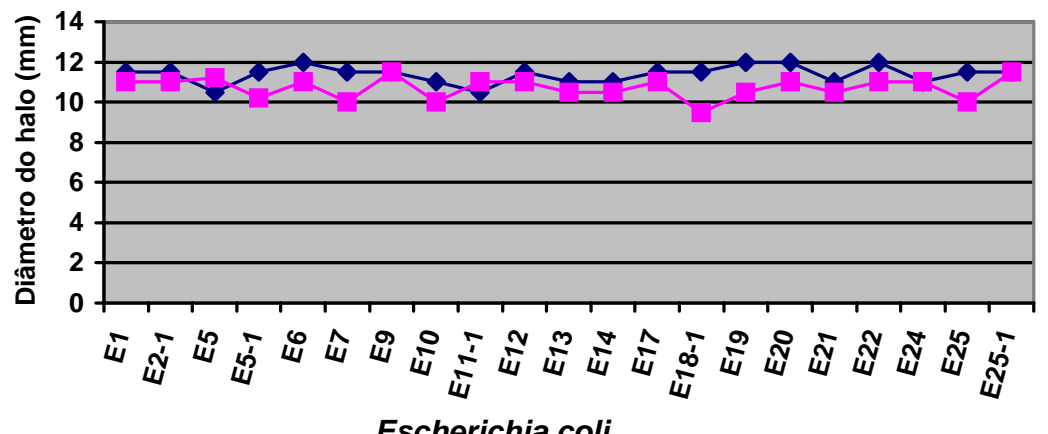

Escherichia coli

Figura 11 : Representação gráfica dos dados da tabela 9

$\longrightarrow$-vinagre branco $30 \%$
$\longrightarrow-$ vinagre tinto $30 \%$ 
Tabela 10 -Distribuição da média do diâmetro dos halos de inibição em milímetros do vinagre branco, tinto a $25,0 \%$ e ácido acético a $1,0 \%$ sobre 21 cepas de Escherichia coli pelo método de difusão de poço, Ribeirão Preto, 2003.

\begin{tabular}{|c|c|c|c|c|c|c|c|c|c|}
\hline \multirow{2}{*}{$\begin{array}{l}\text { Produtos } \\
\text { Cepas }\end{array}$} & \multicolumn{3}{|c|}{ Vinagre branco 25\% } & \multicolumn{3}{|c|}{ Vinagre tinto $25 \%$} & \multicolumn{3}{|c|}{ Ácido acético 1\% } \\
\hline & 1 & 2 & $\mathrm{~m}$ & 1 & 2 & $\mathrm{~m}$ & 1 & 2 & $\mathrm{~m}$ \\
\hline E1 & 10,0 & 10,0 & 10,0 & 10,0 & 10,0 & 10,0 & 11,0 & 11,0 & 11,0 \\
\hline E2-1 & 11,0 & 10,0 & 10,5 & 10,0 & 11,0 & 10,5 & 11,0 & 11,0 & 11,0 \\
\hline E5 & 9,0 & 9,0 & 9,0 & 12,0 & 10,0 & 11,0 & 10,0 & 11,0 & 10,5 \\
\hline E5-1 & 10,0 & 10,0 & 10,0 & 10,0 & 10,0 & 10,0 & 11,0 & 10,0 & 10,5 \\
\hline E6 & 12,0 & 10,0 & 11,0 & 10,0 & 10,0 & 10,0 & 11,0 & 10,0 & 10,5 \\
\hline E7 & 10,0 & 9,0 & 9,5 & 10,0 & 9,0 & 9,5 & 10,0 & 10,0 & 10,0 \\
\hline E9 & 11,0 & 10,0 & 10,5 & 10,0 & 9,0 & 9,5 & 11,0 & 10,0 & 10,5 \\
\hline È10 & 10,0 & 10,0 & 10,0 & 10,0 & 8,0 & 9,0 & 11,0 & 10,0 & 10,5 \\
\hline E11-1 & 10,0 & 9,0 & 9,5 & 11,0 & 9,0 & 10,0 & 10,0 & 10,0 & 10,0 \\
\hline E12 & 10,0 & 10,0 & 10,0 & 10,0 & 10,0 & 10,0 & 11,0 & 10,0 & 10,5 \\
\hline E13 & 10,0 & 10,0 & 10,0 & 10,0 & 10,0 & 10,0 & 11,0 & 10,0 & 10,5 \\
\hline E14 & 9,0 & 11,0 & 10,0 & 10,0 & 9,0 & 9,5 & 10,0 & 9,0 & 9,5 \\
\hline E17 & 11,0 & 10,0 & 10,5 & 11,0 & 10,0 & 10,5 & 11,0 & 10,0 & 10,5 \\
\hline E18-1 & 10,0 & 10,0 & 10,0 & 10,0 & 9,0 & 9,5 & 11,0 & 10,0 & 10,5 \\
\hline E19 & 11,0 & 10,0 & 10,5 & 10,0 & 10,0 & 10,0 & 10,0 & 11,0 & 10,5 \\
\hline E20 & 11,0 & 11,0 & 11,0 & 11,0 & 9,0 & 10,0 & 12,0 & 10,0 & 11,0 \\
\hline E21 & 11,0 & 10,0 & 10,5 & 10,0 & 9,0 & 9,5 & 10,0 & 9,0 & 9,5 \\
\hline E22 & 11,0 & 11,0 & 11,0 & 11,0 & 10,0 & 10,5 & 12,0 & 11,0 & 11,5 \\
\hline E24 & 11,0 & 10,0 & 10,5 & 10,0 & 9,0 & 9,5 & 12,0 & 10,0 & 11,0 \\
\hline E25 & 11,0 & 10,0 & 10,5 & 10,0 & 9,0 & 9,5 & 12,0 & 11,0 & 11,5 \\
\hline E25-1 & 11,0 & 9,0 & 10,0 & 11,0 & 10,0 & 10,5 & 12,0 & 10,0 & 11,0 \\
\hline Total & 220,0 & 209,0 & 214,5 & 217,0 & 220,0 & 208,5 & 230,0 & 214,0 & 222,0 \\
\hline Média & 10,5 & 9,9 & 10,2 & 10,3 & 9,5 & 9,9 & 11,0 & 10,2 & 10,6 \\
\hline
\end{tabular}

m: média dos diâmetros dos halos de inibição 


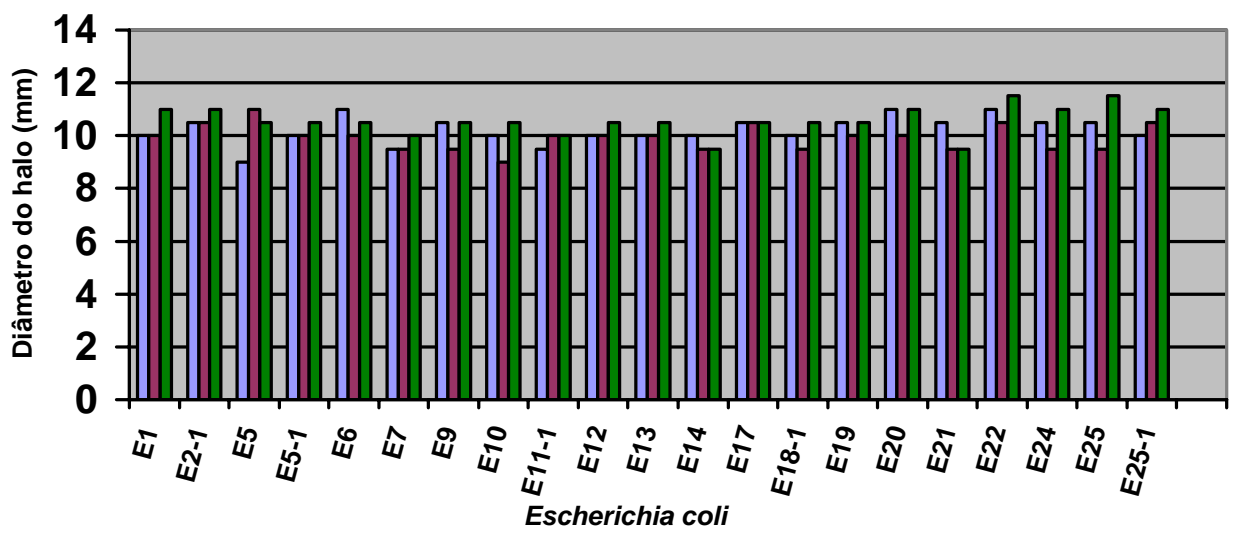

Figura 12: Histograma dos dados da tabela 10

$\square$ vinagre branco $25 \%$

口vinagre tinto $25 \%$

口ácido acético $1 \%$ 
Tabela 11 -Distribuição da média do halo de inibição em milímetros dos vinagres branco e tinto a 10,0\% sobre 21 cepas de $E$. coli pelo método de difusão de poço, Ribeirão Preto, 2003.

\begin{tabular}{|c|c|c|c|c|c|c|}
\hline \multirow{2}{*}{$\begin{array}{c}\text { Produtos } \\
\text { Cepas }\end{array}$} & \multicolumn{3}{|c|}{ Vinagre branco 10\% } & \multicolumn{3}{|c|}{ Vinagre tinto $10 \%$} \\
\hline & 1 & 2 & $\mathrm{~m}$ & 1 & 2 & $\mathrm{~m}$ \\
\hline E1 & 0,0 & 0,0 & 0,0 & $\mathrm{t}$ & $\mathrm{t}$ & 5,0 \\
\hline E2-1 & $\mathrm{t}$ & $\mathrm{t}$ & 5,0 & $\mathrm{t}$ & $\mathrm{t}$ & 5,0 \\
\hline E5 & 0,0 & 0,0 & 0,0 & 0,0 & 0,0 & 0,0 \\
\hline E5-1 & 0,0 & 0,0 & 0,0 & 0,0 & 0,0 & 0,0 \\
\hline E6 & 0,0 & 0,0 & 0,0 & 0,0 & 0,0 & 0,0 \\
\hline E7 & 0,0 & 0,0 & 0,0 & 0,0 & 0,0 & 0,0 \\
\hline E9 & 8,0 & 7,0 & 7,5 & $\mathrm{t}$ & $\mathrm{t}$ & 5,0 \\
\hline È10 & 0,0 & $\mathrm{t}$ & 5,0 & $\mathrm{t}$ & $\mathrm{t}$ & 5,0 \\
\hline E11-1 & 0,0 & 0,0 & 0,0 & 0,0 & 0,0 & 0,0 \\
\hline E12 & $\mathrm{t}$ & $\mathrm{t}$ & 5,0 & $\mathrm{t}$ & $\mathrm{t}$ & 5,0 \\
\hline \multirow[t]{2}{*}{ E13 } & $\mathrm{t}$ & $\mathrm{t}$ & 5,0 & $\mathrm{t}$ & $\mathrm{t}$ & 5,0 \\
\hline & 0,0 & $\mathrm{t}$ & 5,0 & $\mathrm{t}$ & 0,0 & 5,0 \\
\hline \multicolumn{7}{|l|}{ E14 } \\
\hline E17 & $\mathrm{t}$ & $\mathrm{t}$ & 5,0 & $\mathrm{t}$ & 0,0 & 5,0 \\
\hline E18-1 & $\mathrm{t}$ & 0,0 & 5,0 & $\mathrm{t}$ & $\mathrm{t}$ & 5,0 \\
\hline E19 & 0,0 & 0,0 & 0,0 & 0,0 & 0,0 & 0,0 \\
\hline E20 & $\mathrm{t}$ & $\mathrm{t}$ & 5,0 & $\mathrm{t}$ & 0,0 & 5,0 \\
\hline E21 & 0,0 & $\mathrm{t}$ & 5,0 & 0,0 & 0,0 & 0,0 \\
\hline E22 & 0,0 & $\mathrm{t}$ & 2,5 & $\mathrm{t}$ & $\mathrm{t}$ & 5,0 \\
\hline E24 & 0,0 & 0,0 & 0,0 & 0,0 & 0,0 & 0,0 \\
\hline E25 & 0,0 & 0,0 & 0,0 & 0,0 & 0,0 & 0,0 \\
\hline E25-1 & 0,0 & $\mathrm{t}$ & 5,0 & 0,0 & $t$ & 5,0 \\
\hline Total & 38,0 & 57,0 & 47,5 & 55,0 & 45,0 & 50,0 \\
\hline Média & 5,4 & 5,1 & 5,2 & 5,0 & 5,0 & 5,0 \\
\hline
\end{tabular}




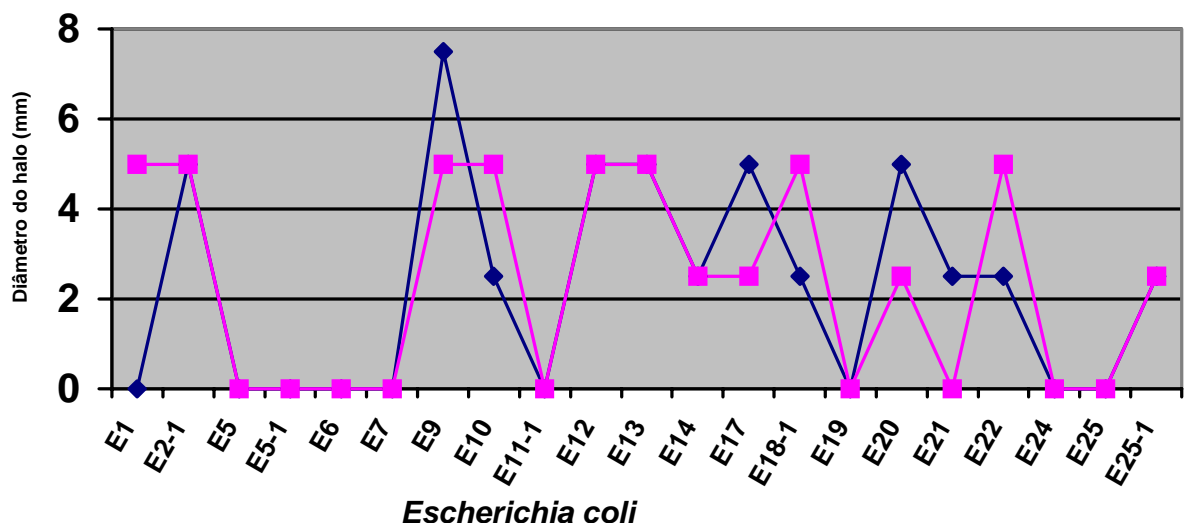

Figura 13: Representação gráfica dos dados da tabela 11.

$\neg$ - vinagre branco $10 \%$ vinagre tinto $10 \%$ 
Tabela 12- Distribuição da média do diâmetro dos halos de inibição em milímetros do ácido acético a 1,0 e $0,7 \%$ sobre 21 cepas de Escherichia coli pelo método de difusão de poço, Ribeirão Preto, 2003.

\begin{tabular}{|c|c|c|c|c|c|c|}
\hline \multirow{2}{*}{$\begin{array}{l}\text { Produtos } \\
\text { Cepas }\end{array}$} & \multicolumn{2}{|c|}{ Ácido acético 1\% } & \multicolumn{4}{|c|}{ Ácido acético 0,7\% } \\
\hline & 1 & 2 & $\mathrm{~m}$ & 1 & 2 & $\mathrm{~m}$ \\
\hline E1 & 11,0 & 11,0 & 11,0 & $\mathrm{t}$ & $\mathrm{t}$ & 5,0 \\
\hline E2-1 & 11,0 & 11,0 & 11,0 & 8,0 & 9,0 & 8,5 \\
\hline E5 & 10,0 & 11,0 & 10,5 & $\mathrm{t}$ & $\mathrm{t}$ & 5,0 \\
\hline E5-1 & 11,0 & 10,0 & 10,5 & $\mathrm{t}$ & 8,0 & 6,5 \\
\hline E6 & 11,0 & 10,0 & 10,5 & 9,0 & 8,0 & 8,5 \\
\hline E7 & 10,0 & 10,0 & 10,0 & $\mathrm{t}$ & $\mathrm{t}$ & 5,0 \\
\hline E9 & 11,0 & 10,0 & 10,5 & 9,0 & 7,0 & 8,0 \\
\hline È10 & 11,0 & 10,0 & 10,5 & 9,0 & 9,0 & 9,0 \\
\hline E11-1 & 10,0 & 10,0 & 10,0 & 9,0 & 9,0 & 9,0 \\
\hline E12 & 11,0 & 10,0 & 10,5 & $\mathrm{t}$ & 8,0 & 6,5 \\
\hline E13 & 11,0 & 10,0 & 10,5 & 10,0 & 9,0 & 9,5 \\
\hline E14 & 10,0 & 9,0 & 9,5 & 9,0 & 7,0 & 8,0 \\
\hline E17 & 11,0 & 10,0 & 10,5 & 9,0 & 8,0 & 8,5 \\
\hline E18-1 & 11,0 & 10,0 & 10,5 & 9,0 & 7,0 & 8,0 \\
\hline E19 & 10,0 & 11,0 & 10,5 & 8,0 & 7,0 & 7,5 \\
\hline E20 & 12,0 & 10,0 & 11,0 & 10,0 & 8,0 & 9,0 \\
\hline E21 & 10,0 & 9,0 & 9,5 & 8,0 & 8,0 & 8,0 \\
\hline E22 & 12,0 & 11,0 & 11,5 & 9,0 & 9,0 & 9,0 \\
\hline E24 & 12,0 & 10,0 & 11,0 & 9,0 & 8,0 & 8,5 \\
\hline E25 & 12,0 & 11,0 & 11,5 & 10,0 & 9,0 & 8,5 \\
\hline E25-1 & 12,0 & 10,0 & 11,0 & 10,0 & 8,0 & 9,0 \\
\hline Total & 230,0 & 214,0 & 222,0 & 170,0 & 161,0 & 165,5 \\
\hline Média & 11,0 & 10,2 & 10,6 & 8,1 & 7,7 & 7,9 \\
\hline
\end{tabular}




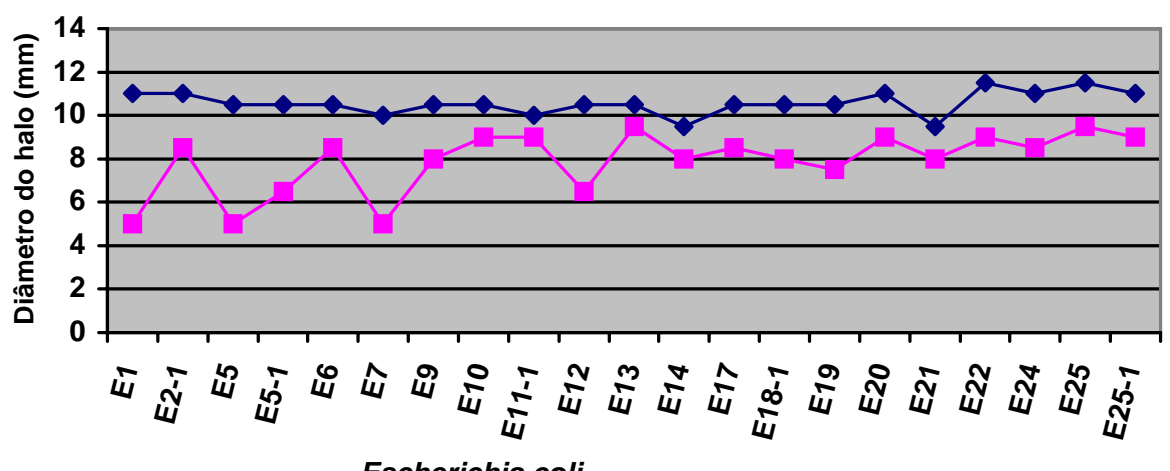

Figura 14: Representação gráfica dos dados da tabela 12 $\neg$ ácido acético 1\% $\longrightarrow$ - ácido acético $0,7 \%$ 
Tabela 13- Distribuição da média do diâmetro dos halos de inibição em milímetros do vinagre branco e tinto a 30,0, 25,0 e 10,0\% sobre 21 cepas de Escherichia coli pelo método de difusão de poço, Ribeirão Preto, 2003.

\begin{tabular}{ccc}
\hline Concentração\% & Vinagre branco & Vinagre tinto \\
\hline 30,0 & 11,4 & 10,7 \\
25,0 & 10,2 & 9,9 \\
10,0 & 5,2 & 5,0 \\
\hline
\end{tabular}

Tabela 14- Distribuição da média do diâmetro dos halos de inibição em milímetros do ácido acético a 1,0 e 0,7\% sobre 21 cepas de Escherichia coli pelo método de difusão de poço, Ribeirão Preto, 2003.

\begin{tabular}{cc}
\hline Concentração\% & Ácido acético \\
\hline 1,0 & 10,6 \\
0,7 & 7,7 \\
\hline
\end{tabular}




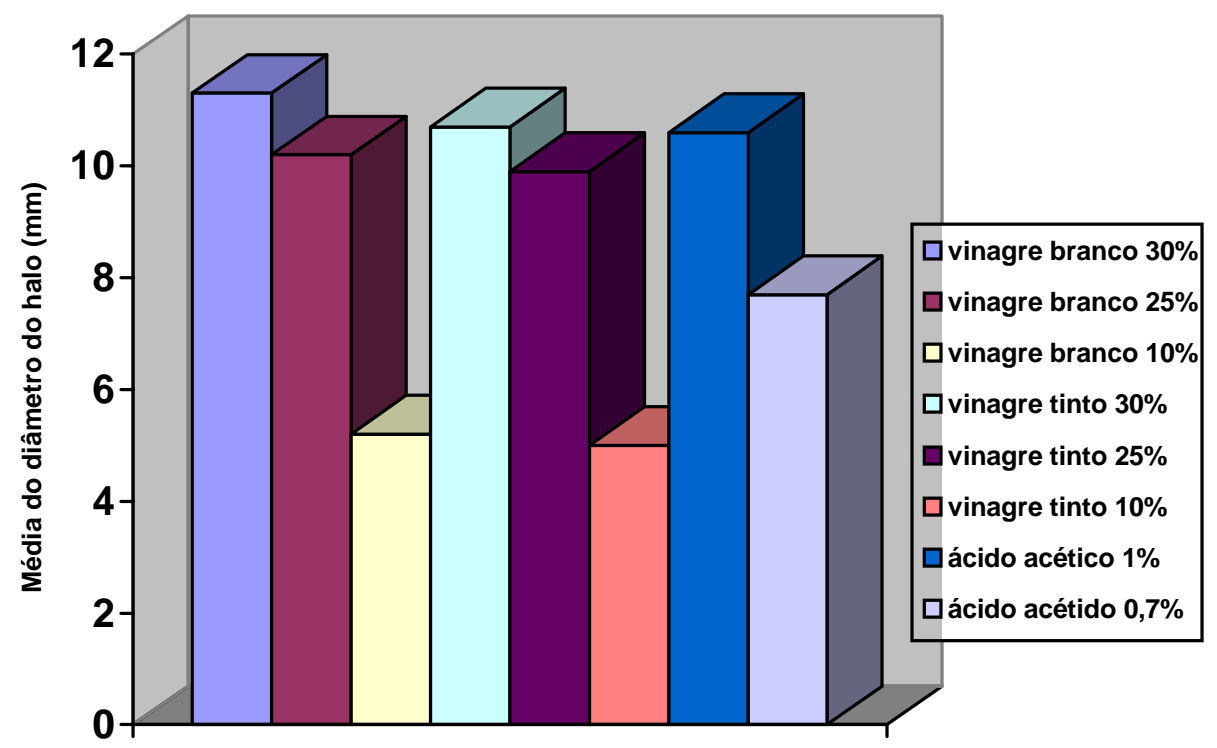

Figura 15: Histograma dos dados apresentados nas tabelas 13 e 14

Tabela 15- Distribuição do diâmetro dos halos de inibição em milímetros do vinagre branco e tinto a 30,0, 25,0 e 10,0\% sobre 22 cepas de Pseudomonas aeruginosa (Pa), Staphylococcus aureus (Sa) e 21 
de Escherichia coli (Ec) pelo método de difusão de poço, Ribeirão Preto, 2003.

\begin{tabular}{cccccccc}
\hline Concentração\% & \multicolumn{3}{c}{ Vinagre branco } & \multicolumn{3}{c}{ Vinagre tinto } \\
& $\mathrm{Pa}$ & $\mathrm{Ec}$ & $\mathrm{Sa}$ & $\mathrm{Pa}$ & $\mathrm{Ec}$ & $\mathrm{Sa}$ \\
\hline 30,0 & 11,5 & 11,4 & 0 & 11,2 & 10,7 & 0 \\
& & & & & & \\
25,0 & 10,6 & 10,2 & 0 & 10,4 & 9,9 & 0 \\
& 5,0 & 5,2 & 0 & 5,0 & 5,0 & 0 \\
10,0 & & & & & & \\
\hline
\end{tabular}

Tabela 16 - Distribuição do diâmetro dos halos de inibição em milímetros do ácido acético a 1,0 e $0,7 \%$ sobre 22 cepas de Pseudomonas aeruginosa ( $\mathrm{Pa})$, Staphylococcus aureus ( $\mathrm{Sa}$ ) e 21 de Escherichia coli (Ec) pelo método de difusão de poço, Ribeirão Preto, 2003.

Concentração \% Ácido acético

\begin{tabular}{cccc} 
& $\mathrm{Pa}$ & Ec & Sa \\
\hline 1,0 & 10,2 & 10,6 & 0 \\
0,7 & 6,5 & 7,7 & 0 \\
\hline
\end{tabular}




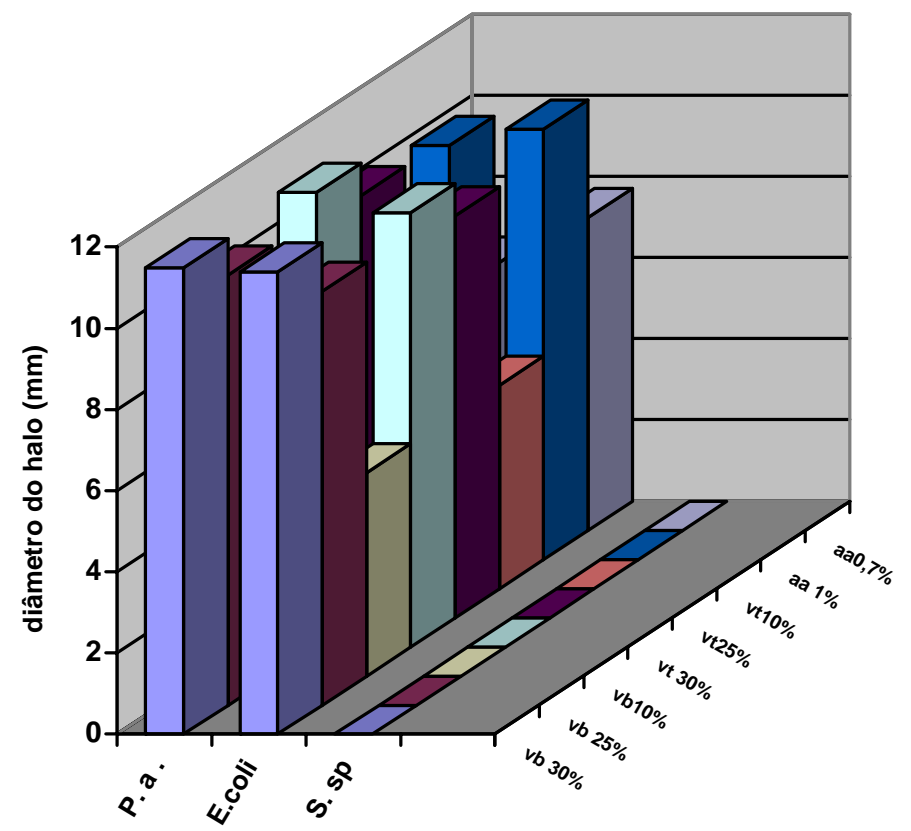

$\square$ vb 30\% $\square$ vb 25\% $\square \mathrm{vb} 10 \%$ $\square$ vt $\mathbf{3 0 \%}$ $\square \mathrm{vt25 \%}$ $\square \mathrm{vt10 \%}$ $\square$ aa 1\% 口аa0,7\%

Figura 16: Histograma dos dados das tabelas 15 e 16 
Tabela 17- Distribuição dos resultados dos testes estatísticos da avaliação dos halos de inibição em milímetros pelo método de difusão de poço sobre 22 cepas de Pseudomonas aeruginosa do vinagre branco (VB), tinto (VT) e do ácido acético (AA) nas concentrações $30,0,25,0,10,0,1,0$ e a $0,7 \%$ respectivamente, Ribeirão Preto, 2003.

\begin{tabular}{|c|c|c|c|}
\hline $\begin{array}{c}\text { Produto do } \\
\text { teste }\end{array}$ & Produtos \% & $\begin{array}{l}\text { Média dos } \\
\text { halos }\end{array}$ & $\begin{array}{c}\text { Nível de } \\
\text { Significância (p) }\end{array}$ \\
\hline \multirow{7}{*}{ VB a $30 \%$} & VB $25 \%$ & 10,6 & 0,29 \\
\hline & VB $10 \%$ & 5,0 & 0 * \\
\hline & VT30\% & 11,2 & 0,9 \\
\hline & VT25\% & 9,9 & $0,01^{*}$. \\
\hline & VT10\% & 5,0 & 0 * \\
\hline & AA1\% & 10,2 & $0,08^{*}$. \\
\hline & $\mathrm{AA} 0,7 \%$ & 6,5 & $0 .{ }^{*}$ \\
\hline \multirow{7}{*}{ VB a $25 \%$} & VB $30 \%$ & 11,5 & 0,29 \\
\hline & VB $10 \%$ & 5,0 & $0^{*}$ \\
\hline & VT30\% & 11,2 & 0,73 \\
\hline & VT25\% & 9,9 & 0,54 \\
\hline & VT10\% & 5,0 & $0 *$ \\
\hline & $\mathrm{AA} 1 \%$ & 10,2 & 0,88 \\
\hline & $\mathrm{AA} 0,7 \%$ & 6,5 & $0 *$ \\
\hline \multirow{7}{*}{ VB a $10 \%$} & VB30\% & 11,5 & $0^{*}$ \\
\hline & VB $25 \%$ & 10,5 & $0^{*}$ \\
\hline & VT30\% & 11,2 & $0^{*}$ \\
\hline & VT25\% & 9,9 & $0 *$ \\
\hline & VT10\% & 5,0 & 0,1 \\
\hline & AA1\% & 10,2 & $0^{*}$ \\
\hline & $\mathrm{AA} 0,7 \%$ & 6,5 & $0 *$ \\
\hline \multirow{7}{*}{ VT a $30 \%$} & VB30\% & 11,5 & 0,99 \\
\hline & VB $25 \%$ & 10,5 & 0,73 \\
\hline & VB $10 \%$ & 5,0 & $0 *$ \\
\hline & VT25\% & 9,9 & 0,01 \\
\hline & VT10\% & 5,0 & $0 *$ \\
\hline & AA1\% & 10,2 & 0,67 \\
\hline & $\mathrm{AA} 0,7 \%$ & 6,5 & $0 *$ \\
\hline \multirow{7}{*}{ VT a $25 \%$} & VB30\% & 11,5 & $0,001^{*}$ \\
\hline & VB $25 \%$ & 10,5 & 0,054 \\
\hline & VB $10 \%$ & 5,0 & $0 *$ \\
\hline & VT30\% & 11,2 & 0,01 \\
\hline & VT10\% & 5,0 & $0^{*}$ \\
\hline & AA1\% & 10,2 & 0,09 \\
\hline & $\mathrm{AA} 0,7 \%$ & 6,5 & $0 *$ \\
\hline \multirow{7}{*}{ VT a $10 \%$} & VB30\% & 11,5 & $0 *$ \\
\hline & VB $25 \%$ & 10,5 & 0 * \\
\hline & VB $10 \%$ & 5,0 & 0,1 \\
\hline & VT30\% & 11,2 & $0^{*}$ \\
\hline & VT25\% & 9,9 & $0 *$ \\
\hline & AA1\% & 10,2 & $0 *$ \\
\hline & $\mathrm{AA} 0,7 \%$ & 6,5 & 0 * \\
\hline \multirow{7}{*}{ AA a $1 \%$} & VB30\% & 11,5 & $0,008^{*}$ \\
\hline & VB $25 \%$ & 10,5 & 0,08 \\
\hline & VB $10 \%$ & 5,0 & $0 *$ \\
\hline & VT30\% & 11,2 & 0,06 \\
\hline & VT25\% & 9,9 & 0,09 \\
\hline & VT10\% & 5,0 & $0 *$ \\
\hline & $\mathrm{AA} 0,7 \%$ & 6,5 & 0 * \\
\hline \multirow{7}{*}{$\mathrm{AA}$ a $0,7 \%$} & VB30\% & 11,5 & $0 *$ \\
\hline & VB $25 \%$ & 10,5 & $0^{*}$ \\
\hline & VB $10 \%$ & 5,0 & $0 *$ \\
\hline & VT30\% & 11,2 & $0 *$ \\
\hline & VT25\% & 9,9 & $0 *$ \\
\hline & VT10\% & 5,0 & $0^{*}$ \\
\hline & AA1\% & 10,2 & 0 * \\
\hline
\end{tabular}

* diferença estatisticamente significante 
Tabela 18- Distribuição dos resultados dos testes estatísticos da avaliação dos halos de inibição em milímetros pelo método de difusão de poço sobre 21 cepas de $E$. coli do vinagre branco (VB), tinto (VT) e do ácido acético (AA) nas concentrações 30,0, 25,0, 10,0\%, 1,0\% e a,7\% respectivamente, Ribeirão Preto, 2003.

\begin{tabular}{|c|c|c|c|}
\hline Produto do teste & Produtos \% & Média dos halos & $\begin{array}{c}\text { Nível de } \\
\text { Significância (p) }\end{array}$ \\
\hline \multirow{7}{*}{ VB a $30 \%$} & VB $25 \%$ & 10,2 & 0,091 \\
\hline & VB $10 \%$ & 5,2 & 0 * \\
\hline & VT30\% & 10,7 & 0,72 \\
\hline & VT25\% & 9,9 & $0,01^{*}$ \\
\hline & VT10\% & 5,0 & $0 *$ \\
\hline & AA1\% & 10,6 & 0,05 \\
\hline & $\mathrm{AA} 0,7 \%$ & 7,7 & $0 *$ \\
\hline \multirow{7}{*}{ VB a $25 \%$} & VB 30\% & 11,4 & 0,09 \\
\hline & VB $10 \%$ & 5,2 & $0 *$ \\
\hline & VT30\% & 10,7 & 0,92 \\
\hline & VT25\% & 9,9 & 0,99 \\
\hline & VT10\% & 5,0 & $0 *$ \\
\hline & AA1\% & 10,6 & 0,98 \\
\hline & $\mathrm{AA} 0,7 \%$ & 7,7 & $0 *$ \\
\hline \multirow{7}{*}{ VB a $10 \%$} & VB30\% & 11,4 & 0* \\
\hline & VB $25 \%$ & 10,2 & 0 * \\
\hline & VT30\% & 10,7 & 0 * \\
\hline & VT25\% & 9,9 & 0 * \\
\hline & VT10\% & 5,0 & 1,0 \\
\hline & AA1\% & 10,6 & $0^{*}$ \\
\hline & $\mathrm{AA} 0,7 \%$ & 7,7 & $0 *$ \\
\hline \multirow{7}{*}{ VT a $30 \%$} & VB30\% & 11,4 & 0,72 \\
\hline & VB $25 \%$ & 10,2 & 0,92 \\
\hline & VB $10 \%$ & 5,2 & $0 *$ \\
\hline & VT25\% & 9,9 & 0,54 \\
\hline & VT10\% & 5,0 & $0^{*}$ \\
\hline & AA1\% & 10,6 & 1,0 \\
\hline & $\mathrm{AA} 0,7 \%$ & 7,7 & $0 *$ \\
\hline \multirow{7}{*}{ VT a $25 \%$} & VB30\% & 11,4 & $0,01^{*}$ \\
\hline & VB $25 \%$ & 10,2 & 0,99 \\
\hline & VB $10 \%$ & 5,2 & $0 *$ \\
\hline & VT30\% & 10,7 & 0,54 \\
\hline & VT10\% & 5,0 & $0 *$ \\
\hline & AA1\% & 10,6 & 0,76 \\
\hline & $\mathrm{AA} 0,7 \%$ & 7,7 & $0 *$ \\
\hline \multirow{7}{*}{ VT a $10 \%$} & VB30\% & 11,4 & 0* \\
\hline & VB $25 \%$ & 10,2 & 0 * \\
\hline & VB $10 \%$ & 5,2 & 1,0 \\
\hline & VT30\% & 10,7 & $0^{*}$ \\
\hline & VT25\% & 9,9 & 0 * \\
\hline & AA1\% & 10,6 & 0 * \\
\hline & $\mathrm{AA} 0,7 \%$ & 7,7 & $0 *$ \\
\hline \multirow{7}{*}{ AA a $1 \%$} & VB30\% & 11,4 & 0,50 \\
\hline & VB $25 \%$ & 10,2 & 0,96 \\
\hline & VB $10 \%$ & 5,2 & $0 *$ \\
\hline & VT30\% & 10,7 & 1 \\
\hline & VT25\% & 9,9 & 0.76 \\
\hline & VT10\% & 5,0 & 0* \\
\hline & $\mathrm{AA} 0,7 \%$ & 7,7 & 0 * \\
\hline \multirow{7}{*}{$\mathrm{AA}$ a $0,7 \%$} & VB30\% & 11,4 & 0 * \\
\hline & VB $25 \%$ & 10,2 & 0 * \\
\hline & VB $10 \%$ & 5,2 & $0 *$ \\
\hline & VT30\% & 10,7 & 0 * \\
\hline & VT25\% & 9,9 & $0 *$ \\
\hline & VT10\% & 5,0 & 0 * \\
\hline & AA1\% & 10,6 & 0 * \\
\hline
\end{tabular}

* diferença estatisticamente significante 
Tabela 19- Distribuição dos resultados da Concentração Inibitória Mínima de vinagre branco, tinto (Castelo) e ácido acético PA (Merck) sobre 20 cepas hospitalar/campo de Pseudomonas aeruginosa, Ribeirão Preto, 2003.

\begin{tabular}{ccccccc}
\hline $\begin{array}{c}\text { Concentração } \\
\text { Porcento }\end{array}$ & \multicolumn{2}{c}{$\begin{array}{c}\text { Vinagre branco } \\
\text { No }\end{array}$} & $\%$ & \multicolumn{2}{c}{ Vinagre tinto } & \multicolumn{2}{c}{ Ácido acético } \\
\hline 0,25 & 0 & 0 & 0 & 0 & $N^{0}$ & $\%$ \\
0,50 & 0 & 0 & 0 & 0 & & 100,0 \\
0,75 & 0 & 0 & 0 & 0 & & \\
1,00 & 0 & 0 & 0 & 0 & & \\
1,50 & 18 & 90,0 & 20,0 & 100,0 & & \\
2,00 & 20 & 100,0 & & & & \\
3,00 & & & & & & \\
4,00 & & & & & &
\end{tabular}




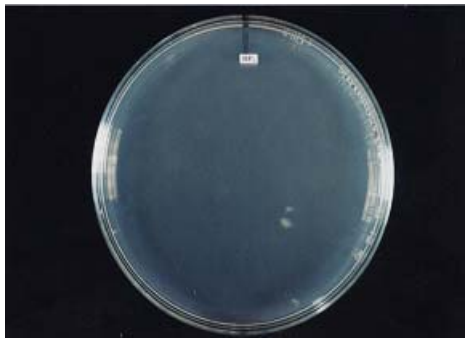

A

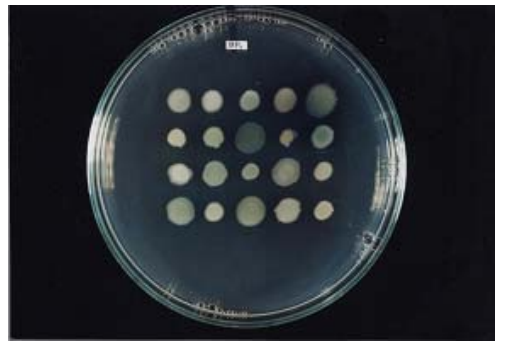

B

Figura 17: Vista Panorâmica da CIM do vinagre branco sobre 20 cepas de Pseudomonas aeruginosa: A-2,0 e B - 1,0\%)

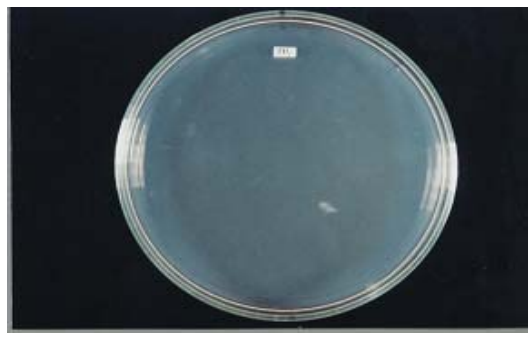

A

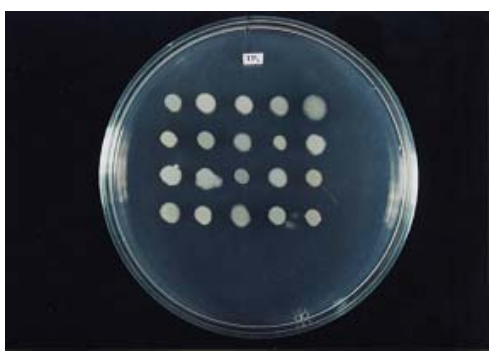

B

Figura 18: Vista Panorâmica da CIM do vinagre tinto sobre 20 cepas de Pseudomonas aeruginosa: A - 1,5 e B -1,0\%.

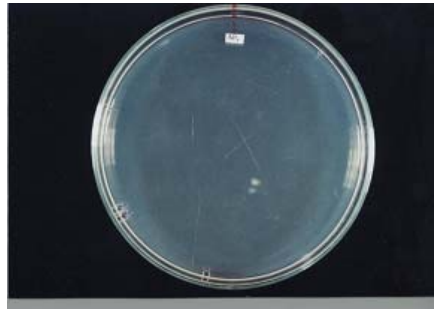

A

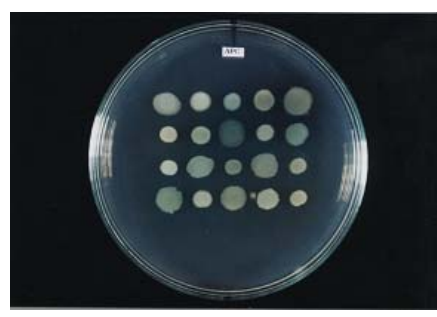

B

Figura 19: Vista Panorâmica da CIM do ácido acético sobre 20 cepas de Pseudomonas aeruginosa : A - 0,25\% e B -controle. 
Tabela 20- Distribuição dos resultados da Concentração Inibitória Mínima de vinagre branco, tinto (Castelo) e ácido acético PA (Merck) sobre 20 cepas hospitalar/campo de Escherichia coli, Ribeirão Preto, 2003

\begin{tabular}{|c|c|c|c|c|c|c|}
\hline \multirow{2}{*}{$\begin{array}{l}\text { Concentração } \\
\text { Porcento }\end{array}$} & \multicolumn{2}{|c|}{ Vinagre branco } & \multicolumn{2}{|c|}{ Vinagre tinto } & \multicolumn{2}{|c|}{ ácido acético } \\
\hline & $\mathrm{N}^{\mathrm{O}}$ & $\%$ & $\mathrm{~N}^{\mathrm{O}}$ & $\%$ & $\mathrm{~N}^{\mathrm{O}}$ & $\%$ \\
\hline 0,25 & 0 & 0 & 0 & 0 & 20 & 100 \\
\hline 0,50 & 0 & 0 & 0 & 0 & & \\
\hline 0,75 & 0 & 0 & 0 & 0 & & \\
\hline 1,00 & 0 & 0 & 0 & 0 & & \\
\hline 1,50 & 16 & 80 & 20 & 100 & & \\
\hline 2,00 & 20 & 100 & & & & \\
\hline 3,00 & & & & & & \\
\hline 4,00 & & & & & & \\
\hline
\end{tabular}




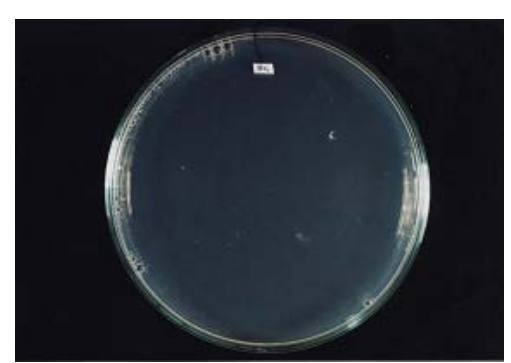

A

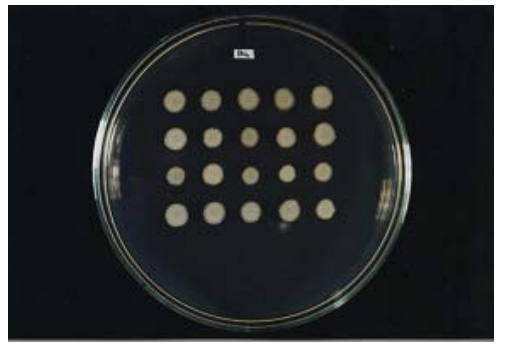

B

Figura 20: Vista Panorâmica da CIM do vinagre branco sobre 20 cepas de $E$. coli : A 2,0 e $B-1,0 \%$.

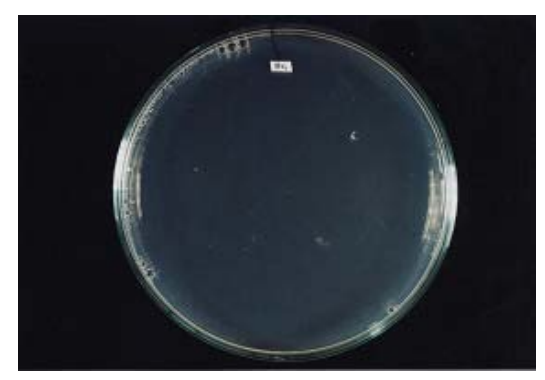

A

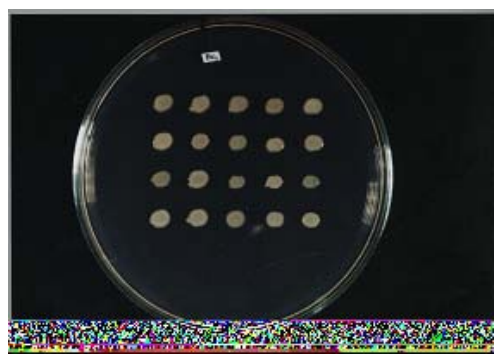

B

Figura 21: Vista Panorâmica da CIM do vinagre tinto sobre 20 cepas de E. coli: A - 1,5 e B - $1,0 \%$.

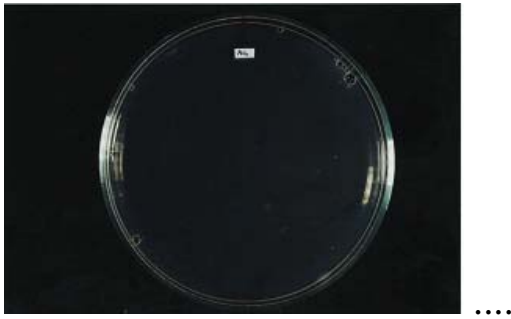

A

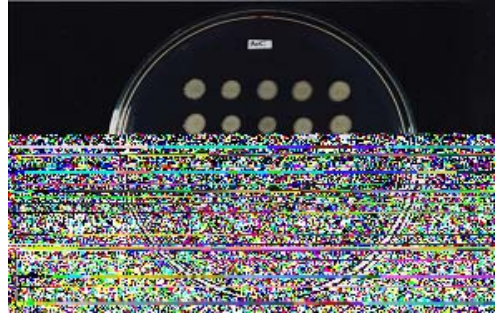

B

Figura 22: Vista Panorâmica da CIM do ácido acético sobre 20 cepas de E. coli : A $0,25 \%$ e B-controle. 
Tabela 21 - Distribuição dos resultados da Concentração Inibitória Mínima de vinagre branco, tinto (Castelo) e ácido acético PA (Merck) sobre 12 cepas hospitalar/campo e 8 cepas comunidade, de Staphylococcus aureus (total 20 cepas), Ribeirão Preto, 2003.

\begin{tabular}{ccccccc}
\hline Concentração & \multicolumn{2}{c}{ Vinagre branco } & \multicolumn{2}{c}{ Vinagre tinto } & \multicolumn{2}{c}{ Ácido acético } \\
Porcento & $N^{0}$ & $\%$ & $N^{0}$ & $\%$ & $N^{\circ}$ & $\%$ \\
\hline 0,25 & 0 & 0 & 0 & 0 & 20 & 100 \\
0,50 & 0 & 0 & 0 & 0 & & \\
0,75 & 0 & 0 & 0 & 0 & & \\
1,00 & 0 & 0 & 0 & 0 & & \\
1,50 & 0 & 0 & 0 & 0 & & \\
2,00 & 0 & 0 & 0 & 0 & & \\
3,00 & 20 & 100 & 20 & 100 & & \\
4,00 & & & & & & \\
\hline
\end{tabular}




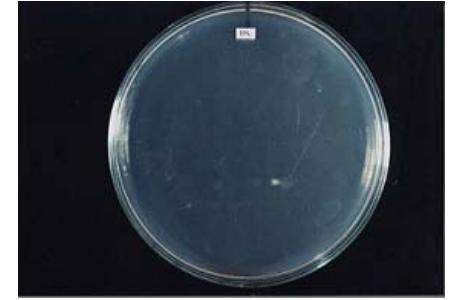

A

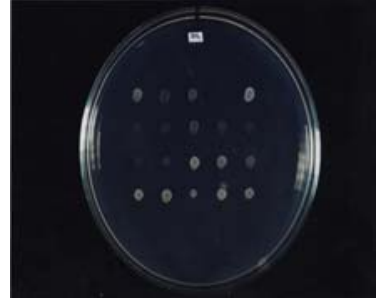

B

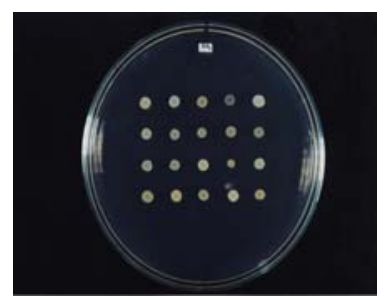

C

Figura 23: Vista Panorâmica da CIM do vinagre branco sobre 20 cepas de S. aureus A $-3,0$, B - 2,0 e C -1,5\%).

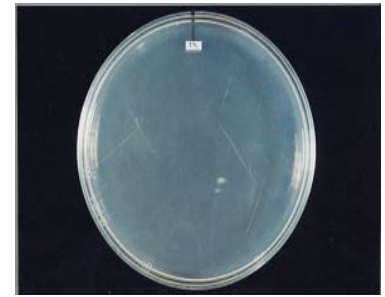

A

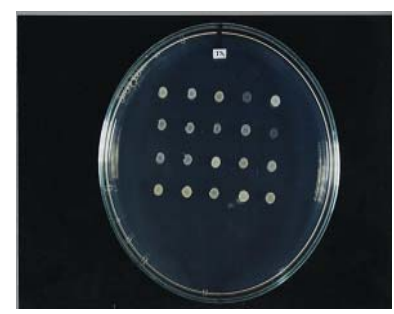

B

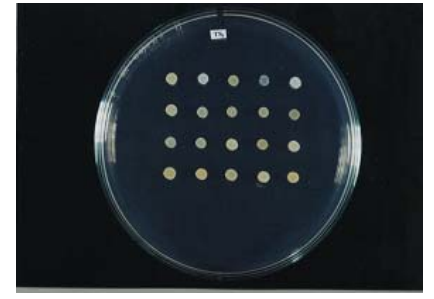

C

Figura 24: Vista Panorâmica da CIM do vinagre tinto sobre 20 cepas de S. aureus A 3,0 , B - 1,5 e C - $1,0 \%$.

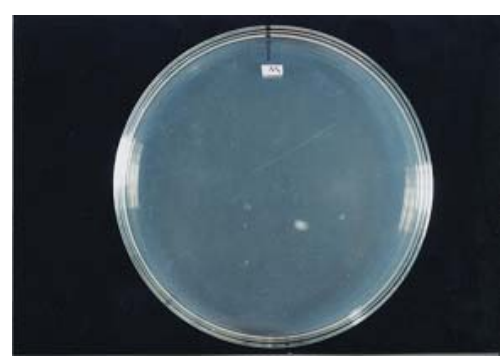

A

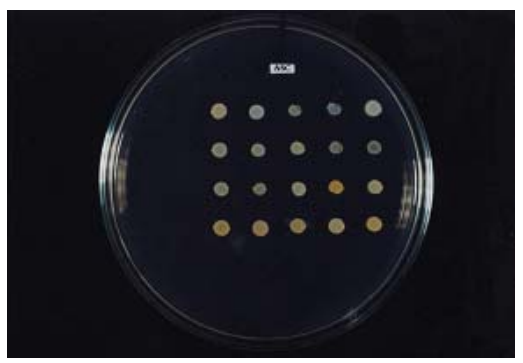

B

Figura 25: Vista Panorâmica da CIM do ácido acético sobre 20 cepas de S. aureus : A $0,25 \%$ e B - controle. 
Tabela 22- Distribuição dos resultados da Concentração Inibitória Mínima de vinagre branco, tinto (Castelo) e ácido acético PA (Merck) sobre 20 cepas de Pseudomonas aeruginosa (Pa), Escherichia coli (Ec) e Staphylococcus aureus (Sa), Ribeirão Preto, 2003.

\begin{tabular}{cccccccccc}
\hline Concentração & \multicolumn{1}{c}{ Vinagre branco } & \multicolumn{1}{c}{ Vinagre tinto } & \multicolumn{1}{c}{ Ácido acético } \\
& & & & & & & & & \\
Porcento & Pa & Sa & Pa & Ec & Sa & Pa & Ec & Sa \\
\hline 0,25 & 0 & 0 & 0 & 0 & 0 & 0 & 100 & 100 & 100 \\
0,50 & 0 & 0 & 0 & 0 & 0 & 0 & & & \\
0,75 & 0 & 0 & 0 & 0 & 0 & 0 & & & \\
1,00 & 0 & 0 & 0 & 0 & 0 & 0 & & & \\
1,50 & 0 & 0 & 0 & 100 & 100 & 0 & & & \\
2,00 & 100 & 100 & 0 & & & 0 & & & \\
3,00 & & & 100 & & & 100 & & & \\
4,00 & & & & & & & & & \\
\hline
\end{tabular}

Tabela 23 - Distribuição dos resultados da atividade citotóxica do vinagre branco, tinto (Castelo) e do ácido acético (PA) sobre Artemia salina Leach, Ribeirão Preto, 2003.

\begin{tabular}{|c|c|c|c|}
\hline Concentração & $\begin{array}{c}\text { Vinagre branco } \\
\%\end{array}$ & $\begin{array}{c}\text { Vinagre tinto } \\
\%\end{array}$ & $\begin{array}{c}\text { Ácido acético } \\
\%\end{array}$ \\
\hline Puro & $100^{*}$ & 100 & 100 \\
\hline 20.000ppm & 100 & 100 & 100 \\
\hline 10.000ppm & 100 & 100 & 100 \\
\hline 5.000ppm & 100 & 100 & 100 \\
\hline 2.500ppm & $0 * \star$ & 0 & 100 \\
\hline 1.250ppm & 0 & 0 & 100 \\
\hline
\end{tabular}




\section{4- DISCUSSÃo}

A discussão dos dados está apresentada seguindo na seqüência das tabelas, gráficos e figuras conforme demonstrado no resultado.

Para facilitar a leitura e compreensão do leitor compilou-se nas tabelas 15 e 16 e na figura 16 os resultados das tabelas 3 a 14 e figuras 4 a 15 de maneira a síntetizar os dados apresentados. Neste sentido, vale considerar que os resultados apresentados nas tabelas 3 a 16 e figura 10, 15 e 16, foram submetidos à análise estatística pelo teste de variância ANOVA - ONEWAY seguida do teste de comparações múltiplas denominadas Tukey; com nível de significância $\alpha=5 \%$, (Tukey Lloyd \& Fisher, 1993).

$\mathrm{Na}$ análise dos resultados das tabelas 3 a 6 e das figuras 3 a 9 obtida por meio da técnica de poço foi possível verificar que, o vinagre branco e tinto a $30,0 \%$ tem atividade antimicrobiana para as 22 cepas de Pseudomonas aeruginosa. Todavia, na concentração a 25,0 e 10,0\% houve um discreto crescimento em três cepas de Pseudomonas aeruginosa (P1, 3 e 27). O ácido acético a 1,0\% apresentou crescimento tênue em apenas uma cepa (P17) das 22 cepas e na concentração a 0,7\% houve crescimento similar em 14 cepas de Pseudomonas aeruginosa. Portanto, nesta concentração o ácido acético não é efetivo para Pseudomonas aeruginosa.

Os dados mostrados indicam que a solução de vinagre a 10,0\% e ácido acético a $0,7 \%$, não tem atividade sobre Pseudomonas, enquanto que o vinagre a 25,0\% e ácido acético a 1,0\% apresentou atividade antimicrobiana significativa $(p<0,05)$ nas 22 cepas de Pseudomonas. Vale lembrar que, vinagre a 10,0\% contém $0,4 \%$ de ácido acético em sua composição.

Os resultados apresentados na Tabela 5 e ilustrados nas Figuras 7 e 8 não corroboram os achados de Araújo et al. (1995). No estudo in vitro de Araújo e colaboradores com o ácido acético na concentração de 0,25\%, os autores verificaram que o mesmo foi capaz de manter atividade antimicrobiana, isto é, impediu o crescimento de Pseudomonas aeruginosa. Esta contradição parece 
demonstrar a necessidade de realizar outros estudos com vistas a estabelecer congruência nos resultados microbiológicos, e conseqüentemente, culminar num consenso quanto à concentração inibitória dos referidos produtos.

Acresce-se aos achados mencionados o estudo de Pereira (2002) que verificou a resistência de duas cepas de Pseudomonas aeruginosa ao ácido acético a $0,7 \%$.

Com relação à atividade antimicrobiana do vinagre branco e tinto nas concentrações de 30,0 e 25,0\% e ácido acético a 1,0\%, pelo método de poço sobre cepas de E. coli foi possível evidenciar que estes produtos são efetivos, uma vez que inibiu todas as cepas. Já, o vinagre a 10,0\% e o ácido acético a $0,7 \%$ apresentou pouca atividade antimicrobiana (nula ou tênue) sobre tais cepas. Cabe explicar que a cepa $\mathrm{E} 9$ representou uma exceção uma vez que, o vinagre a $10,0 \%$ a inibiu plenamente, enquanto que, o ácido acético a 0,7\% inibiu as 16 cepas de E. coli.

Molineros et al. (1991), verificaram que o ácido acético a 2,5, 5,0 e 99,5\% apresentou atividade antimicrobiana satisfatória sobre cepas de E. coli. Tais resultados contrapõem os nossos achados, considerando que neste estudo o ácido acético inibiu cepas de E. coli em uma concentração inferior $(1,0 \%)$ quando comparada às obtidas por Molineros e colaboradores em que o ácido acético a 1,0\% não apresentou atividade antimicrobiana sobre cepas de E. coli, Pseudomonas e Proteus.

A atividade antimicrobiana dos produtos analisados sobre as cepas de Staphylococcus aureus foi peculiar quando comparada com Pseudomonas aeruginosa e E. coli. Assim, no presente estudo constatou-se que os produtos analisados foram ineficazes sobre as 22 cepas de Staphylococcus aureus demonstrando o halo de inibição $0,0 \mathrm{~mm}$ indicando crescimento bacteriano em todas as concentrações estudadas do vinagre branco e tinto (30,0; 25,0 e 10,0\%) e do ácido acético (1,0 e 0,7\%). Este resultado leva-nos a concluir que o Staphylococcus aureus é resistente à ação do vinagre e ácido acético confirmando o estudo de Rund (2001). Na investigação de Rund ficou 
evidenciado que 78,0\% dos Staphylococcus aureus sobreviveram após 24 horas de incubação ao vinagre em uma concentração de 0,25\%.

Observa-se que a média do diâmetro dos halos de inibição pelo vinagre branco nas concentrações de 30,0, 25,0 e 10,0\% tanto para as cepas de Pseudomonas aeruginosa e de E. coli, mostrou atividade antimicrobiana significativa em comparação ao vinagre tinto.

Ainda é possível extrair da tabela 15 que, a atividade antimicrobiana do vinagre branco a 25,0\% apresentou uma média do halo de inibição de 10,6 mm para Pseudomonas aeruginosa e $10,2 \mathrm{~mm}$ para E. coli. O vinagre tinto na mesma concentração apresentou uma média de 9,9mm para Pseudomonas aeruginosa e $9,9 \mathrm{~mm}$ para $E$. coli com diferença entre as medidas dos halos de $0,5 \mathrm{~mm}$.

Na Tabela 16 o vinagre branco e tinto a 10,0\% apresentou atividade pouco significativa (crescimento tênue) tanto para Pseudomonas aeruginosa quanto para E. coli. O ácido acético a 1,0\%, como já dito anteriormente, na mesma concentração do vinagre a 25,0\% mostrou atividade antimicrobiana para Pseudomonas aeruginosa resultando uma média dos halos de inibição de 10,1 mm e para E. coli de 10,6mm. Todavia, o ácido acético a 0,7\% resultou uma média dos halos de inibição de 6,2 mm para Pseudomonas aeruginosa e $7,7 \mathrm{~mm}$ para E. coli.

No computo geral, o estudo in vitro do ácido acético a 1,0\% e 0,7\% mostraram atividade antimicrobiana significativa sobre Pseudomonas aeruginosa e E. coli e nenhuma ação sobre S. aureus para nível de significância de $\alpha=5 \%$.

Dos testes estatísticos utilizados neste estudo foi possível evidenciar a ação inibitória dos produtos estudados sobre as cepas por meio da medida dos halos pelo Método de Poço.

Assim, constatou-se que nas 22 cepas de Pseudomonas aeruginosa 0 vinagre branco a 30,0\% apresentou maior atividade com média do halo de inibição $(11,5 \mathrm{~mm})$, seguido de vinagre tinto a $30 \%(11,2 \mathrm{~mm})$, vinagre branco a $25,0 \%(10,6 \mathrm{~mm})$, ácido acético a $1,0 \%(10,2 \mathrm{~mm})$, vinagre tinto a $25,0 \%$ 
(9,9mm), ácido acético a 0,7\% (6,5mm), vinagre branco e tinto a 10,0\% $(5,0 \mathrm{~mm})$. Não foi encontrada diferença estatisticamente significante $(p>0,05)$ entre os resultados da ação antimicrobiana (médias das medidas dos halos) para as cepas do vinagre branco e tinto na concentração a 30,0 e 25,0\% e para o ácido acético a 1,0\%. Porém, as soluções de vinagre e ácido acético mencionado obtiveram valores mais elevados de significância $(p<0,05)$ que o ácido acético a 0,7\%, vinagre branco e tinto a 10,0\%. Em síntese, o ácido acético a 0,7\% é mais eficaz que o vinagre, branco e tinto a 10,0\%, e por sua vez entre estes não há diferença significativa $(p<0,05)$.

Quanto à análise estatística dos produtos analisados sobre 21 cepas de Escherichia coli, o vinagre branco a 30,0\% apresentou maior atividade com média do halo de inibição de $11,4 \mathrm{~mm}$, seguido de vinagre tinto a $30,0 \%$ (10,7mm), ácido acético a 1,0\%(10,6 mm), vinagre branco a 25,0\% (10,2mm), vinagre tinto a 25,0\% (9,9mm), ácido acético a 0,7\% $(7,7 \mathrm{~mm})$, vinagre branco $(5,2 \mathrm{~mm})$, tinto a $10,0 \%(5,0 \mathrm{~mm})$, respectivamente. O vinagre branco e tinto a 30,0 e 25,0\% e o ácido acético a 1,0\%, não mostraram diferença estatisticamente significante, porém, são mais eficazes que o vinagre branco e tinto a $10,0 \%$ e ácido acético a $0,7 \%(p<0,05)$. O ácido acético a $0,7 \%$ é mais eficaz que o vinagre branco e tinto a $10,0 \%$, por sua vez estes não tem diferenças significativas para E. coli.

Os estudos de Clifton (1950) e Goodman \& Gilman (1980) mostraram que a ação bactericida da maioria dos anti-sépticos ácidos depende da concentração de hidrogênios que produzem.

Molineros et al. (1991) explicam que o pH mínimo de crescimento para a maior parte das bactérias oscila entre 4 a 4,4 e o ótimo está entre 6,5 a 7,5. Ainda, complementam os autores que o pH em diversas concentrações do ácido acético de 99,5; 25,0; 5,0 e 3,5\% (vinagre comercial) foram sempre inferior ou igual a 2,67, considerando que o $\mathrm{pH}$ do vinagre comercial foi maior que a solução aquosa de ácido acético. Alguns estudiosos atribuem ao conservante adicionado pelos fabricantes (pirossulfito de potássio), a formação 
de sais com o ácido, diminuindo desta forma a quantidade de íons livres de hidrogênio.

Nesse contexto, Akiyama et al. (1999) também realizaram um estudo in vitro com cepas de Staphylococcus aureus, utilizando duas substâncias, ácido acético e ácido clorídrico, sob mesmas condições de $\mathrm{pH}$, verificaram que o ácido acético foi mais efetivo, supondo que essa ação, até certo ponto deva ser do próprio produto e não ao baixo $\mathrm{pH}$.

Nos achados do presente estudo, com relação à ação antimicrobiana do vinagre branco e tinto a 25,0\% e o ácido acético a 1,0\% questiona-se:

Qual é o mecanismo de ação antimicrobiana do vinagre e ácido acético sobre as cepas analisadas?

Dentre as possíveis respostas é possível hipotetizar:

Se na composição química do vinagre e do ácido acético contém álcool, e o mesmo é reconhecido como importante agente antimicrobiano, então se conclui: quanto maior a concentração de álcool dos respectivos produtos maior será a atividade antimicrobiana.

Especificamente, em relação à composição química dos produtos analisados conforme a descrição do fabricante tem-se 90,0\% de álcool e 10,0\% de vinho no vinagre branco. Ao contrário, o vinagre tinto apresenta 90,0\% de vinho e 10,0\% de álcool, e, portanto, com ação antimicrobiana inferior. Esse dado pode justificar a atividade antimicrobiana vinagre branco em relação ao tinto. Assim, a presença de álcool nas soluções de vinagre pode estar interferindo na ação antimicrobiana.

Araújo et al. (1995) constataram que todas as cepas de Pseudomonas spp., incluindo a cepa padrão (ATCC 27853), foram inibidas in vitro pelo ácido acético nas seguintes concentrações: 2,0; 1,0; 0,5 e 0,25\%. Os dados encontrados pelos autores são contraditórios aos nossos resultados quanto à efetividade do ácido acético a 0,5 e 0,25\%. No nosso estudo, o emprego do ácido acético a $0,7 \%$, verificou-se crescimento de 13 cepas das 22 cepas estudadas de Pseudomonas. 
Pereira (2002) verificou que o ácido acético a 0,7\% foi eficaz para as sete cepas de Pseudomonas aeruginosa estudadas, porém, na concentração de ácido acético a 0,4; 0,5 e 0,6\% foram ineficazes para as sete cepas, cinco cepas e quatro cepas, respectivamente.

A concentração igual ou inferior a $0,7 \%$, especificamente a $0,5 \%$, no estudo de Benassati et al. (1994) constatou que pode atuar como agente desinfetante frente às cepas de E. coli, Staphylococcus aureus e Pseudomonas aeruginosa presente nos materiais semicríticos.

Considerando os nossos resultados da atividade antimicrobiana do ácido acético a 1,0\% sobre Pseudomonas e relacionando-os com os obtidos nos estudos de Corbett (1977) e Schaberg \& Truck (1982), é possível verificar que os respectivos resultados são semelhantes.

Outro aspecto que merece consideração se reporta ao vinagre branco a 10,0\% que foi ineficaz para Pseudomonas aeruginosa, E. coli e Staphylococcus aureus. Tais resultados corroboram os achados de Pereira (2002), que das sete cepas de Pseudomonas aeruginosa coletados de feridas de pacientes por meio de swab, somente uma cepa foi sensível ao vinagre branco a 10,0\%. Ao passo que, todas as cepas foram sensíveis ao vinagre branco a 15,0\% (presença de 0,6\% de ácido acético).

Pode-se especular que a ineficácia do vinagre e ácido acético nas concentrações testadas no estudo de nossa autoria seja relacionada à constituição química da parede celular.

Mims et al. (1999) e Fernandes et al. (2000) citam que o principal componente da estrutura da parede celular é um peptidoglicano (mureína) um polímero misto de açúcares hexose ( $\mathrm{N}$-acetilglicosamina e ácido $\mathrm{N}$ acetilmuramínico) e aminoácidos. Nas bactérias Gram-positivas, no caso Staphylococcus sp (cocos Gram-positivo), o peptidoglicano forma uma camada espessa (20-80nm) tornando a parede mais rígida, que suportam maior pressão que as bactérias Gram-negativas. O álcool não solubiliza proteína e açúcar. Nas bactérias Gram-negativas, Pseudomonas aeruginosa e E. coli (bacilo Gram-negativo aeróbio o primeiro e facultativo o segundo), a camada de 
peptidoglicano é delgada (5 a 10nm), mas apresenta uma porção externa de lipopolissacarídeo e lipoproteínas, proteína, fosfolipídeo e ainda dotada de porina, canal para transporte de nutriente e subprodutos (figura 23).

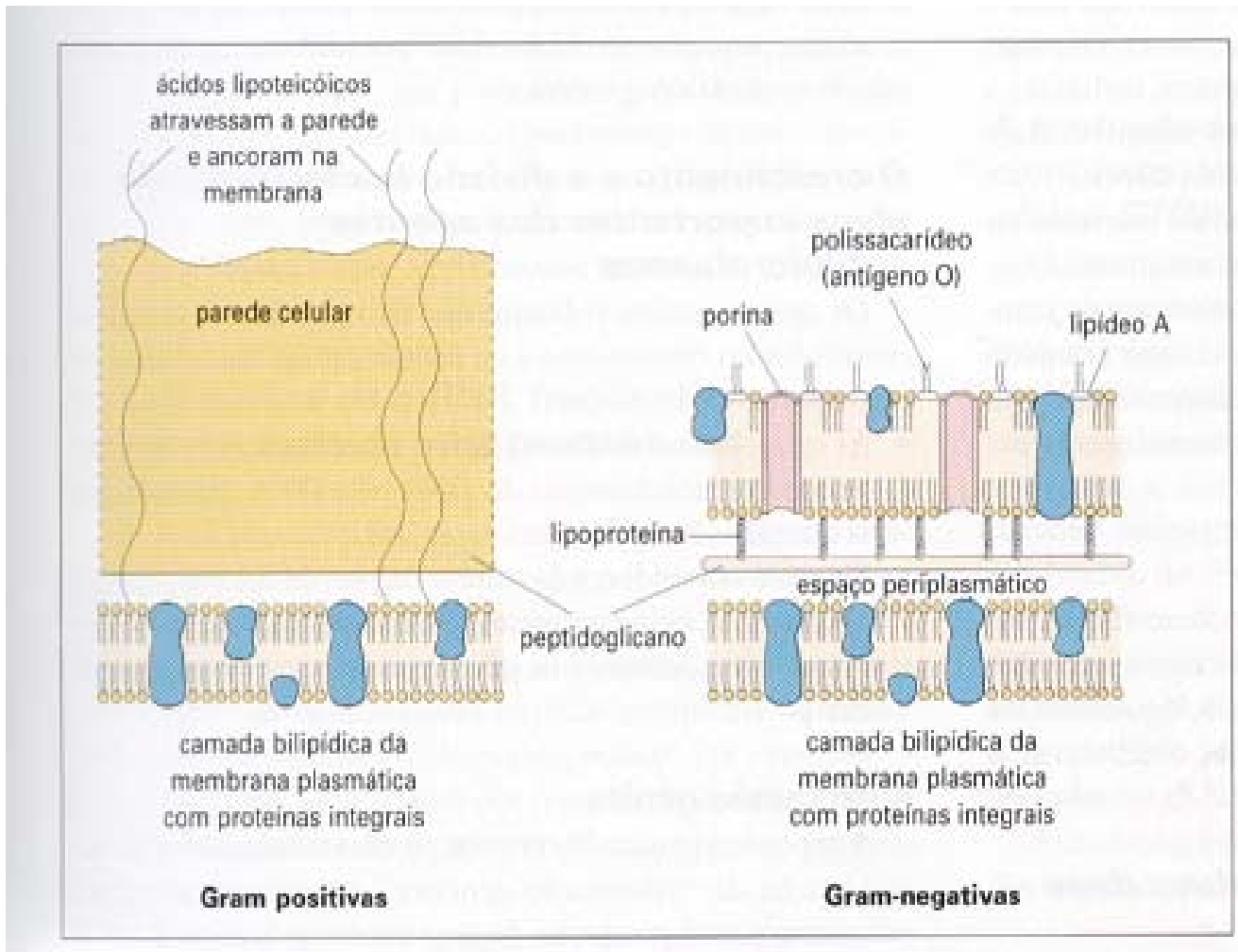

Fonte- Mims et al. Microbiologia médica. 2ed. Editora Manole Ltda. 1999. p.27

Figura 23- Constituição das paredes celulares de bactérias Gram-negativas e Gram-positivas

Conforme ilustração da parede celular da cepa Gram-negativa é possível reconhecer que sua camada fina é complexa e não suporta tanta pressão quanto as Gram-positiva, mas é dissolvida na presença de álcool. E, como o 
vinagre e ácido contém álcool, pode ser esta a fundamentação da atuação do álcool nos componentes da parede celular. Pouco se sabe sobre o mecanismo de ação antimicrobiana do ácido e do vinagre. No entanto, suspeitam que a quantidade de proteína e ou lipídio existente na parede celular possa interferir na referida atividade antimicrobiana.

Essa premissa é sugestiva de que o ácido acético e vinagre conforme -resultados obtidos no presente estudo podem apresentar atividade sobre a complexa parede celular de gram-negativo. São apenas especulações, porém, é premente a necessidade de mais pesquisas que desvelem também quanto ao mecanismo de ação.

Em seqüência passamos a discussão da Concentração Inibitória Mínima (CIM) demonstrado nas tabelas 19 a 22 e figuras 17 a 25.

Vale ressaltar que, o presente estudo avaliou 8 cepas de Staphylococcus aureus da comunidade isoladas de portadores universitários saudáveis, visto que pelo método de poço as 22 cepas se desenvolveram na presença de ácido acético como do vinagre Como estamos preocupados em avaliar a atividade antimicrobiana achamos oportunos estudar também as cepas da comunidade considerando a possibilidade destas cepas em manifestar resistência aos antimicrobianos em menor escala. Assim, hipotetizamos que o baixo grau de resistência das cepas da comunidade facilita sua inibição.

Os dados da Tabela 19 e Figura 17 demonstram que o vinagre tinto inibiu todas as cepas de Pseudomonas aeruginosa na concentração a 1,5\%, 0 vinagre branco a 2,0\%. Na concentração a 1,0\% não inibiu nenhuma destas cepas. O vinagre branco a 1,5\% só não inibiu duas cepas de Pseudomonas aeruginosa (Pa7 e 24) e a 1,0\% ou menos não inibiu nenhuma cepa.

Por outro lado, ainda na Tabela 19 e figura 19 o ácido acético na concentração de $0,25 \%$, foi o que apresentou concentração inibitória mínima das cepas de Pseudomonas estudadas.

Quanto à concentração inibitória de E. coli, conforme demonstrado na Tabela 20 e Figuras 20, 21 e 22 é possível evidenciar que o vinagre branco a 1,5\% não inibiu o crescimento de 4 cepas (Ec 7, 12, 13 e 17), sendo a 
concentração a 2,0\% ideal para ambos os vinagres A Concentração Inibitória Mínima (CIM) do ácido acético foi a 0,25\% quando inibiu todas as cepas de $E$. coli.

Na Tabela 21 e Figuras 23 a 25 é possível extrair que Concentração Inibitória Mínima sobre cepas de Staphylococcus aureus é possível que o vinagre branco e tinto a 3,0\% e ácido acético a 0,25\% inibiu todas as cepas (20).

Neste estudo, a Concentração Inibitória Mínima (CIM) do ácido acético para as cepas de Pseudomonas aeruginosa (20), Escherichia coli (20) e Staphylococcus aureus (20) foi a 0,25\%, e do vinagre branco 2,0\%, para Pseudomonas aeruginosa e E. coli sendo que para Staphylococcus aureus a $3,0 \%$. O vinagre tinto sobre as cepas de Pseudomonas aeruginosa e E. coli inibiram todas as cepas a 1,5\% e sobre as de Staphylococcus aureus a 3,0\%.

Frente aos resultados obtidos tanto Pseudomonas aeruginosa e E. coli quanto Staphylococcus aureus mostraram sensíveis ao ácido acético a 0,25\%. Esse achado vem de encontro a vários estudos que evidenciaram a eficácia deste produto, principalmente, onde há suspeita de Pseudomonas (Araújo et al.,1995; Krasner \& Kane; 1997; e Krasner; Rodeheaver \& Sibbad, 2001).

Com relação à Concentração Inibitória Mínima (CIM) dos produtos químicos testados, não foi verificada diferença entre cepas de Staphylococcus aureus hospitalar e comunidade o que permite inferir que a hipótese inicial foi rejeitada, ou seja, as cepas, embora, distintas foram inibidas pelos produtos testados, e conseqüentemente, apresentaram resultados semelhantes.

Os resultados apresentados na Tabela 23 norteiam a discussão com relação à atividade citotóxica do vinagre e ácido acético sobre Artemia salina Leach. Assim, é possível constatar que o ácido acético em todas as concentrações estudadas foi citotóxico para Artemia salina Leach. Por outro lado, o vinagre branco e tinto em 2.500ppm (diluição de $25 \mu \mathrm{L}$ adicionados em $10 \mathrm{~mL}$ de água correspondendo à concentração de 0,25\%) e 1.250 ppm (12,5 $\mu \mathrm{L}$ adicionados em 10mL de água correspondendo à concentração de 0,125\%) apresentaram toxicidade zero. 
Lineaweaver et al. (1985) estudaram o efeito citotóxico in vitro de quatro antimicrobianos sobre os fibroblastos humanos, entre eles, o ácido acético a $0,25 \%$, observaram que nessa concentração foi possível diminuir a toxicidade ao fibroblasto.

McKenna et al. (1991), citam que o ácido acético a 0,0025\% preserva a função do fibroblasto e inibe Pseudomonas aeruginosa. Por outro lado, duas pesquisas, um in vitro de célula humana e outro in vivo de célula animal (rato), mostraram o efeito atóxico do vinagre e ácido acético.

Nesse sentido, Molineros et al. (1991) verificaram no estudo in vivo desenvolvido em epiderme do abdômen do rato que o ácido acético em concentrações menor ou igual a 3,5\%, danificam somente 4,0 a 5,0\% das células e produz pequena redução da matriz citoplasmática com possibilidade de recuperação celular e tecidual.

Estes resultados corroboram os estudos de cultura de tecidos humanos in vitro de Cooper et al. apud Rund (1997) que constatando que o ácido acético na concentração de $0,25 \%$ é menos tóxico em fibroblastos e queratinócitos humanos, porém, na concentração de 0,0025\% tornou-se não tóxico, entretanto, inútil como anti-séptico.

Ainda, Silva et al. (2002) em estudo in vitro em culturas de células Hep-2 (célula de carcinoma de laringe humana) e Vero (célula de rim de macaco verde africano), verificaram que, tanto o ácido acético na concentração de 0,5 a 5,0\% quanto do vinagre de 5,0\% a 30,0\% não causou efeito citotóxico, após 24 horas de incubação a $37^{\circ} \mathrm{C}$.

Diante dessas pesquisas sobre a citotoxicidade do vinagre e ácido acético é passível de verificação que os resultados são contraditórios, e exigem elucidação por meio de novos estudos.

Embora, as substâncias analisadas tenham relativa toxicidade, por outro lado são biodegradáveis, tem baixo custo e alta disponibilidade o que justifica emanar esforços para elucidar os questionamentos, com vistas subsidiar estudo pré-clínico em modelo animal e viabilizar futuramente a sua aplicabilidade in vivo, como anti-séptico em feridas infectadas. 


\section{5- CONCLUSÃO}

Este estudo que teve como finalidade avaliar a atividade antimicrobiana e a citotoxicidade in vitro do ácido acético e do vinagre por meio de técnicas microbiológicas específicas contribuiu para que elaborássemos as seguintes conclusões:

- No método do poço constatou-se que o vinagre branco e tinto a 30,0\% apresentou atividade significante sobre 22 cepas de Pseudomonas aeruginosa e 21 cepas de Escherichia coli.

-O vinagre branco e tinto 30,0 e $25,0 \%$ e ácido acético a 1,0\%, estatisticamente não mostraram diferença significativa quanto à ação antimicrobiana sobre as cepas de Pseudomonas aeruginosa, porém, as soluções de vinagre e ácido acético mencionado são mais eficazes que o ácido acético a $0,7 \%$, vinagre branco e tinto a 10,0\% ( $p<0.05)$. Em contrapartida, o ácido acético a 0,7\% é mais eficaz que o vinagre, branco e tinto a 10,0\%, e por sua vez entre estes não há diferenças significativas.

- Quanto à atividade antimicrobiana do vinagre branco a 30,0 e 25,0\% e o ácido acético a 1,0\%, sobre 21 cepas de Escherichia coli obtivemos que não há diferença estatisticamente significante, porém, são mais eficazes que o vinagre branco e tinto a 10,0\% e ácido acético a 0,7\% ( $p<0,05)$.

- O ácido acético a 0,7\% é mais eficaz que o vinagre branco e tinto a 10,0\%, por sua vez estes não tem diferenças significativas dessa atividade sobre $E$. coli.

- No computo geral, o estudo in vitro do ácido acético a 1,0 e 0,7\% pelo método do poço mostrou atividade antimicrobiana significativa sobre Pseudomonas aeruginosa e Escherichia coli e nenhuma ação sobre Staphylococcus aureus.

- Com relação à Concentração Inibitória Máxima (CIM) do ácido acético para as (20) cepas de Pseudomonas aeruginosa, (20) Escherichia coli e (20) Staphylococcus aureus foi a $0,25 \%$ e do vinagre branco a 2,0\% para 
Pseudomonas aeruginosa e E. coli sendo que para Staphylococcus aureus a 3,0\%. As cepas de Pseudomonas aeruginosa e E. coli foram todas inibidas pelo vinagre tinto a 1,5\%, e sobre as de Staphylococcus aureus a 3,0\%. Evidenciou-se, também, que Pseudomonas aeruginosa, E. coli e Staphylococcus aureus mostraram sensíveis ao ácido acético a 0,25\%.

- Ainda, com relação à Concentração Inibitória Mínima (CIM) dos produtos químicos testados, não se verificou diferença entre cepas de Staphylococcus aureus hospitalar e comunidade o que permite inferir que a hipótese inicial foi rejeitada. As cepas, embora, distintas foram inibidas pelos produtos testados, ou seja, apresentaram resultados semelhantes.

- Quanto à atividade citotóxica do vinagre e ácido acético sobre Artemia salina Leach constatou-se que: o ácido acético em todas as concentrações estudadas foi citotóxico. Por outro lado, o vinagre branco e tinto em 2.500ppm (diluição de $25 \mu \mathrm{L}$ adicionados em 10mL de água) e 1.250 ppm (12,5 $\mu \mathrm{L}$ adicionados em $10 \mathrm{~mL}$ de água) não apresentaram toxicidade.

Embora, as substâncias analisadas tenham toxicidades variadas, por outro lado, acreditamos ser promissor viabilizar composições químicas que não sejam tóxicas e mantenham ação antimicrobiana de amplo espectro in vivo. Essa busca encontra respaldo nas vantagens atribuídas, especificamente, ao vinagre: produto biodegradável, baixo custo e alta disponibilidade no mercado.

Pode-se especular que a ineficácia do vinagre e ácido acético nas concentrações testadas seja relacionada à constituição química da parede celular das cepas estudadas.

Há grande probabilidade da atividade antimicrobiana do vinagre branco e tinto a $25,0 \%$ e o ácido acético a $1,0 \%$ sobre Pseudomonas aeruginosa e $E$. coli, ser atribuída aos componentes existentes nestes produtos, por exemplo, o álcool.

A parede celular da cepa Gram-negativa possui uma camada fina é complexa que não suporta tanta pressão quanto as Gram-positiva, mas é dissolvida na presença de álcool. E, como o vinagre e ácido contém álcool, pode ser esta a fundamentação da atuação do álcool nos componentes da 
parede celular. Pouco se sabe sobre o mecanismo de ação antimicrobiana do ácido e do vinagre. No entanto, suspeitam que a quantidade de proteína e ou lipídio existente na parede celular possa interferir na referida atividade antimicrobiana.

Essa premissa é sugestiva de que o ácido acético e vinagre podem apresentar atividade sobre a complexa parede celular de Gram-negativo. São apenas especulações, porém, é premente a necessidade de mais pesquisas que desvelem o real mecanismo de ação.

Urge a necessidade de estabelecer congruência nos resultados microbiológicos, e conseqüentemente, culminar no consenso quanto à concentração inibitória mínima, mecanismo de ação e demais indicadores de atividade antimicrobiana. Entretanto, se faz necessário a realização de novos estudos com vistas à elucidação dos questionamentos e das lacunas do conhecimento. Vale reconhecer que o mecanismo de ação do produto químico biocida é fortemente influenciado na presença de um ou vários componentes ativos culminando ou não compatibilidades físico-químicas que reduzem ou aumentam a atividade antimicrobiana.

O presente estudo mostrou a importância da fundamentação científica para o uso de produto químicos em feridas. Haja visto que em alguns serviços de saúde ainda é possível vislumbrar o cuidado de feridas subsidiado na tradição, no conhecimento popular, a exemplo, tem-se a recomendação do uso do ácido acético até a 3,0\%. Cabe destacar o poder citotóxico desse produto já na concentração a 0,125\%, resultado esse evidenciado no presente estudo. Acrescem-se os relatos dos pacientes quanto à ardência, muitas vezes severa, que provavelmente pode ter associação com o processo de danificação das células neoformadas. Ainda, que o estudo mencionado esteja na fase in vitro, acredita-se que não seja recomendável o uso do ácido acético sem modificação da sua formulação química, mesmo reconhecendo sua ação antimicrobiana.

Ainda que, não tenha sido a preocupação nesse momento de buscar correlação entre os dados desse estudo com o uso in vivo é importante atentar que o vinagre e ácido acético tem sido amplamente utilizados como agentes 
antimicrobianos no tratamento de feridas, e muitas vezes em concentrações elevadas que podem causar danos aos tecidos dificultando, assim, o processo de cicatrização.

Estes estudos abordaram aspectos relevantes, alguns polêmicos e outros questionáveis os quais acreditamos ser oportuno explorá-los por meio de investigações respaldadas no rigor ético e metodológico. Cabe destacar que pesquisa com aplicabilidade humana deve seguir a trajetória metodológica da básica (in vitro) para pré-clínica (modelo animal), e finalmente, clínica (em humanos).

A nosso ver é premente despertar nos profissionais da saúde a consciência crítica-reflexiva em relação à utilização das evidências científicas de maneira que possam analisar e aplicar com critério os resultados das pesquisas em prol da qualidade da assistência à saúde. 
6- ANEXOS

\section{ANEXO- A \\ PARECER DO COMITÊ DE ÉTICA EM PESQUISA}

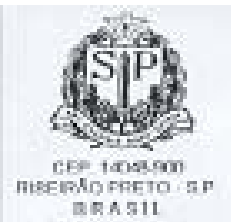

HOSPITAL DNS CLINICAS DN FACULDNDE DE MEDACIUA DE RIBEIRĀO PRETO DA UNIVERSIDADE DE SÃO PMUL.O

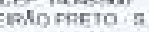

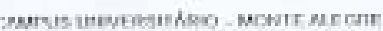

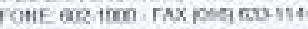

Rilwirso Freto, 22 de junhe de: 1999

Oficio n"1614/99

CEP/STC

Senhora Professora:

O Iraballie intitulacts "DEsinfeccho HOSPITALAR: AVALIAÇAO DA ATIVIDADE ANTIMICROBIANA DE PRODUTOS QUIMICOS COMERCIAIS E DO POLIOL DA MAMONA", FI

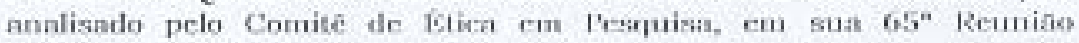
Ordinária renlizada em $21 / 06 / 96$, c encualrado na contegoria: APROVADO, bem como o Termo de Consentimento, de acordo com o Frocesso HCRP n* $7485 / 98$.

Aprovcilo a oportuniclade para npresentar a Vosen Senhoris protestost de testinu c cortsit lerncho.

Itustrissima Senluorn

Profa. Dra. DENISE DE ANDRADE DIAS ANGELO

Tsoola de Enfermagean de Ribeirzie 1'reto-USiP

Fim mãos

\section{ANEXO B}


PROTOCOLO DE MEDIDAS DO HALO DE INIBIÇÃO PELO MÉTODO DE DIFUSÃO DE POÇO

ANTIMICROBIANO:

data

PROJETO:

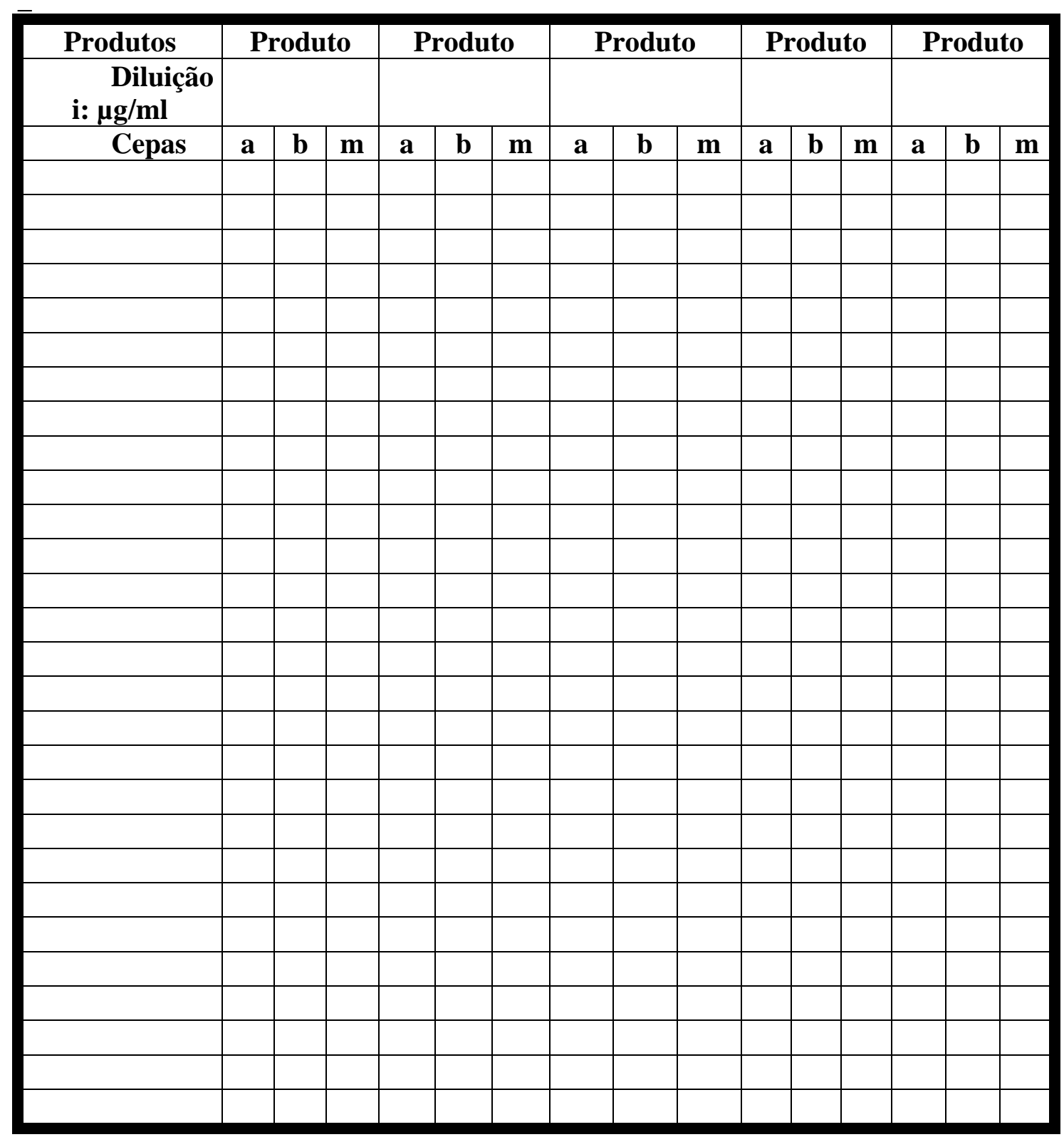

$a, b=$ série duplicada; $m=$ média do diâmetro dos halos de inibição 


\section{ANEXO C}

PROTOCOLO DE CONCENTRAÇÃO INIBITÓRIA MÍNIMA

MÉTODO:

DATA

ANTIMICROBIANO:

CEPAS:

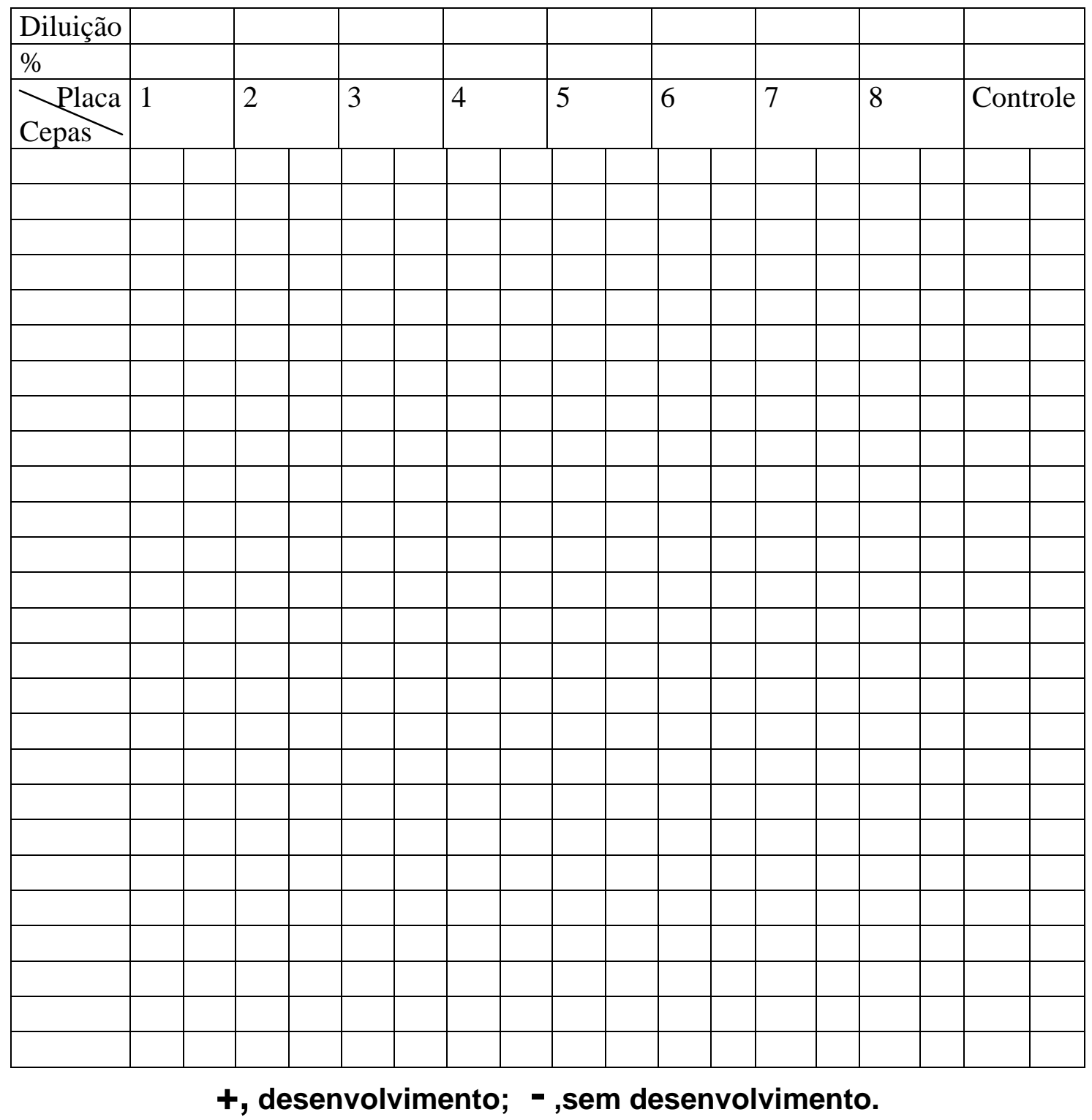




\section{ANEXO D}

\section{(Protocolo.1 a 3)}

Distribuição da atividade antimicrobiana do vinagre branco e tinto a 30\%, 25\% e 10\%, e do ácido acético (PA) a 1\% e 0,7\% sobre as cepas de Pseudomonas aeruginosa pelo Método de Difusão de Poço.

\begin{tabular}{|c|c|c|c|c|c|c|c|c|c|c|c|c|c|c|c|c|c|c|c|c|c|c|c|c|}
\hline \multirow{2}{*}{$\begin{array}{l}\text { Produtos } \\
\text { Cepas }\end{array}$} & \multicolumn{3}{|c|}{\begin{tabular}{|l|} 
Vinagre branco \\
$\mathbf{3 0 \%}$
\end{tabular}} & \multicolumn{3}{|c|}{\begin{tabular}{|l|} 
Vinagre branco \\
$25 \%$
\end{tabular}} & \multicolumn{3}{|c|}{\begin{tabular}{|l|} 
Vinagre \\
branco $10 \%$ \\
\end{tabular}} & \multicolumn{3}{|c|}{$\begin{array}{l}\text { Vinagre tinto } \\
30 \%\end{array}$} & \multicolumn{3}{|c|}{\begin{tabular}{|l|} 
Vinagre tinto \\
$25 \%$
\end{tabular}} & \multicolumn{3}{|c|}{\begin{tabular}{|l|} 
Vinagre tinto \\
$10 \%$
\end{tabular}} & \multicolumn{3}{|c|}{ Ácido acético 1\% } & \multicolumn{3}{|c|}{\begin{tabular}{|l|} 
Ácido acético \\
$0,7 \%$ \\
\end{tabular}} \\
\hline & 1 & 2 & $\mathrm{~m}$ & 1 & 2 & $\mathrm{~m}$ & 1 & 2 & $\mathrm{~m}$ & 1 & 2 & $\mathrm{~m}$ & 1 & 2 & $\mathrm{~m}$ & 1 & 2 & $\mathrm{~m}$ & 1 & 2 & $\mathrm{~m}$ & 1 & 2 & $\mathrm{~m}$ \\
\hline P1 & 12 & 12 & 12 & 12 & 12 & 12 & $\mathrm{t}$ & $\mathrm{t}$ & 5 & 11 & 11 & 11 & 10 & 10 & 10 & $\mathrm{t}$ & $\mathrm{t}$ & 5 & 10 & 10 & 10 & 9 & 9 & 9 \\
\hline P3 & 11 & 14 & 12,5 & 11 & 11,5 & 11,2 & $\mathrm{t}$ & $\mathrm{t}$ & 5 & 11 & 11 & 11 & 10 & 11 & 10,5 & $\mathrm{t}$ & $\mathrm{t}$ & 5 & 11 & 12 & 11,5 & $\mathrm{t}$ & $\mathrm{t}$ & 5 \\
\hline P4 & 13 & 12 & 12,5 & 11 & 12 & 11,5 & 0 & 0 & 0 & 11 & 10 & 10,5 & 11 & 10 & 10,5 & 0 & 0 & 0 & 11 & 10,5 & $\mid 10,7$ & 9 & 9 & 9 \\
\hline P5 & 12 & 12 & 12 & 11 & 11 & 11 & 0 & 0 & 0 & 11 & 11 & 11 & 10 & 10 & 10 & 0 & 0 & 0 & 11 & 11 & 11 & $\mathrm{t}$ & $\mathrm{t}$ & 5 \\
\hline P6 & 13 & 12 & 12,5 & 12 & 10 & 11 & 0 & 0 & 0 & 11 & 11 & 11 & 10 & 10 & 10 & 0 & 0 & 0 & 10 & 11 & 10,5 & 9 & 8 & 8,5 \\
\hline P7 & 11 & 11 & 11 & 10 & 10 & 10 & 0 & 0 & 0 & 11 & 12 & 11,5 & 10 & 10 & 10 & 0 & 0 & 0 & 10 & 10 & 10 & 9 & 9 & 9 \\
\hline P8 & 12 & 11 & 11,5 & 11 & 11 & 11 & 0 & 0 & 0 & 11 & 12 & 11,5 & 10 & 10 & 10 & 0 & 0 & 0 & 12 & 10 & 11,0 & 9 & 9 & 9 \\
\hline P9 & 11 & 10 & 10,5 & 10 & 9 & 9,5 & 0 & 0 & 0 & 12 & 10 & 11 & 99 & 10 & 9,5 & 0 & 0 & 0 & 8 & 10 & 9 & $\mathrm{t}$ & $\mathrm{t}$ & 5 \\
\hline P10 & 12 & 11 & 11,5 & 12 & 12 & 11 & 0 & 0 & 0 & 14 & 11 & 12,5 & 10 & 11 & 10,5 & 0 & 0 & 0 & 11 & 10 & 10,5 & 11 & 9 & 10 \\
\hline P11 & 13 & 13 & 13 & 11 & 11 & 11 & 0 & 0 & 0 & 11 & 10 & 10,5 & 10 & 9 & 9,5 & 0 & 0 & 0 & 10 & 10 & 10 & $\mathrm{t}$ & $\mathrm{t}$ & 5 \\
\hline P12 & 12 & 11 & 11,5 & 10 & 10 & 10 & 0 & 0 & 0 & 11 & 11 & 11 & \begin{tabular}{|l|}
10 \\
\end{tabular} & 10 & 10 & 0 & 0 & 0 & 11 & 9 & 10 & $\mathrm{t}$ & $\mathrm{t}$ & 5 \\
\hline P14 & 11 & 11 & 11 & 11 & 11 & 11 & 0 & 0 & 0 & 12 & 12 & 12 & 10 & 10 & 10 & 0 & 0 & 0 & 10 & 10 & 10 & $\mathrm{t}$ & $\mathrm{t}$ & 5 \\
\hline P15 & 11 & 11 & 11 & 11 & 10 & 10,5 & 0 & 0 & 0 & 11 & 12 & 11,5 & 11 & 10 & 10,5 & 0 & 0 & 0 & 11 & 11 & 11 & $\mathrm{t}$ & 9 & 7 \\
\hline P17 & 11 & 11 & 11 & 9 & 11 & 10 & 0 & 0 & 0 & 11 & 12 & 11,5 & 10 & 10 & 10 & 0 & 0 & 0 & 10 & $\mathrm{t}$ & 7,5 & $\mathrm{t}$ & $\mathrm{t}$ & 5 \\
\hline P18 & 11 & 13 & 12 & 10 & 12 & 11 & 0 & 0 & 0 & 11 & 10 & 10,5 & 11 & 9 & 10 & 0 & 0 & 0 & 10 & 10 & 10 & $\mathrm{t}$ & $\mathrm{t}$ & 5 \\
\hline P20 & 12 & 10 & 11 & 12 & 10 & 11 & 0 & 0 & 0 & 11 & 12 & 11,5 & 10 & 11 & 10,5 & 0 & 0 & 0 & 10 & 10 & 10 & 10 & 10 & 10 \\
\hline P23 & 11 & 11 & 11 & 11 & 11 & 11 & 0 & 0 & 0 & 10 & 10 & 10 & 10 & 8 & 9 & 0 & 0 & 0 & 9 & 10 & 9,5 & $\mathrm{t}$ & $\mathrm{t}$ & 5 \\
\hline P24 & 12 & 10 & 11 & 11 & 10 & 10,5 & 0 & 0 & 0 & 12 & 11 & 11,5 & 12 & 10 & 11 & 0 & 0 & 0 & 12 & 10 & 11 & $t$ & 8 & 6,5 \\
\hline P26 & 11 & 11 & 11 & 10 & 10,5 & 10,2 & 0 & 0 & 0 & 12 & 11 & 11,5 & 10 & 10 & 10 & 0 & 0 & 0 & 10 & 10 & 10 & $\mathrm{t}$ & $\mathrm{t}$ & 5 \\
\hline P27 & 14 & 10 & 12 & 13 & $\mathrm{t}$ & 9 & 0 & 0 & 0 & 11 & 13 & 12 & $\mathrm{t}$ & 11 & 8 & 0 & 0 & 0 & 12 & 10 & 11 & $\mathrm{t}$ & $\mathrm{t}$ & 5 \\
\hline P28 & 11 & 10 & 10,5 & 10 & 11 & 10,5 & 0 & 0 & 0 & 12 & 11 & 11,5 & 10 & 9 & 9,5 & 0 & 0 & 0 & 10 & 10 & 10 & $\mathrm{t}$ & $\mathrm{t}$ & 5 \\
\hline P29 & 10 & 11 & 10,5 & 10 & 10 & 10 & 0 & 0 & 0 & 12 & 10 & 11 & 10 & 9 & 9,5 & 0 & 0 & 0 & 12 & 10 & 11 & $\mathrm{t}$ & $\mathrm{t}$ & 5 \\
\hline Total & 257 & 248 & 252,5 & 239 & 230 & 234,5 & 0,45 & 0,45 & 0,45 & 250 & 244 & 247 & 219 & 218 & 218,5 & 0,45 & 0,45 & 0,45 & 231 & 219,5 & 225,2 & 141 & 145 & 143 \\
\hline Média & 11,7 & 11,3 & 11,5 & 10,9 & 10,4 & \begin{tabular}{|l|}
10,6 \\
\end{tabular} & 0,4 & 0,4 & \begin{tabular}{|l|l|}
0,4 \\
\end{tabular} & 11,4 & 11,1 & 11,2 & 9,9 & 9,9 & 9,9 & \begin{tabular}{|l|}
0,4 \\
\end{tabular} & \begin{tabular}{|l|}
0,4 \\
\end{tabular} & 0,4 & 10,5 & \begin{tabular}{|l|}
10,0 \\
\end{tabular} & \begin{tabular}{|l|}
10,2 \\
\end{tabular} & 6,4 & 6,6 & 6,5 \\
\hline
\end{tabular}




\section{Protocolo $n^{\circ} 2$}

Distribuição da atividade antimicrobiana do vinagre branco e tinto a 30\%, $25 \%$ e 10\%, e do ácido acético

(PA) a $1 \%$ e $0,7 \%$ sobre as cepas de Escherichia coli pelo Método de Difusão de Poço.

\begin{tabular}{|c|c|c|c|c|c|c|c|c|c|c|c|c|c|c|c|c|c|c|c|c|c|c|c|c|}
\hline \multirow{2}{*}{$\begin{array}{l}\text { Produto } \\
\text { Cepas }\end{array}$} & \multicolumn{3}{|c|}{$\begin{array}{l}\text { Vinagre } \\
\text { branco } 30 \%\end{array}$} & \multicolumn{3}{|c|}{$\begin{array}{l}\text { Vinagre branco } \\
25 \%\end{array}$} & \multicolumn{3}{|c|}{\begin{tabular}{|l} 
Vinagre \\
branco $10 \%$
\end{tabular}} & \multicolumn{3}{|c|}{$\begin{array}{l}\text { Vinagre tinto } \\
30 \%\end{array}$} & \multicolumn{3}{|c|}{$\begin{array}{l}\text { Vinagre tinto } \\
25 \%\end{array}$} & \multicolumn{3}{|c|}{\begin{tabular}{|l|} 
Vinagre \\
tinto $10 \%$
\end{tabular}} & \multicolumn{3}{|c|}{$\begin{array}{l}\text { Ácido acético } \\
1 \%\end{array}$} & \multicolumn{3}{|c|}{\begin{tabular}{|l|} 
Ácido acético \\
$0,7 \%$
\end{tabular}} \\
\hline & 1 & 2 & $\mathbf{m}$ & 1 & 2 & $\mathbf{m}$ & 1 & 2 & $\mathbf{m}$ & 1 & 2 & $M$ & 1 & 2 & $m$ & 1 & 2 & $\mathbf{m}$ & \begin{tabular}{|l|}
1 \\
\end{tabular} & 2 & $\mathbf{m}$ & 1 & 2 & $\mathbf{m}$ \\
\hline E1 & 12 & 11 & 11,5 & 10 & 10 & 10 & 0 & 0 & 0 & 11 & 11 & 11 & 10 & 10 & 10 & $t$ & $t$ & 5 & 11 & 11 & 11 & $t$ & $t$ & 5 \\
\hline E2-1 & 12 & 11 & 11,5 & 11 & 10 & 10,5 & $t$ & $t$ & 5 & 11 & 11 & 11 & 10 & 11 & 10,5 & $t$ & $t$ & 5 & 11 & 11 & 11 & 8 & 9 & 8,5 \\
\hline E5 & 10 & 11 & 10,5 & 9 & 9 & 9 & 0 & 0 & 0 & 12 & 10,5 & 11,2 & 12 & 10 & 11 & 0 & 0 & 0 & 10 & 11 & 10,5 & $t$ & $t$ & 5 \\
\hline E5-1 & 11 & 12 & 11,5 & 10 & 10 & 10 & 0 & 0 & 0 & 10 & 10,5 & 10,2 & 10 & 10 & 10 & 0 & 0 & 0 & 11 & 10 & 10,5 & $\mathrm{t}$ & 8 & 6,5 \\
\hline E6 & 12 & 12 & \begin{tabular}{|l|}
12 \\
\end{tabular} & 12 & 10 & 11 & 0 & 0 & 0 & 11 & 11 & 11 & 10 & 10 & 10 & 0 & 0 & 0 & 11 & 10 & 10,5 & 9 & 8 & 8,5 \\
\hline E7 & 11 & 12 & 11,5 & 10 & 9 & 9,5 & 0 & 0 & 0 & 10 & 10 & 10 & 10 & 9 & 9,5 & 0 & 0 & 0 & 10 & 10 & 10 & $t$ & $\mathrm{t}$ & 5 \\
\hline E9 & 12 & 11 & 11,5 & 11 & 10 & 10,5 & 8 & 7 & 7,5 & 12 & 11 & 11,5 & 10 & 9 & 9,5 & $t$ & $t$ & 5 & 11 & 10 & 10,5 & 9 & 7 & 8 \\
\hline È10 & 11 & 11 & \begin{tabular}{|l|}
11 \\
\end{tabular} & 10 & 10 & 10 & 0 & $t$ & 2,5 & 11 & 9 & 10 & 10 & 8 & 9 & $t$ & $\mathrm{t}$ & 5 & 11 & 10 & 10,5 & 9 & 9 & 9 \\
\hline E11-1 & 10 & 11 & 10,5 & 10 & 9 & 9,5 & 0 & 0 & 0 & 12 & 10 & 11 & 11 & 9 & 10 & 0 & 0 & 0 & 10 & 10 & 10 & 9 & 9 & 9 \\
\hline E12 & 12 & 11 & 11,5 & 10 & 10 & 10 & $t$ & $t$ & 5 & 11 & 11 & 11 & 10 & 10 & 10 & $t$ & $t$ & 5 & 11 & 10 & 10,5 & $t$ & 8 & 6,5 \\
\hline E13 & 11 & 11 & \begin{tabular}{|l|}
11 \\
\end{tabular} & 10 & 10 & 10 & $t$ & $t$ & 5 & 10 & 11 & 10,5 & 10 & 10 & 10 & $t$ & $t$ & 5 & 11 & 10 & 10,5 & 10 & 9 & 9,5 \\
\hline E14 & 11 & 11 & 11 & 9 & 11 & 10 & 0 & $t$ & 2,5 & 10 & 11 & 10,5 & 10 & 9 & 9,5 & $t$ & 0 & 2,5 & 10 & 9 & 9,5 & 9 & 7 & 8 \\
\hline E17 & 12 & 11 & 11,5 & 11 & 10 & 10,5 & $t$ & $t$ & 5 & 11 & 11 & 11 & 11 & 10 & 10,5 & $t$ & 0 & 2,5 & 11 & 10 & 10,5 & 9 & 8 & 8,5 \\
\hline E18-1 & 12 & 11 & 11,5 & 10 & 10 & 10 & $t$ & 0 & 2,5 & 10 & 9 & 9,5 & 10 & 9 & 9,5 & $t$ & $\mathrm{t}$ & 5 & 11 & 10 & 10,5 & 9 & 7 & 8 \\
\hline E19 & 12 & 12 & \begin{tabular}{|l|}
12 \\
\end{tabular} & 11 & 10 & 10,5 & 0 & 0 & 0 & 10 & 11 & \begin{tabular}{|l|}
10,5 \\
\end{tabular} & 10 & 10 & 10 & 0 & 0 & 0 & 10 & 11 & 10,5 & 8 & 7 & 7,5 \\
\hline E20 & 12 & 12 & 12 & 11 & 11 & 11 & $t$ & $\mathrm{t}$ & 5 & 12 & 10 & 11 & 11 & 9 & 10 & $\mathrm{t}$ & 0 & 2,5 & 12 & 10 & 11 & 10 & 8 & 9 \\
\hline E21 & 11 & 11 & 11 & 11 & 10 & 10,5 & 0 & $t$ & 5 & 11 & 10 & 10,5 & 10 & 9 & 9,5 & 0 & 0 & 0 & 10 & 9 & 9,5 & 8 & 8 & 8 \\
\hline E22 & 12 & 12 & 12 & 11 & 11 & 11 & 0 & $t$ & 2,5 & 11 & 11 & \begin{tabular}{|l|}
11 \\
\end{tabular} & 11 & 10 & 10,5 & $t$ & $t$ & 2,5 & 12 & 11 & 11,5 & 9 & 9 & 9 \\
\hline E24 & 12 & 10 & 11 & 11 & 10 & 10,5 & 0 & 0 & 0 & 12 & 10 & 11 & 10 & 9 & 9,5 & 0 & 0 & 0 & 12 & 10 & 11 & 9 & 8 & 8,5 \\
\hline E25 & 12 & 11 & 11,5 & 11 & 10 & 10,5 & 0 & 0 & 0 & 10 & 10 & 10 & 10 & 9 & 9,5 & 0 & 0 & 0 & 12 & 11 & 11,5 & 10 & 9 & 8,5 \\
\hline E25-1 & 12 & 11 & 11,5 & 11 & 9 & 10 & 0 & $t$ & 2,5 & 12 & 11 & 11,5 & 11 & 10 & 10,5 & 0 & $t$ & 2,5 & 12 & 10 & 11 & 10 & 8 & 9 \\
\hline Total & 242 & 236 & 239 & 220 & 209 & 214,5 & 38 & 57 & 47,5 & 230 & 220 & 225 & 217 & 200 & 208,5 & 55 & 45 & 50 & 230 & 214 & 222 & 170 & 161 & 165,5 \\
\hline Média & 11,5 & 11,2 & 11,3 & 10,5 & 9,9 & 10,2 & 1,7 & 2,6 & 2,2 & 10,9 & 10,5 & 10,7 & 10,3 & 9,5 & 9,9 & 2,6 & 2,1 & 2,4 & 10,9 & 10,2 & 10,6 & 8,1 & 7,7 & 7,9 \\
\hline
\end{tabular}




\section{Protocolo $\mathrm{n}^{\circ} 3$}

Distribuição da atividade antimicrobiana do vinagre branco e tinto a 30\%, $25 \%$ e 10\%, e do ácido acético (PA) a $1 \%$ e $0,7 \%$ sobre as cepas de Staphylococcus sp pelo Método de Difusão de Poço.

\begin{tabular}{|c|c|c|c|c|c|c|c|c|c|c|c|c|c|c|c|c|c|c|c|c|c|c|c|c|}
\hline \multirow{2}{*}{$\begin{array}{l}\text { Produto } \\
\text { Cepas }\end{array}$} & \multicolumn{3}{|c|}{$\begin{array}{l}\text { Vinagre } \\
\text { branco 30\% }\end{array}$} & \multicolumn{3}{|c|}{$\begin{array}{l}\text { Vinagre } \\
\text { branco 25\% }\end{array}$} & \multicolumn{3}{|c|}{$\begin{array}{l}\text { Vinagre } \\
\text { branco } 10 \%\end{array}$} & \multicolumn{3}{|c|}{$\begin{array}{l}\text { Vinagre tinto } \\
30 \%\end{array}$} & \multicolumn{3}{|c|}{$\begin{array}{l}\text { Vinagre tinto } \\
25 \%\end{array}$} & \multicolumn{3}{|c|}{$\begin{array}{l}\text { Vinagre tinto } \\
10 \%\end{array}$} & \multicolumn{3}{|c|}{$\begin{array}{l}\text { Ácido } \\
\text { acético 1\% }\end{array}$} & \multicolumn{3}{|c|}{$\begin{array}{l}\text { Ácido } \\
\text { acético } \\
0,7 \%\end{array}$} \\
\hline & 1 & 2 & $m$ & 1 & 2 & $\mathbf{m}$ & 1 & 2 & $\mathbf{m}$ & 1 & 2 & $M$ & 1 & 2 & $\mathbf{m}$ & 1 & 2 & m & 1 & 2 & m & 1 & 2 & $\mathbf{m}$ \\
\hline 1.1 & 0 & 0 & 0 & 0 & 0 & 0 & 0 & 0 & 0 & 0 & 0 & 0 & 0 & 0 & 0 & 0 & 0 & 0 & 0 & 0 & 0 & 0 & 0 & 0 \\
\hline 2.5 & 0 & 0 & 0 & 0 & 0 & 0 & 0 & 0 & 0 & 0 & 0 & 0 & 0 & 0 & 0 & 0 & 0 & 0 & 0 & 0 & 0 & 0 & 0 & 0 \\
\hline 3.1 & 0 & 0 & 0 & 0 & 0 & 0 & 0 & 0 & 0 & 0 & 0 & 0 & 0 & 0 & 0 & 0 & 0 & 0 & 0 & 0 & 0 & 0 & 0 & 0 \\
\hline 4.1 & 0 & 0 & 0 & 0 & 0 & 0 & 0 & 0 & 0 & 0 & 0 & 0 & 0 & 0 & 0 & 0 & 0 & 0 & 0 & 0 & 0 & 0 & 0 & 0 \\
\hline 5.5 & 0 & 0 & 0 & 0 & 0 & 0 & 0 & 0 & 0 & 0 & 0 & 0 & 0 & 0 & 0 & 0 & 0 & 0 & 0 & 0 & 0 & 0 & 0 & 0 \\
\hline 6.1 & 0 & 0 & 0 & 0 & 0 & 0 & 0 & 0 & 0 & 0 & 0 & 0 & 0 & 0 & 0 & 0 & 0 & 0 & 0 & 0 & 0 & 0 & 0 & 0 \\
\hline S7.5 & 0 & 0 & 0 & 0 & 0 & 0 & 0 & 0 & 0 & 0 & 0 & 0 & 0 & 0 & 0 & 0 & 0 & 0 & 0 & 0 & 0 & 0 & 0 & 0 \\
\hline 8.5 & 0 & 0 & 0 & 0 & 0 & 0 & 0 & 0 & 0 & 0 & 0 & 0 & 0 & 0 & 0 & 0 & 0 & 0 & 0 & 0 & 0 & 0 & 0 & 0 \\
\hline 9.1 & 0 & 0 & 0 & 0 & 0 & 0 & 0 & 0 & 0 & 0 & 0 & 0 & 0 & 0 & 0 & 0 & 0 & 0 & 0 & 0 & 0 & 0 & 0 & 0 \\
\hline 11.5 & 0 & 0 & 0 & 0 & 0 & 0 & 0 & 0 & 0 & 0 & 0 & 0 & 0 & 0 & 0 & 0 & 0 & 0 & 0 & 0 & 0 & 0 & 0 & 0 \\
\hline 14.1 & 0 & 0 & 0 & 0 & 0 & 0 & 0 & 0 & 0 & 0 & 0 & 0 & 0 & 0 & 0 & 0 & 0 & 0 & 0 & 0 & 0 & 0 & 0 & 0 \\
\hline 15.5 & 0 & 0 & 0 & 0 & 0 & 0 & 0 & 0 & 0 & 0 & 0 & 0 & 0 & 0 & 0 & 0 & 0 & 0 & 0 & 0 & 0 & 0 & 0 & 0 \\
\hline 16.1 & 0 & 0 & 0 & 0 & 0 & 0 & 0 & 0 & 0 & 0 & 0 & 0 & 0 & 0 & 0 & 0 & 0 & 0 & 0 & 0 & 0 & 0 & 0 & 0 \\
\hline S17.1 & 0 & 0 & 0 & 0 & 0 & 0 & 0 & 0 & 0 & 0 & 0 & 0 & 0 & 0 & 0 & 0 & 0 & 0 & 0 & 0 & 0 & 0 & 0 & 0 \\
\hline 18.5 & 0 & 0 & 0 & 0 & 0 & 0 & 0 & 0 & 0 & 0 & 0 & 0 & 0 & 0 & 0 & 0 & 0 & 0 & 0 & 0 & 0 & 0 & 0 & 0 \\
\hline 19.1 & 0 & 0 & 0 & 0 & 0 & 0 & 0 & 0 & 0 & 0 & 0 & 0 & 0 & 0 & 0 & 0 & 0 & 0 & 0 & 0 & 0 & 0 & 0 & 0 \\
\hline 20.5 & 0 & 0 & 0 & 0 & 0 & 0 & 0 & 0 & 0 & 0 & 0 & 0 & 0 & 0 & 0 & 0 & 0 & 0 & 0 & 0 & 0 & 0 & 0 & 0 \\
\hline 21.1 & 0 & 0 & 0 & 0 & 0 & 0 & 0 & 0 & 0 & 0 & 0 & 0 & 0 & 0 & 0 & 0 & 0 & 0 & 0 & 0 & 0 & 0 & 0 & 0 \\
\hline 23.5 & 0 & 0 & 0 & 0 & 0 & 0 & 0 & 0 & 0 & 0 & 0 & 0 & 0 & 0 & 0 & 0 & 0 & 0 & 0 & 0 & 0 & 0 & 0 & 0 \\
\hline 24.5 & 0 & 0 & 0 & 0 & 0 & 0 & 0 & 0 & 0 & 0 & 0 & 0 & 0 & 0 & 0 & 0 & 0 & 0 & 0 & 0 & 0 & 0 & 0 & 0 \\
\hline 26.1 & 0 & 0 & 0 & 0 & 0 & 0 & 0 & 0 & 0 & 0 & 0 & 0 & 0 & 0 & 0 & 0 & 0 & 0 & 0 & 0 & 0 & 0 & 0 & 0 \\
\hline 27.1 & 0 & 0 & 0 & 0 & 0 & 0 & 0 & 0 & 0 & 0 & 0 & 0 & 0 & 0 & 0 & 0 & 0 & 0 & 0 & 0 & 0 & 0 & 0 & 0 \\
\hline Total & 0 & 0 & 0 & 0 & 0 & 0 & 0 & 0 & 0 & 0 & 0 & 0 & 0 & 0 & 0 & 0 & 0 & 0 & 0 & 0 & 0 & 0 & 0 & 0 \\
\hline Média & 0 & 0 & 0 & 0 & 0 & 0 & 0 & 0 & 0 & 0 & 0 & 0 & 0 & 0 & 0 & 0 & 0 & 0 & 0 & 0 & 0 & 0 & 0 & 0 \\
\hline
\end{tabular}

1,2: série duplicada; m: média do diâmetro dos halos de inibição

t: traço/crescimento tênue, para efeito de cálculo foi considerado o valor de 5mm logo todo t considerar o valor 5. 


\section{ANEXO E \\ (Protocolo $n^{\circ} 1$ a 9)}

MÉTODO: CONCENTRAÇÃO INIBITÓRIA MÍNIMA (Protolocos de 1 a

Protocolo $n^{\circ} 1$

ANTIMICROBIANO: VINAGRE CASTELO TINTO

DATA: $16 / 06 / 2003$

CEPAS: Staphylococcus aureus

\begin{tabular}{|c|c|c|c|c|c|c|c|c|c|c|c|c|c|c|c|c|c|c|}
\hline $\begin{array}{l}\text { Diluição } \\
\%\end{array}$ & \multicolumn{2}{|c|}{4,0} & \multicolumn{2}{|c|}{3,0} & \multicolumn{2}{|c|}{2,0} & \multicolumn{2}{|c|}{1,5} & \multicolumn{2}{|c|}{1,0} & \multicolumn{2}{|c|}{0,75} & \multicolumn{2}{|c|}{0,5} & \multicolumn{2}{|c|}{0,25} & & \\
\hline $\begin{array}{l}\text { Placa } \\
\text { Cepa }\end{array}$ & \multicolumn{2}{|c|}{1} & \multicolumn{2}{|c|}{2} & \multicolumn{2}{|c|}{$3 *$} & \multicolumn{2}{|c|}{4} & \multicolumn{2}{|c|}{5} & \multicolumn{2}{|c|}{6} & \multicolumn{2}{|c|}{7} & \multicolumn{2}{|c|}{8} & \multicolumn{2}{|c|}{ controle } \\
\hline S 1.1 & - & - & - & - & + & + & + & + & + & + & + & + & + & + & + & + & + & + \\
\hline S 2.5 & - & - & - & - & + & + & + & + & + & + & + & + & + & + & + & + & + & + \\
\hline S 3.1 & - & - & - & - & + & + & + & + & + & + & + & + & + & + & + & + & + & + \\
\hline S 4.5 & - & - & - & - & + & + & + & + & + & + & + & + & + & + & + & + & + & + \\
\hline S 6.1 & - & - & - & - & + & + & + & + & + & + & + & + & + & + & + & + & + & + \\
\hline S 7.5 & - & - & - & - & + & + & + & + & + & + & + & + & + & + & + & + & + & + \\
\hline S 8.5 & - & - & - & - & + & + & + & + & + & + & + & + & + & + & + & + & + & + \\
\hline S 21.1 & - & - & - & - & + & + & + & + & + & + & + & + & + & + & + & + & + & + \\
\hline S 23.5 & - & - & - & - & + & + & + & + & + & + & + & + & + & + & + & + & + & + \\
\hline S 24.5 & - & - & - & - & + & + & + & + & + & + & + & + & + & + & + & + & + & + \\
\hline S 26.1 & - & - & - & - & + & + & + & + & + & + & + & + & + & + & + & + & + & + \\
\hline S 27.1 & - & - & - & - & + & + & + & + & + & + & + & + & + & + & + & + & + & + \\
\hline A 4.1 & - & - & - & - & + & + & + & + & + & + & + & + & + & + & + & + & + & + \\
\hline A 6.1 & - & - & - & - & + & + & + & + & + & + & + & + & + & + & + & + & + & + \\
\hline A 7.5 & - & - & - & - & + & + & + & + & + & + & + & + & + & + & + & + & + & + \\
\hline A 10.1 & - & - & - & - & + & + & + & + & + & + & + & + & + & + & + & + & + & + \\
\hline A 13.1 & - & - & - & - & + & + & + & + & + & + & + & + & + & + & + & + & + & + \\
\hline A 17.1 & - & - & - & - & + & + & + & + & + & + & + & + & + & + & + & + & + & + \\
\hline A 23.1 & - & - & - & - & + & + & + & + & + & + & + & + & + & + & + & + & + & + \\
\hline A 35.1 & - & - & - & - & + & + & + & + & + & + & + & + & + & + & + & + & + & + \\
\hline
\end{tabular}

*, crescimento fino; +, desenvolvimento; -, sem desenvolvimento $S\left(n^{\circ}\right)=$ cepa hospitalar

$\boldsymbol{A}\left(\boldsymbol{n}^{\circ}\right)=$ cepa comunidade 


\section{Protocolo $\mathbf{n}^{0} 2$}

MÉTODO: CONCENTRAÇÃO INIBITÓRIA MÍNIMA

ANTIMICROBIANO: VINAGRE CASTELO TINTO DATA: 16/06/2003

CEPAS: Escherichia coli.

\begin{tabular}{|c|c|c|c|c|c|c|c|c|c|c|c|c|c|c|c|c|c|c|}
\hline $\begin{array}{l}\text { Diluição } \\
\%\end{array}$ & \multicolumn{2}{|c|}{4,0} & \multicolumn{2}{|c|}{3,0} & \multicolumn{2}{|c|}{2,0} & \multicolumn{2}{|c|}{1,5} & \multicolumn{2}{|c|}{1,0} & \multicolumn{2}{|c|}{0,75} & \multicolumn{2}{|c|}{0,5} & \multicolumn{2}{|c|}{0,25} & & \\
\hline $\begin{array}{l}\text { Rlaca } \\
\text { Cepa }\end{array}$ & \multicolumn{2}{|c|}{1} & \multicolumn{2}{|c|}{2} & \multicolumn{2}{|c|}{3} & \multicolumn{2}{|c|}{4} & \multicolumn{2}{|c|}{5} & \multicolumn{2}{|c|}{6} & \multicolumn{2}{|c|}{7} & \multicolumn{2}{|c|}{8} & \multicolumn{2}{|c|}{ controle } \\
\hline Ec 1 & - & - & - & - & - & - & - & - & + & + & + & + & + & + & + & + & + & + \\
\hline Ec 2 & - & - & - & - & - & - & - & - & + & + & + & + & + & + & + & + & + & + \\
\hline Ec 5 & - & - & - & - & - & - & - & - & + & + & + & + & + & + & + & + & + & + \\
\hline Ec 6 & - & - & - & - & - & - & - & - & + & + & + & + & + & + & + & + & + & + \\
\hline Ec 7 & - & - & - & - & - & - & - & - & + & + & + & + & + & + & + & + & + & + \\
\hline Ec 9 & - & - & - & - & - & - & - & - & + & + & + & + & + & + & + & + & + & + \\
\hline Ec 10 & - & - & - & - & - & - & - & - & + & + & + & + & + & + & + & + & + & + \\
\hline Ec 11 & - & - & - & - & - & - & - & - & + & + & + & + & + & + & + & + & + & + \\
\hline Ec 12 & - & - & - & - & - & - & - & - & + & + & + & + & + & + & + & + & + & + \\
\hline Ec 13 & - & - & - & - & - & - & - & - & + & + & + & + & + & + & + & + & + & + \\
\hline Ec 14 & - & - & - & - & - & - & - & - & + & + & + & + & + & + & + & + & + & + \\
\hline Ec 17 & - & - & - & - & - & - & - & - & + & + & + & + & + & + & + & + & + & + \\
\hline Ec 18 & - & - & - & - & - & - & - & - & + & + & + & + & + & + & + & + & + & + \\
\hline Ec 19 & - & - & - & - & - & - & - & - & + & + & + & + & + & + & + & + & + & + \\
\hline Ec 20 & - & - & - & - & - & - & - & - & + & + & + & + & + & + & + & + & + & + \\
\hline Ec 21 & - & - & - & - & - & - & - & - & + & + & + & + & + & + & + & + & + & + \\
\hline Ec 22 & - & - & - & - & - & - & - & - & + & + & + & + & + & + & + & + & + & + \\
\hline Ec 23 & - & - & - & - & - & - & - & - & + & + & + & + & + & + & + & + & + & + \\
\hline Ec 24 & - & - & - & - & - & - & - & - & + & + & + & + & + & + & + & + & + & + \\
\hline Ec 25 & - & - & - & - & - & - & - & - & + & + & + & + & + & + & + & + & + & + \\
\hline
\end{tabular}

+, desenvolvimento; -, sem desenvolvimento 


\section{Protocolo $n^{0} 3$}

MÉTODO: CONCENTRAÇÃO INIBITÓRIA MÍNIMA

ANTIMICROBIANO: VINAGRE CASTELO TINTO

DATA: $16 / 06 / 2003$

PROJETO: Pseudomonas aeruginosa

\begin{tabular}{|c|c|c|c|c|c|c|c|c|c|c|c|c|c|c|c|c|c|c|}
\hline Diluição & \multicolumn{2}{|c|}{4,0} & \multicolumn{2}{|c|}{3,0} & \multicolumn{2}{|c|}{2,0} & \multicolumn{2}{|c|}{1,5} & \multicolumn{2}{|c|}{1,0} & \multicolumn{2}{|c|}{0,75} & \multicolumn{2}{|c|}{0,5} & \multicolumn{2}{|c|}{0,25} & & \\
\hline $\begin{array}{l}\text { Rlaca } \\
\text { Cepa }\end{array}$ & \multicolumn{2}{|c|}{1} & \multicolumn{2}{|c|}{2} & \multicolumn{2}{|c|}{3} & \multicolumn{2}{|c|}{4} & \multicolumn{2}{|c|}{5} & \multicolumn{2}{|c|}{6} & \multicolumn{2}{|c|}{7} & \multicolumn{2}{|c|}{8} & \multicolumn{2}{|c|}{ controle } \\
\hline Pa 1 & - & - & - & - & - & - & - & - & + & + & + & + & + & + & + & + & + & + \\
\hline Pa 3 & - & - & - & - & - & - & - & - & + & + & + & + & + & + & + & + & + & + \\
\hline $\mathrm{Pa} 4$ & - & - & - & - & - & - & - & - & + & + & + & + & + & + & + & + & + & + \\
\hline $\mathrm{Pa} 5$ & - & - & - & - & - & - & - & - & + & + & + & + & + & + & + & + & + & + \\
\hline $\mathrm{Pa} 6$ & - & - & - & - & - & - & - & - & + & + & + & + & + & + & + & + & + & + \\
\hline $\mathrm{Pa} 7$ & - & - & - & - & - & - & - & - & + & + & + & + & + & + & + & + & + & + \\
\hline Pa 8 & - & - & - & - & - & - & - & - & + & + & + & + & + & + & + & + & + & + \\
\hline Pa 9 & - & - & - & - & - & - & - & - & + & + & + & + & + & + & + & + & + & + \\
\hline $\mathrm{Pa} 12$ & - & - & - & - & - & - & - & - & + & + & + & + & + & + & + & + & + & + \\
\hline $\mathrm{Pa} 18$ & - & - & - & - & - & - & - & - & + & + & + & + & + & + & + & + & + & + \\
\hline Pa 19 & - & - & - & - & - & - & - & - & + & + & + & + & + & + & + & + & + & + \\
\hline $\mathrm{Pa} 20$ & - & - & - & - & - & - & - & - & + & + & + & + & + & + & + & + & + & + \\
\hline $\mathrm{Pa} 21$ & - & - & - & - & - & - & - & - & + & + & + & + & + & + & + & + & + & + \\
\hline $\mathrm{Pa} 22$ & - & - & - & - & - & - & - & - & + & + & + & + & + & + & + & + & + & + \\
\hline $\mathrm{Pa} 24$ & - & - & - & - & - & - & - & - & + & + & + & + & + & + & + & + & + & + \\
\hline $\mathrm{Pa} 25$ & - & - & - & - & - & - & - & - & + & + & + & + & + & + & + & + & + & + \\
\hline $\mathrm{Pa} 22$ & - & - & - & - & - & - & - & - & + & + & + & + & + & + & + & + & + & + \\
\hline $\mathrm{Pa} 26$ & - & - & - & - & - & - & - & - & + & + & + & + & + & + & + & + & + & + \\
\hline $\mathrm{Pa} 27$ & - & - & - & - & - & - & - & - & + & + & + & + & + & + & + & + & + & + \\
\hline $\mathrm{Pa} 28$ & - & - & - & - & - & - & - & - & + & + & + & + & + & + & + & + & + & + \\
\hline Pa 29 & - & - & - & - & - & - & - & - & + & + & + & + & + & + & + & + & + & + \\
\hline
\end{tabular}

+, desenvolvimento; -, sem desenvolvimento 


\section{Protocolo $n^{\circ} 4$}

MÉTODO: CONCENTRAÇÃO INIBITÓRIA MÍNIMA

ANTIMICROBIANO: VINAGRE CASTELO BRANCO DATA: 16/06/2003

CEPAS: Staphylococcus aureus .

\begin{tabular}{|c|c|c|c|c|c|c|c|c|c|c|c|c|c|c|c|c|c|c|}
\hline $\begin{array}{l}\text { Diluição } \\
\%\end{array}$ & \multicolumn{2}{|c|}{4,0} & \multicolumn{2}{|c|}{3,0} & \multicolumn{2}{|c|}{2,0} & \multicolumn{2}{|c|}{1,5} & \multicolumn{2}{|c|}{1,0} & \multicolumn{2}{|c|}{0,75} & \multicolumn{2}{|c|}{0,5} & \multicolumn{2}{|c|}{0,25} & & \\
\hline $\begin{array}{l}\text { Placa } \\
\text { Cepa }\end{array}$ & \multicolumn{2}{|c|}{1} & \multicolumn{2}{|c|}{2} & \multicolumn{2}{|c|}{$3^{*}$} & \multicolumn{2}{|c|}{4} & \multicolumn{2}{|c|}{5} & \multicolumn{2}{|c|}{6} & \multicolumn{2}{|c|}{7} & \multicolumn{2}{|c|}{8} & \multicolumn{2}{|c|}{ controle } \\
\hline S 1.1 & - & - & - & - & + & + & + & + & + & + & + & + & + & + & + & + & + & + \\
\hline S 2.5 & - & - & - & - & + & + & + & + & + & + & + & + & + & + & + & + & + & + \\
\hline S 3.1 & - & - & - & - & + & + & + & + & + & + & + & + & + & + & + & + & + & + \\
\hline S 4.5 & - & - & - & - & + & + & + & + & + & + & + & + & + & + & + & + & + & + \\
\hline S 6.1 & - & - & - & - & + & + & + & + & + & + & + & + & + & + & + & + & + & + \\
\hline S 7.5 & - & - & - & - & + & + & + & + & + & + & + & + & + & + & + & + & + & + \\
\hline S 8.5 & - & - & - & - & + & + & + & + & + & + & + & + & + & + & + & + & + & + \\
\hline S 21.1 & - & - & - & - & + & + & + & + & + & + & + & + & + & + & + & + & + & + \\
\hline S 23.5 & - & - & - & - & + & + & + & + & + & + & + & + & + & + & + & + & + & + \\
\hline S 24.5 & - & - & - & - & + & + & + & + & + & + & + & + & + & + & + & + & + & + \\
\hline S 26.1 & - & - & - & - & + & + & + & + & + & + & + & + & + & + & + & + & + & + \\
\hline S 27.1 & - & - & - & - & + & + & + & + & + & + & + & + & + & + & + & + & + & + \\
\hline A 4.1 & - & - & - & - & + & + & + & + & + & + & + & + & + & + & + & + & + & + \\
\hline A 6.1 & - & - & - & - & + & + & + & + & + & + & + & + & + & + & + & + & + & + \\
\hline A 7.5 & - & - & - & - & + & + & + & + & + & + & + & + & + & + & + & + & + & + \\
\hline A 10.1 & - & - & - & - & + & + & + & + & + & + & + & + & + & + & + & + & + & + \\
\hline A 13.1 & - & - & - & - & + & + & + & + & + & + & + & + & + & + & + & + & + & + \\
\hline A 17.1 & - & - & - & - & + & + & + & + & + & + & + & + & + & + & + & + & + & + \\
\hline A 23.1 & - & - & - & - & + & + & + & + & + & + & + & + & + & + & + & + & + & + \\
\hline A 35.1 & - & - & - & - & + & + & + & + & + & + & + & + & + & + & + & + & + & + \\
\hline
\end{tabular}

*, crescimento fino; +, desenvolvimento; -, sem desenvolvimento

$\boldsymbol{S}\left(\boldsymbol{n}^{\circ}\right)=$ cepa hospitalar

$\boldsymbol{A}\left(\boldsymbol{n}^{\circ}\right)=$ cepa comunidade 


\section{Protocolo $n^{\circ} 5$}

MÉTODO: CONCENTRAÇÃO INIBITÓRIA MÍNIMA

ANTIMICROBIANO: VINAGRE CASTELO BRANCO

DATA: $16 / 06 / 2003$

CEPAS: Escherichia coli

\begin{tabular}{|c|c|c|c|c|c|c|c|c|c|c|c|c|c|c|c|c|c|c|}
\hline $\begin{array}{l}\text { Diluição } \\
\%\end{array}$ & \multicolumn{2}{|c|}{4,0} & \multicolumn{2}{|c|}{3,0} & \multicolumn{2}{|c|}{2,0} & \multicolumn{2}{|c|}{1,5} & \multicolumn{2}{|c|}{1,0} & \multicolumn{2}{|c|}{0,75} & \multicolumn{2}{|c|}{0,5} & \multicolumn{2}{|c|}{0,25} & & \\
\hline Placa & \multicolumn{2}{|c|}{1} & \multicolumn{2}{|c|}{2} & \multicolumn{2}{|c|}{3} & \multicolumn{2}{|c|}{4} & \multicolumn{2}{|c|}{5} & \multicolumn{2}{|c|}{6} & \multicolumn{2}{|c|}{7} & \multicolumn{2}{|c|}{8} & \multicolumn{2}{|c|}{ controle } \\
\hline Ec 1 & - & - & - & - & - & - & - & - & + & + & + & + & + & + & + & + & + & + \\
\hline Ec 2 & - & - & - & - & - & - & - & - & + & + & + & + & + & + & + & + & + & + \\
\hline Ec 5 & - & - & - & - & - & - & - & - & + & + & + & + & + & + & + & + & + & + \\
\hline Ec 6 & - & - & - & $\begin{array}{ll}- \\
-\end{array}$ & - & - & - & - & + & + & + & + & + & + & + & + & + & + \\
\hline Ec 7 & - & - & - & - & - & - & 1 & 2 & + & + & + & + & + & + & + & + & + & + \\
\hline Ec 9 & - & - & - & - & - & - & - & - & + & + & + & + & + & + & + & + & + & + \\
\hline Ec 10 & - & - & - & - & - & - & - & - & + & + & + & + & + & + & + & + & + & + \\
\hline Ec 11 & - & - & - & - & - & - & - & - & + & + & + & + & + & + & + & + & + & + \\
\hline Ec 12 & - & - & - & - & - & - & 3 & 2 & + & + & + & + & + & + & + & + & + & + \\
\hline Ec 13 & - & - & - & - & - & - & + & + & + & + & + & + & + & + & + & + & + & + \\
\hline Ec 14 & - & - & - & - & - & - & - & - & + & + & + & + & + & + & + & + & + & + \\
\hline Ec 17 & - & - & - & - & - & - & 2 & 2 & + & + & + & + & + & + & + & + & + & + \\
\hline Ec 18 & - & - & - & - & - & - & - & - & + & + & + & + & + & + & + & + & + & + \\
\hline Ec 19 & - & - & - & - & - & - & - & - & + & + & + & + & + & + & + & + & + & + \\
\hline Ec 20 & - & - & - & - & - & - & - & - & + & + & + & + & + & + & + & + & + & + \\
\hline Ec 21 & - & - & - & - & - & - & - & - & + & + & + & + & + & + & + & + & + & + \\
\hline Ec 22 & - & - & - & - & - & - & - & - & + & + & + & + & + & + & + & + & + & + \\
\hline Ec 23 & - & - & - & - & - & - & - & - & + & + & + & + & + & + & + & + & + & + \\
\hline Ec 24 & - & - & - & - & - & - & - & - & + & + & + & + & + & + & + & + & + & + \\
\hline Ec 25 & - & - & - & - & - & - & - & - & + & + & + & + & + & + & + & + & + & + \\
\hline
\end{tabular}

+, desenvolvimento; -, sem desenvolvimento 


\section{Protocolo $n^{\circ} 6$}

CONCENTRAÇÃO INIBITÓRIA MÍNIMA

ANTIMICROBIANO: VINAGRE CASTELO BRANCO DATA: 16/06/2003

CEPAS : Pseudomonas aeruginosa

\begin{tabular}{|c|c|c|c|c|c|c|c|c|c|c|c|c|c|c|c|c|c|c|}
\hline $\begin{array}{l}\text { Diluição } \\
\%\end{array}$ & \multicolumn{2}{|c|}{4,0} & \multicolumn{2}{|c|}{3,0} & \multicolumn{2}{|c|}{2,0} & \multicolumn{2}{|c|}{1,5} & \multicolumn{2}{|c|}{1,0} & \multicolumn{2}{|c|}{0,75} & \multicolumn{2}{|c|}{0,5} & \multicolumn{2}{|c|}{0,25} & & \\
\hline $\begin{array}{l}\text { Placa } \\
\text { Cepa }\end{array}$ & \multicolumn{2}{|c|}{1} & \multicolumn{2}{|c|}{2} & \multicolumn{2}{|c|}{3} & \multicolumn{2}{|c|}{4} & \multicolumn{2}{|c|}{5} & \multicolumn{2}{|c|}{6} & \multicolumn{2}{|c|}{7} & \multicolumn{2}{|c|}{8} & \multicolumn{2}{|c|}{ controle } \\
\hline Pa 1 & - & - & - & - & - & - & - & - & + & + & + & + & + & + & + & + & + & + \\
\hline $\mathrm{Pa} 3$ & - & - & - & - & - & - & - & - & + & + & + & + & + & + & + & + & + & + \\
\hline $\mathrm{Pa} 4$ & - & - & - & - & - & - & - & - & + & + & + & + & + & + & + & + & + & + \\
\hline Pa 5 & - & - & - & - & - & - & - & - & + & + & + & + & + & + & + & + & + & + \\
\hline Pa 6 & - & - & - & - & - & - & - & - & + & + & + & + & + & + & + & + & + & + \\
\hline $\mathrm{Pa} 7$ & - & - & - & - & - & - & 1 & - & + & + & + & + & + & + & + & + & + & + \\
\hline Pa 8 & - & - & - & - & - & - & - & - & + & + & + & + & + & + & + & + & + & + \\
\hline Pa 9 & - & - & - & - & - & - & - & - & + & + & + & + & + & + & + & + & + & + \\
\hline Pa 12 & - & - & - & - & - & - & - & - & + & + & + & + & + & + & + & + & + & + \\
\hline $\mathrm{Pa} 18$ & - & - & - & - & - & - & - & - & + & + & + & + & + & + & + & + & + & + \\
\hline Pa 19 & - & - & - & - & - & - & - & - & + & + & + & + & + & + & + & + & + & + \\
\hline $\mathrm{Pa} 20$ & - & - & - & - & - & - & - & - & + & + & + & + & + & + & + & + & + & + \\
\hline $\mathrm{Pa} 21$ & - & - & - & - & - & - & - & - & + & + & + & + & + & + & + & + & + & + \\
\hline $\mathrm{Pa} 22$ & - & - & - & - & - & - & - & - & + & + & + & + & + & + & + & + & + & + \\
\hline $\mathrm{Pa} 24$ & - & - & - & - & - & - & 5 & 4 & + & + & + & + & + & + & + & + & + & + \\
\hline $\mathrm{Pa} 25$ & - & - & - & - & - & - & - & - & + & + & + & + & + & + & + & + & + & + \\
\hline $\mathrm{Pa} 26$ & - & - & - & - & - & - & - & - & + & + & + & + & + & + & + & + & + & + \\
\hline $\mathrm{Pa} 27$ & - & - & - & - & - & - & - & - & + & + & + & + & + & + & + & + & + & + \\
\hline $\mathrm{Pa} 28$ & - & - & - & - & - & - & - & - & + & + & + & + & + & + & + & + & + & + \\
\hline Pa 29 & - & - & - & - & - & - & - & - & + & + & + & + & + & + & + & + & + & + \\
\hline
\end{tabular}

+, desenvolvimento; -, sem desenvolvimento 


\section{Protocolo $\mathrm{n}^{\circ} 7$}

MÉTODO: CONCENTRAÇÃO INIBITÓRIA MÍNIMA

ANTIMICROBIANO: ÁCIDO ACÉTICO P.A (Merck) DATA: 16/06/2003

CEPAS: Staphylococcus aureus

\begin{tabular}{|c|c|c|c|c|c|c|c|c|c|c|c|c|c|c|c|c|c|c|}
\hline $\begin{array}{c}\text { Diluição } \\
\%\end{array}$ & \multicolumn{2}{|c|}{4,0} & \multicolumn{2}{|c|}{3,0} & \multicolumn{2}{|c|}{2,0} & \multicolumn{2}{|c|}{1,5} & \multicolumn{2}{|c|}{1,0} & \multicolumn{2}{|c|}{0,75} & \multicolumn{2}{|c|}{0,5} & \multicolumn{2}{|c|}{0,25} & & \\
\hline $\begin{array}{l}\text { Placa } \\
\text { Cepa }\end{array}$ & \multicolumn{2}{|c|}{1} & \multicolumn{2}{|c|}{2} & \multicolumn{2}{|c|}{3} & \multicolumn{2}{|c|}{4} & \multicolumn{2}{|c|}{5} & \multicolumn{2}{|c|}{6} & \multicolumn{2}{|c|}{7} & \multicolumn{2}{|c|}{8} & \multicolumn{2}{|c|}{ controle } \\
\hline S 1.1 & - & - & - & - & - & - & - & - & - & - & - & - & - & - & - & - & + & + \\
\hline S 2.5 & - & - & - & - & - & - & - & - & - & - & - & - & - & - & - & - & + & + \\
\hline S 3.1 & - & - & - & - & - & - & - & - & - & - & - & - & - & - & - & - & + & + \\
\hline S 4.5 & - & - & - & - & - & - & - & - & - & - & - & - & - & - & - & - & + & + \\
\hline S 6.1 & - & - & - & - & - & - & - & - & - & - & - & - & - & - & - & - & + & + \\
\hline S 7.5 & - & - & - & - & - & - & - & - & - & - & - & - & - & - & - & - & + & + \\
\hline S 8.5 & - & - & - & - & - & - & - & - & - & - & - & - & - & - & - & - & + & + \\
\hline S 21.1 & - & - & - & - & - & - & - & - & - & - & - & - & - & - & - & - & + & + \\
\hline S 23.5 & - & - & - & - & - & - & - & - & - & - & - & - & - & - & - & - & + & + \\
\hline S 24.5 & - & - & - & - & - & - & - & - & - & - & - & - & - & - & - & - & + & + \\
\hline S 26.1 & - & - & - & - & - & - & - & - & - & - & - & - & - & - & - & - & + & + \\
\hline S 27.1 & - & - & - & - & - & - & - & - & - & - & - & - & - & - & - & - & + & + \\
\hline A 4.1 & - & - & - & - & - & - & - & - & - & - & - & - & - & - & - & - & + & + \\
\hline A 6.1 & - & - & - & - & - & - & - & - & - & - & - & - & - & - & - & - & + & + \\
\hline A 7.5 & - & - & - & - & - & - & - & - & - & - & - & - & - & - & - & - & + & + \\
\hline A 10.1 & - & - & - & - & - & - & - & - & - & - & - & - & - & - & - & - & + & + \\
\hline A 13.1 & - & - & - & - & - & - & - & - & - & - & - & - & - & - & - & - & + & + \\
\hline A 17.1 & - & - & - & - & - & - & - & - & - & - & - & - & - & - & - & - & + & + \\
\hline A 23.1 & - & - & - & - & - & - & - & - & - & - & - & - & - & - & - & - & + & + \\
\hline A 35.1 & - & - & - & - & - & - & - & - & - & - & - & - & - & - & - & - & + & + \\
\hline
\end{tabular}

+ , desenvolvimento; -, sem desenvolvimento

$\mathbf{S}\left(\boldsymbol{n}^{\circ}\right)=$ cepa hospitalar

$\boldsymbol{A}\left(\boldsymbol{n}^{\circ}\right)=$ cepa comunidade 


\section{Protocolo $n^{\circ} 8$}

MÉTODO: CONCENTRAÇÃO INIBITÓRIA MÍNIMA ANTIMICROBIANO: ÁCIDO ACÉTICO PA (Merck) DATA: 16/06/2003 CEPAS: Escherichia coli

\begin{tabular}{|c|c|c|c|c|c|c|c|c|c|c|c|c|c|c|c|c|c|c|}
\hline $\begin{array}{c}\text { Diluição } \\
\%\end{array}$ & \multicolumn{2}{|c|}{4,0} & \multicolumn{2}{|c|}{3,0} & \multicolumn{2}{|c|}{2,0} & \multicolumn{2}{|c|}{1,5} & \multicolumn{2}{|c|}{1,0} & \multicolumn{2}{|c|}{0,75} & \multicolumn{2}{|c|}{0,5} & \multicolumn{2}{|c|}{0,25} & & \\
\hline $\begin{array}{l}\text { Placa } \\
\text { Cepa }\end{array}$ & \multicolumn{2}{|c|}{1} & \multicolumn{2}{|c|}{2} & \multicolumn{2}{|c|}{3} & \multicolumn{2}{|c|}{4} & \multicolumn{2}{|c|}{5} & \multicolumn{2}{|c|}{6} & \multicolumn{2}{|c|}{7} & \multicolumn{2}{|c|}{8} & \multicolumn{2}{|c|}{ controle } \\
\hline Ec 1 & - & - & - & - & - & - & - & - & - & - & - & - & - & - & - & - & + & + \\
\hline Ec 2 & - & - & - & - & - & - & - & - & - & - & - & - & - & - & - & - & + & + \\
\hline Ec 5 & - & - & - & - & - & - & - & - & - & - & - & - & - & - & - & - & + & + \\
\hline Ec 6 & - & - & - & - & - & - & - & - & - & - & - & - & - & - & - & - & + & + \\
\hline Ec 7 & - & - & - & - & - & - & - & - & - & - & - & - & - & - & - & - & + & + \\
\hline Ec 9 & - & - & - & - & - & - & - & - & - & - & - & - & - & - & - & - & + & + \\
\hline Ec 10 & - & - & - & - & - & - & - & - & - & - & - & - & - & - & - & - & + & + \\
\hline Ec 11 & - & - & - & - & - & - & - & - & - & - & - & - & - & - & - & - & + & + \\
\hline Ec 12 & - & - & - & - & - & - & - & - & - & - & - & - & - & - & - & - & + & + \\
\hline Ec 13 & - & - & - & - & - & - & - & - & - & - & - & - & - & - & - & - & + & + \\
\hline Ec 14 & - & - & - & - & - & - & - & - & - & - & - & - & - & - & - & - & + & + \\
\hline Ec 17 & - & - & - & - & - & - & - & - & - & - & - & - & - & - & - & - & + & + \\
\hline Ec 18 & - & - & - & - & - & - & - & - & - & - & - & - & - & - & - & - & + & + \\
\hline Ec 19 & - & - & - & - & - & - & - & - & - & - & - & - & - & - & - & - & + & + \\
\hline Ec 20 & - & - & - & - & - & - & - & - & - & - & - & - & - & - & - & - & + & + \\
\hline Ec 21 & - & - & - & - & - & - & - & - & - & - & - & - & - & - & - & - & + & + \\
\hline Ec 22 & - & - & - & - & - & - & - & - & - & - & - & - & - & - & - & - & + & + \\
\hline Ec 23 & - & - & - & - & - & - & - & - & - & - & - & - & - & - & - & - & + & + \\
\hline Ec 24 & - & - & - & - & - & - & - & - & - & - & - & - & - & - & - & - & + & + \\
\hline Ec 25 & - & - & - & - & - & - & - & - & - & - & - & - & - & - & - & - & + & + \\
\hline
\end{tabular}

+, desenvolvimento; -, sem desenvolvimento 


\section{Protocolo $n^{\circ} 9$}

MÉTODO: CONCENTRAÇÃO INIBITÓRIA MÍNIMA

ANTIMICROBIANO: ÁCIDO ACÉTICO PA (Merck) DATA: 16/06/2003

CEPAS : Pseudomonas aeruginosa

\begin{tabular}{|c|c|c|c|c|c|c|c|c|c|c|c|c|c|c|c|c|c|c|}
\hline $\begin{array}{c}\text { Diluição } \\
\%\end{array}$ & \multicolumn{2}{|c|}{4,0} & \multicolumn{2}{|c|}{3,0} & \multicolumn{2}{|c|}{2,0} & \multicolumn{2}{|c|}{1,5} & \multicolumn{2}{|c|}{1,0} & \multicolumn{2}{|c|}{0,75} & \multicolumn{2}{|c|}{0,5} & \multicolumn{2}{|c|}{0,25} & & \\
\hline $\begin{array}{l}\text { Placa } \\
\text { Cepa }\end{array}$ & \multicolumn{2}{|c|}{1} & \multicolumn{2}{|c|}{2} & \multicolumn{2}{|c|}{3} & \multicolumn{2}{|c|}{4} & \multicolumn{2}{|c|}{5} & \multicolumn{2}{|c|}{6} & \multicolumn{2}{|c|}{7} & \multicolumn{2}{|c|}{8} & \multicolumn{2}{|c|}{ controle } \\
\hline Pa 1 & - & - & - & - & - & - & - & - & - & - & - & - & - & - & - & - & + & + \\
\hline $\mathrm{Pa} 3$ & - & - & - & - & - & - & - & - & - & - & - & - & - & - & - & - & + & + \\
\hline $\mathrm{Pa} 4$ & - & - & - & - & - & - & - & - & - & - & - & - & - & - & - & - & + & + \\
\hline Pa 5 & - & - & - & - & - & - & - & - & - & - & - & - & - & - & - & - & + & + \\
\hline Pa 6 & - & - & - & - & - & - & - & - & - & - & - & - & - & - & - & - & + & + \\
\hline $\mathrm{Pa} 7$ & - & - & - & - & - & - & - & - & - & - & - & - & - & - & - & - & + & + \\
\hline Pa 8 & - & - & - & - & - & - & - & - & - & - & - & - & - & - & - & - & + & + \\
\hline $\mathrm{Pa} 9$ & - & - & - & - & - & - & - & - & - & - & - & - & - & - & - & - & + & + \\
\hline $\mathrm{Pa} 12$ & - & - & - & - & - & - & - & - & - & - & - & - & - & - & - & - & + & + \\
\hline Pa 18 & - & - & - & - & - & - & - & - & - & - & - & - & - & - & - & - & + & + \\
\hline Pa 19 & - & - & - & - & - & - & - & - & - & - & - & - & - & - & - & - & + & + \\
\hline $\mathrm{Pa} 20$ & - & - & - & - & - & - & - & - & - & - & - & - & - & - & - & - & + & + \\
\hline $\mathrm{Pa} 21$ & - & - & - & - & - & - & - & - & - & - & - & - & - & - & - & - & + & + \\
\hline $\mathrm{Pa} 22$ & - & - & - & - & - & - & - & - & - & - & - & - & - & - & - & - & + & + \\
\hline $\mathrm{Pa} 24$ & - & - & - & - & - & - & - & - & - & - & - & - & - & - & - & - & + & + \\
\hline $\mathrm{Pa} 25$ & - & - & - & - & - & - & - & - & - & - & - & - & - & - & - & - & + & + \\
\hline Pa 26 & - & - & - & - & - & - & - & - & - & - & - & - & - & - & - & - & + & + \\
\hline $\mathrm{Pa} 27$ & - & - & - & - & - & - & - & - & - & - & - & - & - & - & - & - & + & + \\
\hline $\mathrm{Pa} 28$ & - & - & - & - & - & - & - & - & - & - & - & - & - & - & - & - & + & + \\
\hline Pa 29 & - & - & - & - & - & - & - & - & - & - & - & - & - & - & - & - & + & + \\
\hline
\end{tabular}

+, desenvolvimento; -, sem desenvolvimento 


\section{7- REFERÊNCIAS BIBLIOGRÁFICAS*}

AKIYAMA, H.; YAMAZAKI, O.; TADA, J.; ARATA, J. Effects of acetic acid on biofilms formed by Staphylococcus aureus. Acta Dermatol. Res., v. 291, p. 570-573, 1999.

ALEXANDER, J. W. The contribuitions of infection control to a century of surgical progress. Ann. Sug., v. 4, n. 201, p. 423-428, 1985.

AMINIFARSHIDMEHR, N. The management of chronic suppurative otitis media with acid media solutions. Am. J. Otol., v. 17, n. 1, p. 24-25, 1996.

ARAÚJO, G. F.; BATISTA, J. E.; MONTEIRO NETO, V.; ROCHA, A. M. F.; LIMA, L. A. M. L. Eficácia in vitro do ácido acético em Pseudomonas spp. Acta Cir. Bras., v. 10, n. 4, p. 201-203, 1995.

BAJAY, M. H.; JORGE, S. A.; DANTAS, S. R. P. E. (Coord.). Tratamento de feridas. Universidade Estadual de Campinas. São Paulo, 1999, 79p.

BELINSON, J. L; PRETORIUS, R. G.; ZHANG, W. H.; WU, L. Y.; QIAO, Y. L.; ELSON, P. Cervical cancer screening by simple visual inspection after acetic acid. Obstt. Gynecol, v. 98, n. 3, p. 441-444, esp. 2001.

*Diretrizes para apresentação de Teses e dissertações à USP: consulta Eletrônica, www.teses.usp.br, São Paulo, 2001.

*Associação Brasileira de Normas Técnicas ABNT. Informação e documentação: referências, elaboração. NBR6023/2000. Rio de Janeiro. ABNT, 2000. 
BENASSATTI, H. E.; MARFII, L. M.; OCCHIONERO, M. Ácido acético: su capacidad desinfectante. Acta Bioquím. Clin. Latinoam., v. 28, n. 3, p. 4114119, 1994.

BERGSTRON, N.; ALlMAN, R. M.; AlVAREZ, O. M.; BENNETT, C. E.;CARLSON, C. E.; FRANTZ, R. A.; GARBER, S. L.; GOSNELI, D.; JACKSON, B. S.; KAMINSKI, M. V.; KEMP, M. G.; KROUSKOP, T. A.; LEWIS, V. L.; MAKLEBUST, J.; MARGOLIS, D. J.; MARVEL, R. M.; REGER, S. I.; RODEHEAVER, G. T.; SALCIDO, R.; XAKELLIS, G. C.; YARKONY, G. M. Pressure ulcer treatment: quick reference guide for clinicans. Advances in wound care. v. 8, n. 2, p.22-44, 1995.

BÍBLIA. Português. Bíblia sagrada. Traduzido pelo Centro Bíblico de São Paulo. 15. ed. São Paulo: Ave Maria, 1970. Edição Claretiana.

BORGES, E. L.; SAAR, S. R. C.; LIMA, V. L. A. N.; GOMES, F. S. L.; MAGALHÃES, M. B. B. Feridas: como tratar. Belo Horizonte: Coopmed, 2001. $144 p$.

BORGES, E. L ; COUTO, T. Tratamento e cicatrização de feridas - Parte II. Nursing Ed., v.3, n. 23, p. 25-29, 2000.

BORGES, E. L. Tratamento de feridas: avaliação de um protocolo. Minas Gerais, 2000. 159p. Dissertação de Mestrado, Escola de Enfermagem da Universidade Federal de Minas Gerais. Belo Horizonte.

BRASIL. Leis e Decretos; Ministério da Saúde. Diário Oficial da União, Portaria n 930 de 27 de agosto de 1992, Brasília. 
BRASIL. Diretrizes e normas regulamentadoras de pesquisa envolvendo seres humanos. Conselho Nacional de Saúde, Resolução n 196/96 de 10 de outubro de 1996.

BUDAVARI, S.; O"NEIL, M. J.; SMITH, A.; HECKELMAN, P.E. The merck index. 11ed. USA: RahWay, 1989. 1606p.

CÂNDIDO, L. C. Nova abordagem no tratamento de feridas. São Paulo: Editora SENAC São Paulo, 2001. 282p.

CENTRE FOR MEDICAL EDUCATION. El programa de las heridas. Scotland.: The University of Dundee, 1994. 188p.

CARR, P. Wound care. Home healthcare nurse. v. 11, n. 1, p. 51-53, 1993.

CLIFTON CH. W. Introduction to the bacteria. NewYork: Mc Graw Hill Co., 1950.

CORBETT, C. E. Farmacodinâmica. Rio de Janeiro: Guanabara Koogan, 1977. 955p.

CORUM, G. M. Characteristics and prevention of wound infection. J. ET nursing. v. 20, n. 1., p. 21-25, 1993.

COTRAN, R. S.; KUMAR, V.; ROBBINS, S. Patologia - estrutural e funcional. 5. ed. Rio de Janeiro: Guanabara Koogan, 1994. 1276p. 
CRONJE, H. S.; VAN RENSBURG, E.; COOREMAN, B. F.; NIEMAND, T.; BEYER, E. Speculoscopy versus the acetic acid test for cervical neoplasia. Int. J. Gynaecol. Obstest., v. 69, n. 3, p. 249-253, 2000.

CRUSE, P. J. E.; MCPHEDRAN, N. Cura e tratamento das feridas. In: SABISTON-JR, D. C. Fundamentos de cirurgia de Sabiston. São Paulo: Manole, 1991. 2v. v. 1, cap. 8, p. 143-148.

DEALEY, C. Cuidando de feridas: um guia para as efermeiras. São Paulo: Atheneu, 1996. 255p.

Cuidando de feridas: um guia para as enfermeiras. 2ed. São Paulo: Atheneu Editora, 2001. 216p.

DECLAIR, V. Efeitos do triglicérides de cadeia média na aceleração do processo de cicatrização de feridas. Nutrição Enteral e Esportiva. n. 5, p.4-8, 1994.

DOUGHTY, D. A. A rational approach to the use of topical antiseptics. J. Wound/Ostomy Continente Nursing. v. 21, n.6, p. 224-231, 1994.

ESTEVES, C. H. A. Realidade da terapia hiperbárica no tratamento de feridas. Ver. Escola de Enfermagem da USP, v. 33, p. 160-161, 1999. Edição especial

FERRAZ, E. M. Infecção da ferida na cirurgia do aparelho digestivo. Pernambuco, 1990. 154fl. Tese para concurso público para preenchimento do cargo de Prof. Titular da Disciplina de Cirurgia Abdominal do Departamento de Cirurgia do Centro de Ciências da Saúde Universidade Federal de Pernambuco. Recife. 
Manual de Controle de infecção em cirurgia do Colégio Brasileiro de Cirurgiões. São Paulo: Editora Pedagógica Universitária Ltda., 1982.

FERNANDES, A. T.; FERNANDES, M. A. V., RIBEIRO, N. F. Infecção hospitalar e sua interface na área da saúde. Rio de Janeiro: Atheneu, 2000.

FRANTZ, R. A.; GARDNER, S. Eldely skin care. Principles of chronic wounds. J. Gerontol Nursing. v. 30, n. 9, p.35-44, 1994.

GALVANE, J. O.; ROTELI-MARTINS, C. M.; TADINI, V. Achados da inspeção visual com ácido acético para rastreamento de câncer do colo uterino. DST- J. Bras. Doenças Sex. Transm. v. 14, n.1, p. 43-45, 2002.

GLIDE, S. Cleaning choices. Nursing Times. v. 88, n. 19, p. 74-78, 1992.

GOODMAN, L. S., GILMAN, A. The pharmacological basis of therapeutics. $6^{\text {th }}$. New York,: Mac Millan Publishing Co., Inc., 1980, p. 964-965, 1971.

GROOVE, D. C.; RANDALL W. A. Assay methods of antibiotics: a laboratory manual - antibiotics monographs, 2. Medical Encyclopedia Inc; New York, 1955.

HADDAD, M. C. L. Influência do açúcar no processo de cicatrização de incisões cirúrgicas infectadas. Londrina. 1994. 83p Dissertação (Mestrado). Departamento de Histologia da Universidade Estadual de Londrina, Paraná.

HANSSON, C.; FAERGERMANN, J. The effect of antiseptic solutions on microorganisms venous leg ulcers. Acta Derm. Venereol (Stockh), v. 75, p. 31-33, 1995. 
JUNG, H. H.; CHO, S. D.; YOO, C. K.; LIM, H. H.; CHAE, S. W. Vinegar treatment in the management of granular myringitis. J. Laryngol. Otol., v. 116, n. 3, p. 176-180, 2002.

KERSTER, H. W, SCHAEFFER, D. J. Brine shrimp (Artemia salina) nauplii as a teratogen teratogen test system. Ecotoxicol Envirom Saf., n.59, v. 3, p. 250252. 1983.

KRASNER, D. L.; RODEHEAVER, G. T.; SIBBALD, R. G. Chronic wound care: a clinical source book for healthcare profissionals. $3^{\text {rd }}$ ed. HMP Comunications, 2001. 760p.

KRASNER, D. L.; KANE, D. Chronic wound care: a clinical source book for healthcare professionals. $2^{\text {nd }}$ ed. USA:Health Management Publications, Inc Wayne, PA. 1997. 427p.

KUMAR, V.; COTRAN, R. S.; ROBBINS, S. Patología básica. $5^{\mathrm{a}}$ ed Rio de Janeiro: Guanabara-Koogan, 1992, 608p.

LINEAWEAVER, W.; MCMORRIS, S.; SOUCY, D.; HOWARD, R. Cellular and bacterial toxicities of topical antimicrobials. Plast. Reconst. Surg., 1985, n. 75, v. 3, p. 394-396

LOGARTO PARRA, A.; SILVA YHENEBRA, R.; GUERRA SARDIÑAS, I.; IGLESIAS BUELA, L. Comparative study of the assay of Artemia salina L. and the estimate of the medium lethal dose (LD50 value) in mice, to determine oral acute toxicity of plant extrasts. Phytomedicine, v.8, n.5, p. 395-400. 2001. 
MARTINDALE, W. The extra Pharmacopeia. Thiry-first Edition- London: Evaluated information on the world's drugs and medicines. The Royal pharmaceutical society. Edited by Janes E. F. Reynolds. 1996, 2739p.

MARTINS, E. A. P. Avaliação de três técnicas de limpeza do sítio cirúrgico infectado utilizando soro fisiológico para remoção de microrganismos. São Paulo, 2000. Dissertação de Mestrado, Escola de Enfermagem da Universidade de São Paulo, Universidade de São Paulo.

MAZZOLA, P. G. et al. Eficácia dos agentes químicos no programa de limpeza, desinfecção e esterilização. LAES \& HAES, São Paulo, v. 22, n. 127, p. 100126.

MCKENNA, P. J.; LEHR, G. S.; LEIST, P.; WELLING, R. E. et al. Antisseptic effectiveness with fibroblast preserevation. Ann. Plast. Surg. v. 27, n. 3, p. 265-268, 1991.

MILNER, S. M. Acetic acid to treat Pseudomonas aeruginosa in superficial wounds and burns. Lancet, v. 340, n.4, p. 61, 1992.

MIMS, C.; PLAYFAIR, J.; ROITT, I.; WAKELIN, D.; WILLIAMS, R. Microbiologia médica. 2.ed. Manole,1999. 584p.

MOLINEROS J. R. B.; BENAVIDES, J. E.; GUERRERO, M. L.; BURBANO, R. El empleo del ácido acético como antiséptico: un enfoque racional. Rev. Colomb. Ortop. Traumatol. v. 5, n. 2, p. 117-124, 1991.

MONETTA, L. Uso da papaína nos curativos feitos pela enfermagem. Rev. Bras. Enf., v. 40, n.1, p.66-73, 1987 
Análise evolutiva do processo de cicatrização em úlceras diabéticas, de pressão e venosas com uso da papaína. São Paulo, 1998. 192fl. Dissertação (Mestrado) Escola de Enfermagem, Universidade de São Paulo.

MORISON, M.; MOFFATT, C.; BRIDEL-NIXON, J.; BALE, S. A colour guide to the nursing management of chronic wounds. 2. ed. London: Mosby, 1997. 298p.

MORRISON, R. T.; BOYD, R. N. Química orgânica. 4. ed. Lisboa: Fundação Caloriste Gulbenkian. 1983.

MURPHY, A. Cleaning solutions. Nursing Times, v.91, n. 22, p. 78-80, 1995.

NAGOBA, B. S et al. Acetic acid treatment of pseudomonal postoperative wound infection. J. Hosp. Infect., v.36, n.3, p.243-244,1997

NCCLS. Methods for dilution antimicrobial susceptibily tests for bacteria that grow aerobically: approved standard. 5. ed. v. 20, n. 2, p.197-A5. 2000.

NOGUEIRA, M. J. C. Fitoterapia popular e enfermagem comunitária. São Paulo, 1983. 257 fl. Tese (Livre - Docência) - Escola de Enfermagem, Universidade de São Paulo.

OHNISHI, M.; UTYAMA, I. K. A.; JANENE, S. M. A.; PEREIRA, F. Feridas: cuidados e condutas. Londrina: Universidade Estadual de Londrina, 2001.

OJALA, T.; VUORELLA, P.; KIVIRANTA, J.; VUORELA, H.; HILTUNEM, R. A bioassay using Artemia salina for detecting phofotoxicity of plant coumarins. Planta Med., v. 65, n. 8, p. 715-718. 1999. 
PELKA, M.; DANZL, C.; DISTLER, W.; PETSCHELT, A. A new screening test for toxicity testing of dental materials. J. Dent., v. 28, n. 5, p. 341-345, 2000.

PEREIRA, D. S. de A. Estudo in vitro da ação de ácido acético em Pseudomonas aeruginosa isolada de feridas. Londrina, $2002.27 p$. Monografia, Curso de Especialização em Biologia Aplicada à Saúde, Universidade Estadual de Londrina.

PHILLIPS, I.; LOBO, A. Z.; FERNANDES, R.; GUNDARA, N. S. Acetic acid in the treatment of superficial wounds infected by Pseudomonas aeruginosa. Lancet, v. 6, p. 11-12, 1968.

PIEPER, B.; CALIRI, M. H. L. Nontraditional wound care: a review of the evidence for the use of sugar, papaya/papain, and fatty acids.. Journal of WOCN, v. 30, n. 4, p.175-183, 2003.

POGUE, B. W.; KAUFMAN, H. B.; ZELENCHUK, A.; HARPER, W.; BURKE, G. C.; BURKE, E. E.; HARPER, D. M. Analysis of acetic acid-induced whitening of high-grade squamous intraepithelial lesions. J. Biomed. Opt., v. 6, n. 4, p. 397403, 2001.

POLETTI, N. A. A. O cuidado de enfermagem a pacientes com feridas crônicas. A busca de evidências para a prática. Ribeirão Preto, 2000. 269p. Dissertação de Mestrado Escola de Enfermagem de Ribeirão Preto, Universidade de São Paulo.

RICHEY, H.G. Química orgânica. Rio de Janeiro: Prentice-Hall do Brasil, 1986, $418 p$. 
RIJSWIJK,V. The language of wounds. In: Krasner D.; Kane, D. Chronic Wound Care. $2^{\text {nd }}$ ed. USA: Wayne. Health management publications, Inc., 1997. Ch. 13, p 5-8.

RODEHEAVER, G. T. Wound cleasing, wound irrigation, wound disinfection. In; Krasner, D.; Kane, D. Chronic wound care: A clinical source book for healthcare professionals. $2^{\text {nd }}$ Edition. USA: Wayne. Health management publications, Inc., 1997. Ch. 13, p. 97-107.

. Wound cleasing, wound irrigation, wound disinfection. In: Krasner, D. L.,; Rodeheaver, G. T.; Sibbald, R. G. (eds). Chronic wound care: a clinical source book for healthcare professionals. $3^{\text {rd }}$ ed. Wayne, PA: HMP Comunications, 2001. Ch. 38, p.369-383

RUND, C. R. Alternative topical therapies for wound care. In: Krasner, D. \& Kane, D. Chronic wound care: A clinical source book for Healthcare professionals. $2^{\text {nd }}$ ed. USA: Wayne. Health management publications, Inc., 1997. Ch. 28, p.219-226.

SANKARANARAYANAN, R.; WESLEY, R.; SOMATHAN, T.; DHAKAD, N.; SHYAMALAKUMARY, B.; AMMA, S. N.; DARKIN, M. D.; NAIR, M. K.. Visual inspection of the uterine cervix after the application of acetic acid in the detection of cervical carcinoma and its precursors. Cancer, v. 83, n. 10, p. 2150-2156, 1998.

SANTOS PIMENTA, L. P.; PINTO, G. B.; TAKAHASHI, J. A.; SILVA, L. G.; BOAVENTURA, M. A. Biological screening of Annonaceous Brazilian Medicinal Plants using Artemia salina (brine shrimp test). Phytomedicine, v. 10, n. 2-3, p. 209-212. 2003 
SEO, T. S.; OH, J. H.; ION, Y.; LIM, J. W.; PARK, S. J.; CHANG, S. C.; JEON, Y. H. Acetic acid as a esclerosing agent for renal cysts: comparison with ethanol in follow-up results. Cardiovasc. Intervent. Radiol., v. 23, n. 3, p. 171$181,2000$.

SCHABERG, D. R.; TURCK, M. Doenças causadas por bacilos entéricos gramnegativos. In: BRAUN-WALD, E. Medicina interna. 11 ed. Rio de Janeiro: Guanabara, 1982. p. 543-549.

SHUTTLEWORTH, E.; BANFIELD, K. Light relief. Nursing Times, v. 93, n.16, p. 70-78, 1997.

SILVA, M. R. L.; PEREIRA, D. A. S.; LINHARES, R. E. C.; PELAYO, J. S. Ácido acético como tratamento alternativo para feridas contaminadas por Pseudomonas aeruginosa e seu efeito em células Hep-2 e Vero. Biosaúde, v. 4, Ed. Especial, 2002.

SINGH, V.; SEHGAL, A.; PARASHARI, A.; SODHANI, P.; SATYANARAYANA, L. Early detection of cervical cancer through acetic acid application- an aided visual inspection. Singapore Med. J., v..42, n. 8, p. 351-354, 2001.

THOMAZ, J. B.; HERDY, C. D. C. Fundamentos de Cirurgia Vascular e Angiologia. São Paulo: Fundação BYK, 1997.

TIAGO, F. Tratamento de úlceras de estase venosa com bota de Unna e carvão ativado. Rev. Bras. Enfermagem, v. 49, n. 2, p. 215-224, 1996

THORP, M. A.; KRUGER, J.; OLIVER, T. S.. The antibacterial activity of acetic acid and Burrow's solution as topical otological preparations. J. Laryngol Octology, v. 112, p. 925-928, 1998. 
TUKEY LLOYD, D.; FISHER, G. V. B. Bioestatistics a methodology for the health sciences new york. 1993. A wiley - Interscience Publication, 991p.

WALDROP, J; DOUGHTY, D. Wound-healing physiology. In: Bryant, R. A.. Acute e chronic wounds - nursing management. $2^{\text {nd }}$ ed. St. Louis: Mosby. 2000. Ch. 2, p. 17-39.

WALSH, M.; FORD, P. Nursing rituals: research and rational actions. Oxford: Butterworth-Heinemann, 1992.

WHIPPLE, A. O. História da cirurgia in:Christopher Davis, Clínica cirúrgica. Loyal Davis. Rio de Janeiro: Guanabara-Koogan, 1961.

WILLIAMS, B.; EPSTEIN, S. The wonder drugs. Avon Books, New York, 1967.

WINTER, G. D. Formation of scab and the rate of epithelization on superficial wounds in the skin of the domestic pig. Nature, v. 193, p. 293-294, 1962.

WOODART, Daniel. Irrigation with acetic acid. Ann. Emer. Med., v.8, n.8, p.911, 1989.

YAMADA, B. F. A. Terapia tópica de feridas: limpeza e desbridamento. Revista da Escola de Enfermagem da USP. V. 33, p.133-140, 1999. Edição Especial. 


\section{8-APÊNDICE}

\section{Apêndice 1}

Meios de cultura, composição e preparação

Meios de cultura, composição, modo de preparo e finalidade.

Müeller Hinton - MH (Oxoid)

Componentes:

Infusão de carne. $300,0 \mathrm{~g}$

Hidrolisado de caseína $17,5 \mathrm{~g}$

Amido $1,5 \mathrm{~g}$

Ágar $17,0 \mathrm{~g}$

Água destilada $1.000,0 \mathrm{~mL}$

\section{Preparação:}

Preparação do $\mathrm{MH}$

Foram pesados 20,9g do produto desidratado Agar Müeller Hinton- MH (Oxoid) em balança eletrônica (Marte) e colocados em um balão. Foi adicionado 550,0mL de água destilada, homogeneizado e aquecido até atingir fervura por três vezes, para a fusão do ágar. Em seguida, foi distribuído aproximadamente, $4,0 \mathrm{~mL}$ em tubos de ensaio $(12 \times 125 \mathrm{~mm})$, tamponados e esterilizados em autoclave (Fabbe-Bimar) a $120^{\circ} \mathrm{C}$ durante 20 minutos. Após a esterilização, os tubos foram mantidos em posição inclinada até a solidificação. (Manutenção das cepas).

Preparação do $\mathrm{MH}$ para camada base

Este meio foi utilizado também para o preparação da camada base. Foram pesados 20,9g do produto desidratado Ágar Mueller Hinton - MH (Oxoid) em balança eletrônica (Marte) e colocados em um balão. Foi adicionado 
550,0mL de água destilada, tamponados e esterilizados em autoclave (FabbeBimar) a $120^{\circ} \mathrm{C}$ durante 20 minutos. Após a esterilização, foi mantido em banho-maria até atingir, aproximadamente, $50^{\circ} \mathrm{C}$, para evitar a solidificação. Em seguida, distribuídos em volumes de $10,0 \mathrm{~mL}$ em placas de Petri (20×100mm) esterilizadas, com o auxílio de uma pipeta de $20,0 \mathrm{~mL}$ em fluxo laminar. Após a solidificação as placas foram mantidas a $37^{\circ} \mathrm{C}$ até adicionar a camada seed de MH. (Obtenção da camada base).

Preparação do MH para camada de semeadura - seed

Este produto foi também preparado para obtenção da camada de semeadura ou seed. Foram pesados 20,9g do produto desidratado Ágar Mueller Hinton - MH (Oxoid) em balança elétrica (Marte) e colocados em um balão. Foi adicionado $550,0 \mathrm{~mL}$ de água destilada, homogeneizado e aquecido até atingir fervura por três vezes, para a fusão do ágar. Em seguida, foi distribuído em volumes de $15,0 \mathrm{~mL}$ em cerca de 25 tubos de ensaio $(18 \times 180 \mathrm{~mm})$, tamponados e esterilizados em autoclave (Fabbe-Bimar) a $120^{\circ} \mathrm{C}$ durante 20 minutos. Após a esterilização, foi mantido em banho-maria até atingir, aproximadamente $50^{\circ} \mathrm{C}$. Após a adição dos inóculos, estes foram distribuídos em volumes de $5,0 \mathrm{~mL}$ em placas, com a camada base $(20 \times 100 \mathrm{~mm})$, com o auxílio de uma pipeta de 10,0mL em fluxo laminar em duplicatas. Em seguida, foram mantidas sob refrigeração para evitar crescimento dos microrganismos inoculados. (Obtenção da camada seed).

Cabe ressaltar que para cada cepa foram preparados 25 tubos de ensaio (12x125mm) cada um com $4,0 \mathrm{~mL}$ de $\mathrm{MH}$ para reativação das cepas, 50 placas de Petri $(20 \times 100 \mathrm{~mm})$ com $15,0 \mathrm{~mL}$ de $\mathrm{MH}$, sendo $10,0 \mathrm{~mL}$ para camada base e $5,0 \mathrm{~mL}$ de $\mathrm{MH}$ adicionado do inóculo. 
$>$ - MacConkey Agar - Mc (Difco)

Componentes:

Peptona......................................200,0g

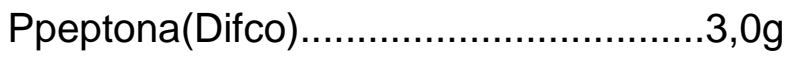

Lactose .......................................10,0

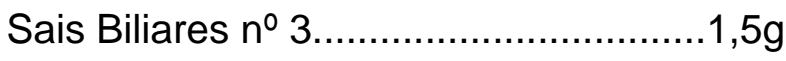

Cloreto de Sódio.................................5,0g

Ágar..........................................13,5g

Vermelho neutro............................. $0,03 \mathrm{~g}$

Violeta cristal................................... $0,001 \mathrm{~g}$

Água destilada......................1.000,0mL

Preparação:

Foi pesado $18,75 \mathrm{~g}$ do produto desidratado MacConkey Agar-Mc (Difco) em balança eletrônica (Marte), transferido para um erlenmeyer de 500,0mL e adicionado de 375,0mL de água destilada. Em seguida, homogeneizou-se evitando a adesão do ágar na parede e no fundo do recipiente. Prosseguindo foi colocado tampão de algodão, encapsulado com papel e esterilizados em autoclave a $120^{\circ} \mathrm{C}$ por 20 minutos. Após esta etapa, cerca de $20,0 \mathrm{~mL}$ foi distribuído em placas de Petri (20X100mm).(Avaliação da pureza das cepas).

Ágar hipercloretado (salgado) - Ni

Componentes:

Nutriente $8,0 \mathrm{~g}$

Cloreto de sódio..............................75,0g

Agar..........................................15,0g

Emulsão da gema do ovo a 50\%.......1,0\% 
Água destilada. $1.000,0 \mathrm{~mL}$

Preparação:

A emulsão de ovo é constituída de 10,0 mL de gema de ovo e 10,0mL de salina com 1\% de ácido fênico.

À base de $250,0 \mathrm{~mL}$ de $\mathrm{Ni}$, a cerca de $50^{\circ} \mathrm{C}$ foi adicionado de emulsão de gema de ovo a 50,0\% e homogeneizada. Em seguida, foram distribuídas em volumes de aproximadamente $20,0 \mathrm{~mL}$ em placa de Petri (20x100mm) com auxílio de uma pipeta em fluxo laminar. (Avaliação da pureza da cultura).

\section{Caldo Müller Hinton - MHb (Difco)}

Componentes:

Infusão de carne bovina. $30,0 \mathrm{~g}$

Casamino ácidos $17,5 \mathrm{~g}$

Amido solúvel $1,5 \mathrm{~g}$

Água destilada. $1.000,0 \mathrm{~mL}$

Preparação:

Foram pesados 3,15g do produto desidratado Müller Hinton Broth $\mathrm{MHb}$ (Difco) em balança eletrônica (Marte), colocado em um cálice graduado e adicionado de 150,0mL de água destilada. Em seguida homogeneizado até dissolver completamente e distribuídos em volumes de, aproximadamente $5,0 \mathrm{~mL}$ em tubos de ensaio ( $15 \times 125 \mathrm{~mm}$ ), tamponados e esterilizados em autoclave a $120^{\circ} \mathrm{C}$ por 20 minutos.(Obtenção do inóculo). 
Apêndice 2

Diluição dos produtos para teste piloto, técnica de poço (well) e Determinaçãoda Concentração Inibitória Mínima (CIM).

Preparação:

Em tubos de ensaio (16x160 mm), foram adicionados, 7,0mL de água destilada esterilizada e 3,0mL de vinagre para obter uma solução de vinagre a $30 \%$ e $7,5 \mathrm{~mL}$ de água destilada esterilizada e $2,5 \mathrm{~mL}$ de vinagre para obter uma solução a 25\% .Por fim, 9,0mL de água destilada esterilizada e $1,0 \mathrm{~mL}$ de vinagre constituiu uma solução a $10 \%$.

Para obtenção de uma solução de ácido acético a 1\% foram adicionados em tubo de ensaio $9,9 \mathrm{~mL}$ de água destilada esterilizada e $0,1 \mathrm{~mL}$ de ácido acético(PA) e para o ácido acético a 0,7\% adicionou-se 1,5mL de água destilada esterilizada e 3,5mL da ácido acético a $1 \%$.

Após a diluição dos antimicrobianos, 2,0 $\mu \mathrm{L}$ das soluções foram transferidos para poços das placas de Petri formada de camada base e seed, conforme protocolo estabelecido.

Técnica do poço (well)

A determinação da atividade antimicrobiana foi efetuada pela técnica do Poço em camada dupla Groove \& Randall (1955).

Preparação do inoculo

Os inóculos foram preparados segundo NCCLS (2000).

As cepas conservadas de Pseudomonas aeruginosa e Escherichia coli foram semeadas por esgotamento em placas com meio Mc e as de Staphylococcus aureus em placas com Ni. O intuito deste procedimento foi para verificar se cepas estavam puras. Após incubação a $37^{\circ} \mathrm{C}$ por 24 horas, as colônias características em placas Mc foram transferidas para tubos com $\mathrm{MH}$ 
inclinado, enquanto que as do meio Ni depois de 48 horas, também, repicadas em tubos com $\mathrm{MH}$ inclinado.

Decorrido o período de incubação à temperatura de $37^{\circ} \mathrm{C}$ por 24 horas, foram preparadas suspensões bacterianas escala 0.5 de McFarland, que corresponde, aproximadamente a $1,5 \times 10^{7}$ ufc (unidades formadoras de colônia), em solução salina a 0,85\% de $\mathrm{NaCl}$. Das suspensões foi transferida $1 \%$ para tubos contendo $\mathrm{MH}$, homogeneizados e 5,0 $\mathrm{mL}$ transferidos para placa de Petri com camada base para formar a camada seed.

Preparação das placas para técnica do poço (well)

A camada base, foi obtida com 10,0mL do meio sólido $\mathrm{MH}$ em placas de $20 \times 100 \mathrm{~mm}$ esterilizadas. A seguir foram adicionadas de $5,0 \mathrm{~mL}$ do meio $\mathrm{MH}$ a cerca de $50^{\circ} \mathrm{C}$, adicionada de $1,0 \mathrm{~mL}$ do inóculo, para formar a camada seed. Após a solidificação foram colocadas em refrigerador para evitar o desenvolvimento de microrganismo revelador.

Decorrido o tempo de solidificação da camada seed, foram perfurados poços num total de oito, em fluxo laminar, com auxílio de canudo de refrigerante de 4,0mm de diâmetro desinfetado, direcionado por um protocolo colocado sob a placa (Anexo - F). Em seguida o ágar recortado foi removido com palito de madeira esterilizado.

A seguir, $20,0 \mu \mathrm{L}$ de produto antimicrobiano em teste (vinagre branco e tinto a 30,0, 25,0 e 10,0\% e ácido acético a 1,0 e 0,7\%) foram aplicados com auxílio de pipeta automática desinfetada e ponteira esterilizada. Os produtos em teste foram aplicados no sentido horário, sendo o primeiro poço de vinagre branco a $30,0 \%$, o segundo de vinagre branco a $25,0 \%$ e o terceiro a $10,0 \%$. 0 quarto poço do vinagre tinto a $30,0 \%$, o quinto a $25,0 \%$ e o sexto do vinagre tinto a $10,0 \%$. O ácido acético a $1,0 \%$ no sétimo poço e a $0,7 \%$ no último poço (Anexo-F).

Estas placas foram mantidas à temperatura ambiente por cerca de 60 minutos para a difusão de agente antimicrobiano antes do início do 
desenvolvimento do microrganismo. Decorrido este período as placas foram incubadas a $37^{\circ} \mathrm{C}$ por cerca de 24,0 horas (FIGURA 1).

Decorrido o período de incubação foi realizada a leitura e mensuração do halo de inibição.

O diâmetro do halo de inibição foi medido utilizando a escala em $\mathrm{mm}$, indicando inibição de crescimento microbiano, halo maior que $5 \mathrm{~mm}$, a letra $\mathrm{t}$, apontando crescimento fino/tênue, traço, sendo padronizado o diâmetro do halo em $5 \mathrm{~mm}$ e 0 mostrando desenvolvimento microbiano ou ineficácia do produto, sem atividade antimicrobiana.

E em seguida a seleção das placas para documentação fotográfica.

Para realização da Técnica de Difusão de Poço, os antimicrobianos analisados foram vinagre branco (VB) e vinagre tinto (VT) a 30, 25 e 10\% da marca Castelo-ägrio; e o ácido acético a 1 e 0,7\% da Merck (PA).

$\mathrm{O}$ vinagre da marca Castelo foi selecionado para o presente estudo por apresentar menor custo e maior consumo na cidade de Londrina e Ribeirão Preto. Assim sendo, uma vez confirmada a sua eficácia contra infecções causadas por microrganismos testados, este pode ser indicado com segurança para uso domiciliar. A opção por estes produtos é também explicada para ser um comparativo com os estudos realizados por Pereira (2002) que utilizou o vinagre da marca Castelo.

\section{Concentração Inibitória Mínima (CIM)}

A diluição do produto foi efetuada em 8 tubos em diferentes proporções de vinagre branco e tinto e de ácido acético ( Figura 3).

As diluições foram preparadas de tal maneira que em 2,0mL, após a adição de $18,0 \mathrm{~mL}$ do meio $\mathrm{MH}$ a cerca de $50^{\circ} \mathrm{C}$, apresentasse o produto na concentração de 4,0, 3,0, 2,0, 1,5, 1,0, 0,75, 0,5 e 0,25\%. O contrôle foi preparado com adição de água esterilizada. As diluições, bem como, as placas foram preparadas no dia do procedimento. Os resultados da Concentração 
Inibitória Mínima foram registrados no Anexo C. Após a leitura algumas placas foram selecionadas para documentação fotográfica. 